\title{
Pressão arterial, crescimento alcançado e estado nutricional de crianças de seis e de dez anos de idade de escolas públicas de Florianópolis, Santa Catarina
}

Jane Laner Cardoso

Tese apresentada ao Programa de PósGraduação em Saúde Pública para obtenção do título de Doutor em Ciências

Área de Concentração: Saúde, Ciclos de Vida e Sociedade

Orientador: Prof. Dr. Claudio Leone

SÃO PAULO

2014 
Dedico este trabalho aos meus filhos, Cristiane e Marco Antônio, pelo apoio incondicional. A vocês meu amor eterno e o desejo que a solidariedade, $o$ amor e os laços de nossa família levemos para eternidade.

Em especial quero dedicar ao meu filho Alexandre que me estimulou a estudar e fazer doutorado e, sempre me incentivou a tornar meus sonhos realidade e não apenas sonhar. Ele não se encontra fisicamente entre nós, mas nos momentos difíceis de prosseguir senti que estava sempre ao meu lado e tenho certeza que estará sempre presente guiando meus passos. A você todo meu amor eterno. 


\section{AGRADECIMENTOS}

Ao meu orientador Professor Doutor Claudio Leone, pela possibilidade de conviver com um verdadeiro mestre, por toda a paciência e tranquilidade, em cada momento de sua orientação e, por todo o aprendizado de cada passo da elaboração dessa tese, cujos ensinamentos contribuíram de forma incomensurável para me estimular a fazer da pesquisa, um dos objetivos da minha vida.

Agradeço as minhas chefias das Secretarias de Saúde do Estado e Município, pela compreensão no cumprimento de minhas jornadas de trabalho em prol da pesquisa e minha formação.

Às Secretarias de Educação Municipal e Estadual, que me concederam a possibilidade de fazer das escolas públicas o cenário de minha pesquisa.

Aos professores e outros profissionais das escolas pesquisadas que sempre nos acolheram com interesse, dedicação e cooperação com a coleta de dados.

Meus sinceros agradecimentos, sem nominar aqui, às minhas amigas e amigos, companheiros de trabalho, cujo apoio foi imprescindível.

Pela cooperação carinhosa agradeço em especial, Janaína Paula Costa da Silva, Tais Costa e Susana Moritz. 
Às crianças que sempre foram o motivo da minha vida profissional meus profundos agradecimentos, pois sem sua participação essa pesquisa não poderia ocorrer.

Agradeço também, Adriana Nishimoto Kinoshita e Tiele de Cássia Libardoni, pela dedicação, ética e compromisso com a coleta de dados dessa pesquisa. Sem suas ajudas, não teria conseguido completar minha amostra com êxito.

À Adriana Kinoshita, Juliano Caliari e Tamy Vefago, meu genro e noras por acompanharem e colaborarem com amor e carinho com a nossa família, para que com serenidade continuássemos nossa caminhada. 


\section{RESUMO}

Introdução: A detecção de hipertensão arterial sistêmica (HAS) em crianças vem aumentando e tem sido relacionada ao aumento da prevalência da obesidade na infância. A evidência da transição nutricional em escolares torna importante o desenvolvimento de pesquisas que avaliem a relação entre pressão arterial (PA), crescimento e estado nutricional em escolares. Objetivos: Avaliar a PA, o crescimento e o estado nutricional de crianças de seis e sete anos e de nove e dez anos de idade de escolas públicas de Florianópolis, SC. Métodos: estudo transversal, analítico de uma amostra aleatória e probabilística de 1082 escolares, de dois grupos de idade. Foram avaliados indicadores antropométricos e de composição corporal: peso $(\mathrm{P})$, estatura $(E)$, prega cutânea tricipital (PCT), circunferência da cintura $(C C)$, cintura abdominal (CA), razão de CC/E e CA/E e índice de massa Corporal (IMC), área gorda (AGB) e área muscular do braço (AMB), analisados pelos referenciais da OMS de 2007 e de Frisancho. Os níveis pressóricos foram classificados individualmente em percentis em relação ao referencial norteamericano, para sexo, idade e estatura, segundo o preconizado pelo National High Blood Pressure Education Program Working Group on High Blood Pressure in Children and Adolescents (NHBPEP). Analisou-se a correlação entre crescimento, estado nutricional, composição corporal e a PA nos dois grupos etários e as relações com peso de nascimento e estado nutricional. A análise de risco para a razão CC/E (sensibilidade e especificidade) foi calculada pela curvas ROC. Resultados: os escolares apresentaram crescimento adequado, superior ao do referencial; observou-se pressão arterial alterada em $13,8 \%$ das crianças, com frequência maior para as mais velhas (17,6\%). A análise isolada da PA sistólica e da diastólica revelou a mesma tendência. Quanto ao estado nutricional verificou-se $25,1 \%$ das crianças com sobrepeso e 13,0\% com obesidade, destas 4,4\% apresentavam obesidade grave, mais frequente nos meninos $(7,1 \%)$, independentemente da idade. Os níveis de PA (sistólica e/ou diastólica) foram maiores quanto maior o escore $z$ 
de estatura. Quanto a composição corporal, a PA elevada esteve associada de maneira significante a maiores escores $z$ de IMC, AGB, AMB, PCT, CC, razão da CC/E e CA/E e a uma menor proporção (\%) de AMB. Na Análise de Regressão Múltipla a CC/E mostrou uma OR de 25842,37 e pela curva ROC o ponto de corte otimizado para razão da CC/E foi $>0,49, \quad(56,1 \%$ de Sensibilidade e $72,6 \%$ de Especificidade). Conclusões: Os escolares têm crescimento adequado, superior ao proposto pela OMS e sem relação com o peso de nascimento. Apresentam também prevalência elevada (13.7\%) de préhipertensão e hipertensão arterial, que tende a aumentar com a idade. Têm prevalência elevada $(42,5 \%)$ de sobrepeso, obesidade e obesidade grave, que é proporcionalmente mais elevada entre meninos (7,1\%). Apresentam maiores níveis de PA quanto maior o seu crescimento em estatura e um maior risco de elevação de PA associado a uma maior massa corpórea, maior AMB e menor proporção (\%) de AMB. A razão de circunferência da cintura para a estatura em escolares além de apresentar correlação com a PA elevada, se mostra, para ambos os sexos e nas diferentes idades, um bom marcador de alterações de pressão arterial.

Descritores: Pressão arterial. Obesidade. Composição corporal. Criança. Escolar 


\begin{abstract}
Introduction: The detection of Systemic Arterial Hypertension (SAH) in children is increasing and is being associated with increased prevalence of obesity in childhood. The evidence of the nutritional transition in schoolchildren makes it important to develop studies to evaluate the relationships between blood pressure (BP), growth and nutritional status of schoolchildren. Objectives: Evaluate BP, growth and nutritional status of children six and seven, and nine and 10 years of age, who attend public schools in Florianópolis, Santa Catarina
\end{abstract} Method: A cross sectional analytical study of a probabilistic sample of 1,082 school children from two age groups. The following anthropometric and body composition data were evaluated: Weight $(\mathrm{W})$, Height $(\mathrm{H})$, Triceps Skinfold Thickness (TST), Waist Circumference (WC), Abdominal Waist (AW), ratio of $\mathrm{WC} / \mathrm{H}$ and $\mathrm{AW} / \mathrm{H}$, Body Mass Index (BMI), Arm Fat Area (AFA) and Arm Muscle Area (AMA). These measurements were analysed based on the WHO reference (2007) and Frisancho tables. Blood pressure levels were individually classified in percentiles according to the U.S. benchmark test in relation to sex, age and height in line with the recommendations of the National High Blood Pressure Education Program Working Group on High Blood Pressure in Children and Adolescents (NHBPEP). We analysed the correlation between growth, nutritional status, body composition and BP of the two age groups, as well as the relationship between birth weight and nutritional status. Sensitivity and specificity analyses for the WC/H ratio were calculated by ROC curve. Results: The results showed that the school children had adequate growth and that these measurements were higher than the U.S. benchmark; blood pressure changes were observed in $13.8 \%$ of children, most often in the older group (17.6\%). The separate analysis of systolic and diastolic blood showed the same trend. Regarding nutritional status, $25.1 \%$ were overweight and $13.0 \%$ were obese; $4.4 \%$ of the sample evinced severe obesity (more frequent in boys, at $7.1 \%$ ) regardless of age. BP levels (systolic/diastolic) were higher in children 
with high z-scores for height. BP also was significantly associated with higher zscores for BMI, AFA, AMA, TST and $\mathrm{WC}, \mathrm{WC} / \mathrm{H}$ and $\mathrm{AW} / \mathrm{H}$ ratio, and an AMA smaller proportion (\%). In the multiple regression analysis, the $\mathrm{WC} / \mathrm{H}$ and $\mathrm{AW} / \mathrm{H}$ showed an OR of 25842.37, and in the ROC curve, the optimized cut-off point for the $\mathrm{WC} / \mathrm{H}$ was $>0.49$ (56.1\% of Sensitivity and $72.6 \%$ of Specificity). Conclusions: The school-children evinced adequate growth, higher than the values proposed by WHO, regardless their birth weight. They also showed a high frequency of pre-high blood pressure and of hypertension (13.7\%), which tends to increase with age. They had a high prevalence $(42.5 \%)$ of being overweight and obese, especially severely obese (7.1\% higher in boys). They presented greater BP levels associated with a higher stature, as well as an increased risk of BP elevation associated with a higher body mass index, a higher AMB and a smaller AMA proportion (\%). The ratio of waist circumference to height in school aged children, in addition to its correlation with elevated BP, has shown to be a good marker of changes in blood pressure for both sexes and in different age groups.

Descriptors: Pressure arterial. Obesity. Body composition. Child. School children. 


\section{ÍNDICE}

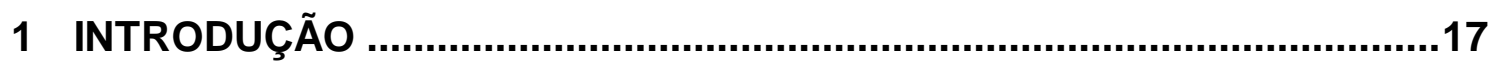

2 OBJETIVOS

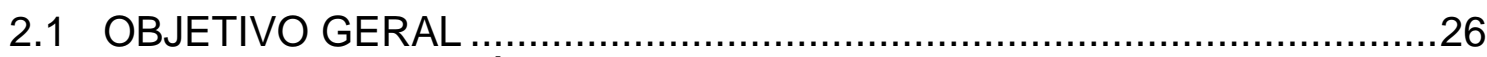

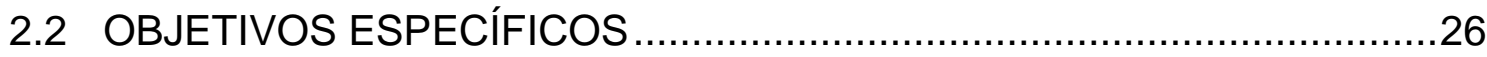

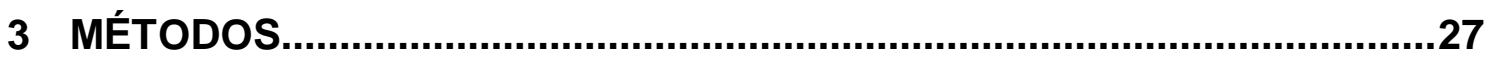

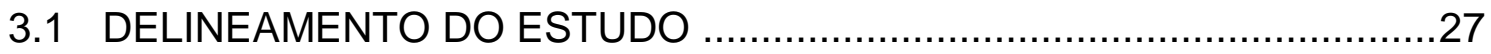

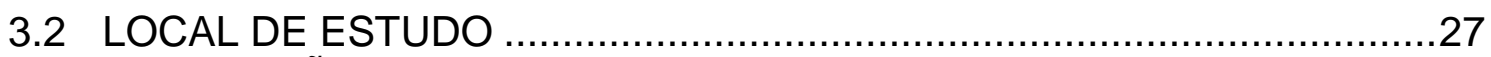

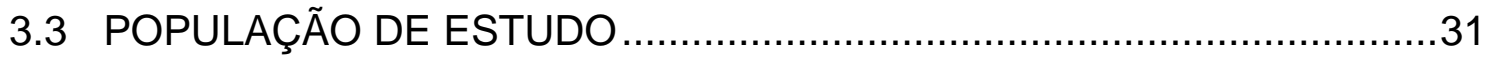

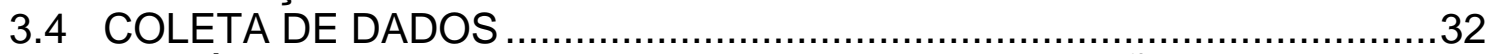

3.5 VARIÁVEIS DE ESTUDO E SUA OPERACIONALIZAÇÃO …......................

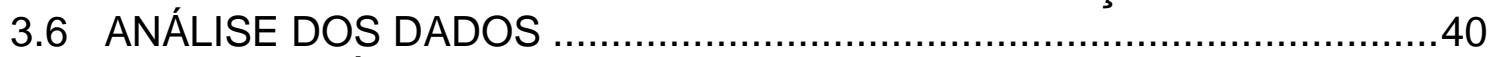

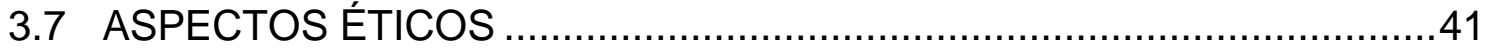

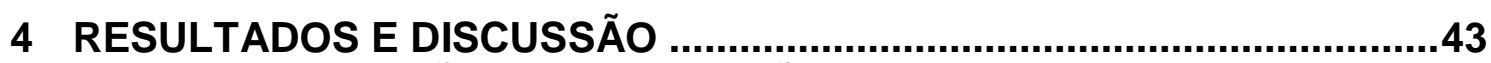

4.1 CARACTERIZAÇÃO DA POPULAÇÃO DO ESTUDO............................43

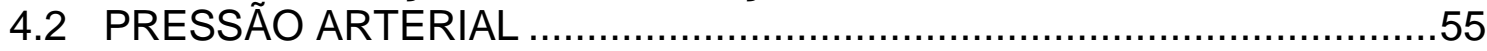

4.2.1 Pressão Arterial e Peso de Nascimento .........................................58

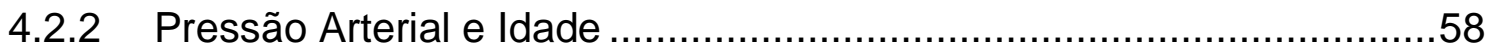

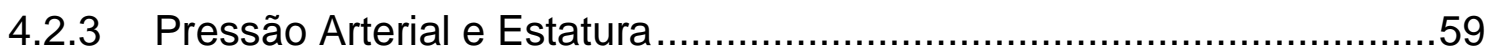

4.2.4 Pressão Arterial e Estado Nutricional ................................................67

4.2.5 Pressão Arterial e Composição Corporal.............................................70

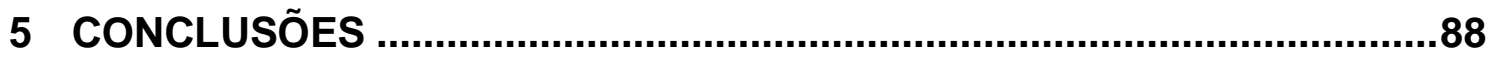

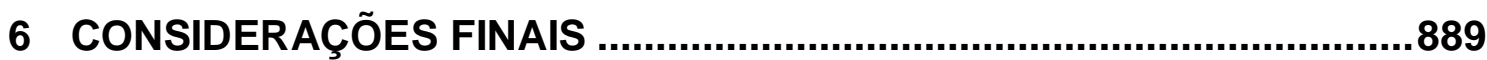

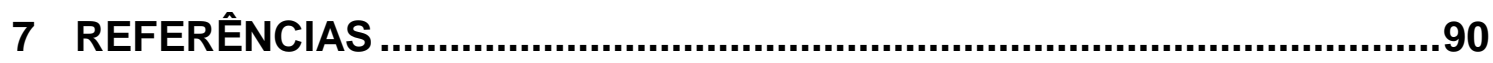

8 ANEXOS 


\section{LISTA DE ABREVIATURAS E SIGLAS}

\%AGB - Percentual de área gorda do braço

\%AMB - Percentual de área muscular do braço

\%AMBc - Percentual de área muscular do braço

AGB - Área gorda do braço

AMB - Área muscular do braço

ATB - Área total do braço

CA - Circunferência abdominal

CA/E - Razão circunferência abdominal para estatura

CB - Circunferência do braço

CC - Circunferência da cintura

CC/E - Razão circunferência da cintura para estatura

CIA - Software Confidence Interval Analysis

DCNT - Doenças crônicas não transmissíveis

DCV - Doenças cardiovasculares

ESF - Equipes de Saúde da Família

G1 - Grupo 1

G2 - Grupo 2

HAS - Hipertensão arterial sistêmica

IDH - Índice de Desenvolvimento Humano

IMC - Índice de Massa Corporal

NHANES III - National Health and Nutrition Examination Survey

NHBPEP - National High Blood Pressure Education Program

OMS - Organização Mundial da Saúde

PA - Pressão arterial

PAD - Pressão arterial diastólica

PAS - Pressão arterial sistólica

PCT - Prega cutânea tricipital

POF - Pesquisa de Orçamento Familiar 


$\begin{array}{ll}\text { PSE } & \text { - Programa Saúde na Escola } \\ \text { RCV } & \text { - Risco cardiovascular } \\ \text { SC } & \text { - Santa Catarina } \\ \text { SINASC } & \text { - Sistema de Nascidos Vivos } \\ \text { SISVAN } & \text { - Vigilância Alimentar e Nutricional do Escolar } \\ \text { SUS } & \text { - Sistema Único de Saúde } \\ \text { UDESC } & \text { - Universidade Estadual de Santa Catarina } \\ \text { UFSC } & \text { - Universidade Federal de Santa Catarina } \\ \text { zAGB } & \text { - Escore } z \text { da área gorda do braço } \\ \text { zAMB } & - \text { Escore } z \text { da área muscular do braço } \\ \text { zCB } & - \text { Escore } z \text { da circunferência do braço } \\ \text { zCC } & - \text { Escore } z \text { da circunferência da cintura } \\ \text { zE } & - \text { Escore } z \text { da estatura } \\ \text { zIMC } & - \text { Escore } z \text { do índice de massa corpórea } \\ \text { zP } & - \text { Escore } z \text { do peso } \\ \text { zPCT } & - \text { Escore } z \text { da prega cutânea tricipital }\end{array}$




\section{LISTA DE FIGURAS}

Figura 1 - Mapa de Florianópolis com escolas municipais e estaduais........ 28

Figura 2 - Distribuição do peso de nascimento dos escolares segundo os grupos de idade.

Figura 3 - Curva de distribuição da frequência de escolares segundo escore $z$ da estatura.

Figura 4 - Curvas de distribuição da frequência de escolares segundo escore $z$ de estatura por sexo.

Figura 5 - Curvas de distribuição da frequência de escolares segundo escore $z$ de estatura por grupos de idade.

Figura 6 - Distribuição da frequência de escolares segundo escore z de peso para idade.

Figura 7 - Curvas de distribuição da frequência de escolares segundo escore $z$ de peso por sexo.

Figura 8 - Curvas de distribuição da frequência de escolares segundo escore $z$ de peso por idade.

Figura 9 - Curvas de distribuição da frequência de escolares segundo escore $z$ de IMC

Figura 10 - Distribuição dos escolares segundo estado nutricional com base no escore $z$ de Índice de Massa Corporal dos escolares.

Figura 11 - Curva de distribuição da frequência de escolares segundo o escore $z$ da circunferência da cintura.

Figura 12 - Relação da Pressão arterial sistólica (PAS) dos escolares com escore $z$ de estatura (HAZ).

Figura 13 - Relação da Pressão arterial diastólica (PAD) dos escolares com escore $z$ de estatura (HAZ).

Figura 14 - Relação da Pressão arterial sistólica (PAS) dos escolares do G1 com escore z de estatura (HAZ 6-7). 
Figura 15 - Relação da Pressão arterial diastólica (PAD) dos escolares do G1 com escore z de estatura (HAZ 6-7).

Figura 16 - Relação da Pressão arterial sistólica (PAS) dos escolares do G2 com escore $z$ de estatura (HAZ 9-10)

Figura 17 - Relação da Pressão arterial diastólica (PAD) dos escolares com escore $z$ de estatura do G2 (HAZ 9-10)

Figura 18 - Relação da Pressão arterial sistólica (PAS) dos escolares com escore $z$ de estatura do sexo feminino (HAZ F).

Figura 19 - Relação da Pressão arterial diastólica (PAD) dos escolares com escore $z$ de estatura do sexo feminino (HAZ F).

Figura 20 - Relação da Pressão arterial sistólica (PAS) dos escolares com escore $z$ de estatura do sexo masculino (HAZ M).

Figura 21 - Relação da Pressão arterial diastólica (PAD) dos escolares com escore $z$ de estatura do sexo masculino (HAZ M).

Figura 22- Relação da Pressão arterial sistólica (PAS) dos escolares e ZIMC.

Figura 23 - Relação da Pressão arterial diastólica (PAD) dos escolares e zIMC (OMS).

Figura 24 - Relação da Pressão arterial sistólica dos escolares (PAS) e Circunferência da cintura (CC) em centímetros.

Figura 25 - Relação da Pressão arterial diastólica (PAD) dos escolares e Circunferência de Cintura (CC) em centímetros.

Figura 26 - Relação da Pressão arterial sistólica (PAS) dos escolares e escore $z$ de Circunferência de cintura (zCC)

Figura 27 - Relação da Pressão arterial diastólica (PAD) dos escolares e escore $z$ de Circunferência de cintura ( $z C C)$. .72

Figura 28 - Relação da Pressão arterial sistólica (PAS) com a razão da circunferência cintura pela estatura (CC/E) em escolares.

Figura 29 - Relação da Pressão arterial diastólica (PAD) e razão da circunferência da cintura pela estatura (CC/E).

Figura 30 - Relação da Pressão arterial sistólica (PAS) e razão da circunferência abdominal pela estatura (CA/E)

Figura 31 - Relação da Pressão arterial diastólica (PAD) e razão da circunferência abdominal pela estatura (CA/E).

Figura 32 - Relação da Pressão arterial sistólica (PAS) dos escolares e $z$ de Área Magra do Braço (zAMB). 
Figura 33 - Relação da Pressão arterial diastólica (PAD) dos escolares e z de Área Magra do Braço (zAMB).

Figura 34 - Relação da Pressão arterial sistólica (PAS) e escore z de Área Gorda do Braço (zAGB).

Figura 35 - Relação da Pressão arterial diastólica (PAD) e escore z de Área Gorda do Braço (AGB).

Figura 36 - Relação da Pressão Arterial Sistólica (PAS) dos escolares com escore $z$ de Prega cutânea Tricipital (zPCT)

Figura 37 - Relação da Pressão arterial diastólica (PAD) dos escolares com escore $z$ de Prega cutânea Tricipital (zPCT).

Figura 38 - Relação entre a Pressão arterial sistólica (PAS) e porcentagem da área muscular do braço (\%AMB).

Figura 39 - Relação entre a Pressão arterial diastólica (PAD) e porcentagem da área muscular do braço (\%AMB).

Figura 40 - Área Sob a Curva ROC da CC/E .85 


\section{LISTA DE TABELAS}

Tabela 1 - Distribuição das frequências dos escolares segundo sexo e faixa etária.

Tabela 2 - Distribuição dos escolares segundo o diagnóstico nutricional e sexo.

Tabela 3 - Medidas de tendência central e dispersão das características antropométricas dos escolares segundo grupos de idades.

Tabela 4 - Medidas de tendência central e dispersão das características antropométricas dos escolares segundo sexo.

Tabela 5 - Médias dos indicadores de composição corporal dos escolares, segundo os grupos de idades.

Tabela 6 - Médias de indicadores de composição corporal dos escolares, segundo o sexo.

Tabela 7 - Medianas e dispersão dos valores da prega cutânea tricipital (PCT) e da relação da cintura abdominal pela estatura (CA/E) dos escolares, segundo grupos de idade e sexo.

Tabela 8 - Distribuição dos escolares conforme a classificação de sua alteração de Pressão Arterial Sistólica (PAS) ou Diastólica (PAD).

Tabela 9 - Distribuição das frequências de escolares conforme classificação de Pressão Arterial dos escolares por sexo.

Tabela 10 - Distribuição das frequências de escolares conforme classificação de PAS e PAD alteradas dos escolares, por grupos etários.

Tabela 11 - Regressão Binária Logística Stepwise Backward de Wald .84

Tabela 12 - Ponto de Corte, Sensibilidade e Especificidade da Razão da CC/E 


\section{INTRODUÇÃO}

A Hipertensão Arterial Sistêmica (HAS) em crianças tornou-se um foco de interesse crescente devido à sua elevada prevalência, que vem sendo relacionada ao aumento da obesidade infantil, embora evidências atuais sugiram que outros fatores também estejam associados à elevação da Pressão Arterial (PA) tais como estilo de vida, falta de atividade física, comportamento sedentário e ingestão dietética de sal ${ }^{1-7}$.

Inquéritos realizados em crianças e adolescentes americanos nos períodos de 1988-1994 e 1999 a 2002 mostraram que a pressão arterial sistólica aumentou ligeiramente $(1,3 \mathrm{mmHg})$, a diastólica aumentou substancialmente $(8,4 \mathrm{mmHg})$ e a prevalência de pressão arterial elevada cresceu de $2,7 \%$ para $3,7 \%$ levando os autores a concluir que os níveis de PA estavam em elevação. Os mesmos observaram também, que o Índice de Massa Corporal (IMC) está mais fortemente associado com a Pressão Arterial Sistólica (PAS) do que com a Pressão Arterial Diastólica (PAD) em crianças e, que esse aumento seria decorrência da epidemia de obesidade. Estudos, sobre as discordâncias de tendências seculares de elevação da PA e obesidade em crianças e adolescentes, verificaram um aumento, porém não tão acentuado quanto à pressão arterial média, na última década, como seria esperado nessas análises a partir da situação epidemiológica de obesidade $e^{3,8-11}$.

Uma pesquisa sobre o aumento de HAS na infância mostrou que a proporção de crianças com diagnóstico de hipertensão durante a hospitalização dobrou nos últimos 20 anos, mostrando que a hipertensão em crianças já não pode ser considerada como um diagnóstico apenas para ser observado, pois a 
doença pode ter consequências importantes em pacientes pediátricos em termos de manifestações clínicas, complexidade e o do custo global de tratamento $^{12,13}$

Outras pesquisas atuais ${ }^{14,15}$ verificam que com o aumento de excesso de peso há um crescimento mundial da prevalência de HAS na infância e adolescência e que, essa guarda relação direta com o grau da obesidade, sendo considerado efeito aditivo: quanto maior o IMC maior a possibilidade de HAS, podendo associar-se à hiperinsulinemia e à presença de gordura centrípeta. Isto justifica a inclusão da avaliação de PA em estudos, com a finalidade de verificar Risco Cardiovascular (RCV) e sua relação com o excesso de peso ${ }^{16-18}$. A possibilidade de desenvolvimento de doenças crônicas, já na infância, exige pensar em políticas de saúde, dando ênfase à prevenção ${ }^{11,19-22}$.

Em crianças brasileiras estudos recentes revelaram prevalências de HAS que variam de $3,6 \%$ a $16,6 \%$ e sugerem que a HAS do adulto pode ter início na infância. Porém, em decorrência da falta da medição de PA em crianças e a crença de que hipertensão arterial não ocorre nesta faixa etária, muitas vezes deixa-se de fazer o diagnóstico de HAS, já nesta fase da vida, onde a intervenção precoce poderia prevenir agravamento desta patologia no futuro ${ }^{23,24}$.

A obesidade é considerada a epidemia do século XXI pela Organização Mundial da Saúde (OMS). O aumento da sua prevalência é observado em todas as faixas etárias, especialmente nos países em desenvolvimento, o que a caracteriza como um importante problema de saúde pública. Os números totais estimados de adultos com sobrepeso e obesos em 2005 no mundo foram de 
937 milhões e 396 milhões, respectivamente. Para 2030, o respectivo número de adultos com sobrepeso e obesidade havia sido projetado para ser de 1,35 bilhões e 573 milhões de indivíduos, entretanto se as tendências seculares recentes continuarem crescentes, os números absolutos seriam projetados para o total de 2,160 bilhões de sobrepeso e 1,12 bilhão de indivíduos obesos ${ }^{11,25-28}$.

A obesidade infantil afeta tanto os países desenvolvidos quanto os em desenvolvimento e todos os grupos socioeconômicos, independentemente da idade, sexo ou etnia. Estima-se que em todo o mundo mais de 22 milhões de crianças menores de cinco anos são obesas e que uma em cada 10 crianças tenha excesso de peso. A prevalência de excesso de peso varia no mundo: na África e na Ásia estaria ao redor de 10\% e nas Américas e na Europa acima dos $20 \%$, enquanto nos Estados Unidos, já afeta parcela mais significativa da população ${ }^{29-31}$.

No Brasil, a Pesquisa de Orçamento Familiar (POF) realizada em 20082009, constatou que o sobrepeso e a obesidade aumentaram, atingindo, respectivamente, $21,7 \%$ e $5,9 \%$ dos adolescentes e $34,8 \%$ e $16,6 \%$ das crianças nos anos pesquisados. Ao iniciar a infância, o excesso de peso já pode predispor os indivíduos a Doenças Crônicas Não Transmissíveis (DCNT), como a dislipidemia, diabetes mellitus tipo 2 (DM2) e PA elevada ${ }^{31,32,33}$.

No Brasil, desde 2007 as DCNT se tornaram uma prioridade de saúde pública, por serem responsáveis por $72 \%$ das mortes. A hipertensão e outras doenças cardiovasculares vêm aumentando e respondem por $30 \%$ das mortes, representando altos custos, diretos ou indiretos para o sistema de saúde no país ${ }^{22,34}$. 
Considerando que a obesidade está relacionada ao desenvolvimento de doenças crônicas, a identificação de crianças com fatores de risco é de grande interesse, tanto clínica quanto na saúde pública, pois o ganho de peso na infância está fortemente associado com o risco de doença cardiovascular no futuro. Além disso, a obesidade infantil pode levar a alterações neurológicas, endócrinas, cardiovasculares, pulmonares, complicações gastrointestinais, renais e músculo esquelético. Também tem sido descrito que as crianças com sobrepeso e obesidade são mais propensas a ter baixa autoestima, taxas mais elevadas de transtornos de ansiedade, depressão e outras distúrbios psicológicos que, por sua vez, podem afetar o desempenho na escola ${ }^{31}$.

Os padrões de crescimento intrauterino podem desempenhar um papel significativo na etiologia da obesidade, modificando gordura e massa magra corporal, os mecanismos neuroendócrinos de controle do apetite e as capacidades funcionais do pâncreas. Existe uma importante relação entre peso ao nascer e IMC alcançado na vida adulta ${ }^{35-38}$, sendo que a elevação do peso de nascimento tem sido linearmente associada com o aumento da prevalência da obesidade infantil. Além disso, bebês de baixo peso ao nascer mostram tendência significativa de acumular adiposidade central e resistência à insulina muito cedo na vida. Esses dois fatores são conhecidos, por aumentar o risco cardiovascular e, o crescimento acelerado e o aumento da adiposidade precoce elevam as chances das crianças se tornarem adultos obesos. A combinação de baixo peso ao nascer e maior IMC está associado também, a um alto risco cardiovascular ${ }^{39-42}$.

Como consequência, diversos estudos tem sugerido uma associação entre o peso ao nascer com obesidade na infância e na vida adulta e com o 
aumento do risco para Doenças Cardiovasculares (DCV), obesidade abdominal e síndorme metabólica ${ }^{35,43-49}$. Vários pesquisadores sugerem que um crescimento fetal e na primeira infância adequados poderiam levar a reduções substanciais na incidência de DCV na idade adulta ${ }^{7,50,51}$.

Estudo sobre a correlação do peso ao nascer e a obesidade infantil observam que esta independe do peso e do comprimento ao nascimento, porém conclui que a razão média de ganho de peso por crescimento de altura em cm, desde o nascimento, demonstra correlação com o IMC de crianças em idade pré-escolar ${ }^{52}$.

Uma pesquisa de metanálise, contrariamente ao estudo anterior evidenciou ainda artigos que relacionam o baixo peso ao nascer como preditor de gordura corporal, particularmente na região abdominal, mostrando inclusive, uma associação do catch-up growth com sobrepeso e obesidade ${ }^{53}$.

Outros fatores estão relacionados à obesidade, como por exemplo, a predisposição genética, mas as proporções epidêmicas dessa condição indicam que o ambiente desempenha um papel significativo no crescimento da prevalência do excesso de peso como um todo ${ }^{54}$.

O fácil acesso aos alimentos de alta densidade energética e a diminuição de atividade física, a exposição a alimentos processados e baratos que contêm grandes quantidades de gordura, sal e açúcar, embalados ou vendidos em grandes porções, em associação com o sedentarismo decorrente de um maior acesso aos meios de transporte -, e do aumento de atividades de lazer passivas, incluindo a TV e jogos de computador são descritos como motivos para a importante elevação da prevalência da 
obesidade que é observada desde o século passado. Ainda, considerando que o risco de obesidade é maior para crianças, quando pelo menos um dos pais tem excesso de peso, é concebível imaginar que também, um ambiente familiar mais adequado pode fazer diferença na determinação desse agravo ${ }^{55-57}$.

As transformações sucessivas nos determinantes sociais ocorridas no Brasil, nas últimas três décadas e o crescimento da renda, a industrialização e mecanização da produção, urbanização, maior acesso a alimentos em geral, incluindo os processados, e a globalização de hábitos não saudáveis produziram uma rápida transição nutricional, expondo cada vez mais a população ao risco de doenças crônicas. Estudos que analisam os fatores socioeconômicos da população indicam que a obesidade acontece nas populações de todas as categorias sociais, porém, atualmente naqueles de menor renda a sua prevalência tende a ser maior, e que também, há relação desse desfecho com a menor escolaridade das famílias ${ }^{58-61}$.

A ascensão social das famílias com a exposição ampla a publicidade com apelo ao consumo de alimentos, particularmente daqueles obesogênicos, e guloseimas de menor preço e pior qualidade, também contribui com o aumento da obesidade, sobretudo em camadas sociais mais vulneráveis, sendo as crianças o grupo populacional que é mais diretamente influenciado, inclusive pelos hábitos alimentares de suas famílias. As práticas de alimentação são importantes determinantes das condições de saúde na infância e influenciam no crescimento e desenvolvimento infantil, sendo o consumo de alimentos ricos em gorduras e muito calóricos, um risco para o desenvolvimento da obesidade e de doenças crônicas, como a hipertensão arterial, que podem iniciar na própria infância ${ }^{60,62-66}$. 
Quanto à avaliação nutricional, importantes evidências científicas recomendam a utilização do IMC em conjunto com a circunferência abdominal para identificar situações de risco cardiovascular ${ }^{67-75}$. Em adultos se considera que o tecido adiposo intra-abdominal é o tipo mais relevante clinicamente de gordura corporal e que leva a complicações metabólicas como HAS, hiperinsulinemia, diabetes tipo 2 e dislipidemia ${ }^{76,77}$.

Em crianças e adolescentes, o estudo de Bugalusa ${ }^{85}$ sobre a relação da Circunferência Abdominal (CA) e de pregas cutâneas com a concentração de lípideos e insulina identificou a importância de avaliar distribuição de gordura corporal. Diversos autores recomendam medir a CA em crianças, considerando que sua obtenção é fácil e pode ajudar a identificar os casos que deveriam se submeter a outras avaliações como análise de lípidios, insulina e pesquisa de outros fatores preditivos para DCV. Também, a avaliação de pregas cutâneas pode ser eficiente na medida em que fornecem estimativas mais precisas e exatas da gordura e massa corporal e, valores elevados, estão associados a disfunções fisiológicas como hipertensão arterial $^{64,78-84,86-87}$.

Dentre os índices relacionados à elevação da PA, o mais estudado é o IMC que é comumente utilizado para identificar obesidade. No entanto, a Circunferência da Cintura (CC), em comparação com o IMC, é melhor para a investigação de alterações metabólicas, tais como hipertensão e glicemia de jejum alterada e é considerada como muito útil na detecção de riscos cardiovasculares e metabólicos. Embora o aumento da CC seja bem definido como um fator de risco em adultos e em crianças, poucos estudos investigaram a sua associação com a elevação da pressão arterial ${ }^{6,76,88-91}$. Além da CC, 
outros índices como a relação cintura-quadril e a relação cintura-altura têm sido usados para prever o risco de obesidade e suas comorbidades, e também, para avaliar o acúmulo de adiposidade central ${ }^{72,92,93}$.

Em adultos, a razão da Circunferência Abdominal pela Estatura (CAE/E) é cada vez mais utilizada, para avaliar o risco para as doenças relacionadas com a adiposidade central. A lógica deste índice é que, para uma dada altura, existe um grau aceitável de gordura armazenada na parte superior do corpo. Um valor limite de 0,50 de razão de $C A / E$ é proposto como um meio simples de indicar a quantidade de acúmulo de gordura corporal superior em adultos, que, quando superado é indicativo de risco para saúde. Esta razão demonstra que esse é um método não invasivo, prático e superior em sua capacidade de prever fatores de RCV, quando comparada a outros indicadores, como o IMC ou o percentual de gordura corpórea, entretanto, sua utilização ainda não foi completamente estudada em crianças, particularmente entre as mais jovens ${ }^{85,94-97}$.

Em relação a intervenções que diminuam esses riscos considera-se que, o ambiente escolar é propício para o estímulo a hábitos saudáveis de vida, porque as crianças passam grande parte de seu tempo nesse local e, a escola é um local importante para a implementação de políticas de saúde como a prevenção da obesidade e a redução do excesso de peso. As escolas, além disso, possuem também ferramentas pedagógicas que permitem a inserção dessas temáticas no currículo, exercendo deste modo, influência direta no desenvolvimento infantil, e que, além disso, podem contribuir para que ocorram mudanças nos hábitos alimentares das famílias e até na comunidade escolar ${ }^{66}$. 
Em Florianópolis, a transição nutricional já descrita em pesquisa realizada em 2002 por Soar et al. ${ }^{98,}$ encontraram prevalências de sobrepeso e obesidade de $17,9 \%$ e $6,7 \%$, respectivamente, em escolares de escolas públicas. Na última Pesquisa Nacional de Saúde do Escolar - PeNSE 2012 -, realizadas com alunos do $9^{\circ}$ ano do Ensino Fundamental, nas Capitais brasileiras, Florianópolis é o segundo local do País, em que a maior parcela dos escolares se percebiam gordos ou muito gordos $(21,9 \%)$, sendo que na pesquisa de 2009 os percentuais já eram semelhantes ${ }^{81}$.

Em decorrência da epidemia de obesidade que ocorre em nosso país e a elevação da PA que também é descrita em crianças, bem como as suas inter-relações e possíveis determinantes, e a necessidade de aprofundar o seu conhecimento nessa região, de modo a fornecer subsídios que contribuam para a realização de intervenções precoces, optou-se por realizar a presente pesquisa na cidade de Florianópolis.

Com esta finalidade, avaliou-se a PA em escolares de duas gerações de educandos - uma que estava no início do ensino fundamental, aos seis anos de idade e outra no quarto ano escolar aos dez anos de idade - quando a criança se encontra na transição para a adolescência e início da puberdade -, buscando analisar a sua correlação com o crescimento alcançado, o estado nutricional, a composição corporal e o peso de nascimento das crianças, indicadores considerados como preditivos do risco de elevação da pressão arterial. 


\section{OBJETIVOS}

\subsection{OBJETIVO GERAL}

Avaliar a pressão arterial, o crescimento, o estado nutricional e a composição corporal, assim como suas respectivas relações em crianças em idade escolar.

\subsection{OBJETIVOS ESPECÍFICOS}

Analisar em escolares de seis e sete anos e de nove e dez anos de idade, frequentadores de escolas públicas:

a) A prevalência de pré-hipertensão e de hipertensão arterial.

b) O crescimento alcançado.

c) A prevalência de sobrepeso e de obesidade.

d) As relações entre elevação da pressão arterial e indicadores de composição corporal: o índice de massa corpórea, a prega cutânea tricipital, a área gorda e a área muscular do braço, a razão da circunferência da cintura e da circunferência abdominal pela estatura.

e) As relações entre peso de nascimento, crescimento, estado nutricional, composição corporal e a elevação da pressão arterial.

f) A utilização da razão da circunferência da cintura para a estatura como marcador indicativo de elevação de pressão arterial em escolares. 


\section{MÉTODOS}

\subsection{DELINEAMENTO DO ESTUDO}

Esse é um estudo transversal e analítico da pressão arterial, crescimento e estado nutricional dos seguintes grupos etários de escolares das escolas municipais e estaduais de Florianópolis: de seis e sete anos e de nove e dez anos de idade.

\subsection{LOCAL DE ESTUDO}

O presente estudo foi realizado em Florianópolis que é a Capital de Santa Catarina (SC) e está localizada no centro-leste do Estado, banhada pelo Oceano Atlântico, sendo que grande parte do município (97,23\%) está situada na llha de Santa Catarina. A economia básica do município são as atividades de comércio, prestação de serviços públicos, indústria de transformação e turismo. A área do município, que inclui a parte continental, perfaz $436,5 \mathrm{~km}^{2}$. A porção continental tem área apenas de $12,1 \mathrm{~km}^{2}$ e limita-se a oeste com 0 município de São José.

Segundos dados do IBGE ${ }^{99}$ de 2011, a população de Florianópolis é de 427.298 habitantes e representa 6,8\% da população estadual. De 1991-2000, o município teve uma taxa média de crescimento anual de 3,3\% e uma taxa de urbanização que passou de 94 a 97\%. Em 2000, o Índice de Desenvolvimento Humano (IDH) foi 0,875 , sendo que valores maiores que 0,8 são considerados elevados. 
Figura 1 - Mapa de Florianópolis com escolas municipais e estaduais.

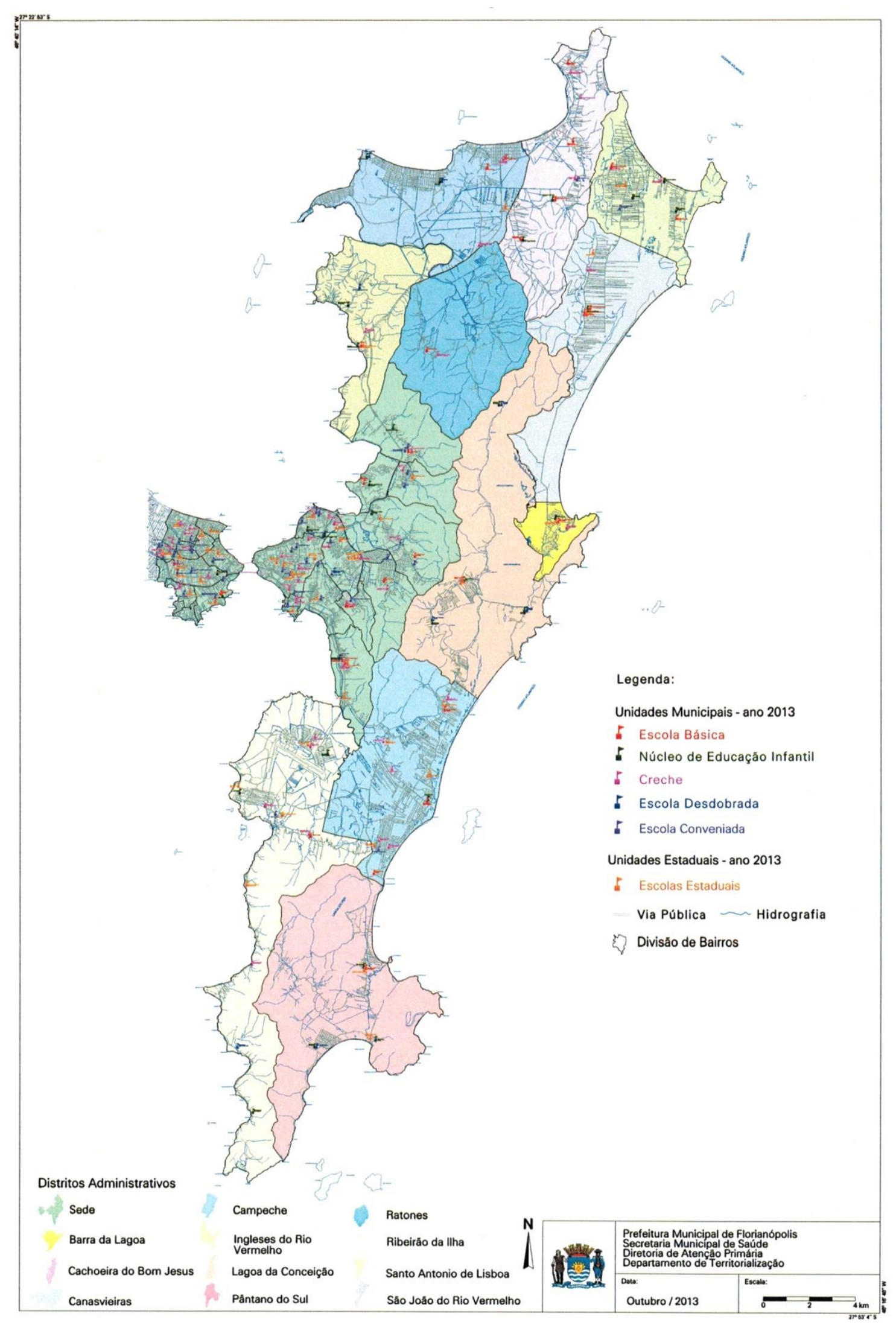


A renda per capita média de Florianópolis cresceu 95,03\% nas últimas duas décadas. A extrema pobreza (medida pela proporção de pessoas com renda domiciliar per capita inferior a $R \$ 70,00$ reais em agosto de 2010) passou de $2,75 \%$ em 1991 para $1,10 \%$ em 2000 e para 0,27\% em 2010. A desigualdade diminuiu: o Índice de Gini, que mede a concentração de renda passou de 0,55 em 1991 para 0,56 em 2000 e para 0,54 em 2010. Florianópolis é também a cidade brasileira que mais enriqueceu nas últimas três décadas. Seu PIB per capita cresceu, em média, $6 \%$ por ano e atualmente é $R \$ 19,6$ mil - acima da média brasileira ${ }^{99}$.

Quanto à distribuição populacional houve um incremento de 78.925 habitantes em Florianópolis (crescimento de 18,78\%) no período entre 2000 e 2010, mas foi desigual entre os grupos etários, com diminuição importante da proporção de menores de dez anos e aumento significativo da proporção de idosos $^{99}$. Tal fato, aponta para a necessidade de implementação de políticas públicas de saúde com foco na promoção de saúde, qualidade de vida e prevenção de doenças crônico-degenerativas já a partir da infância.

O Sistema Único de Saúde (SUS) em Florianópolis se organiza com a finalidade de buscar um sistema de saúde equânime, integral e resolutivo, para propiciar o atendimento com qualidade dos problemas de saúde da população local por meio de ações articuladas entre os diferentes níveis de complexidade da atenção à saúde.

Quanto à saúde infantil a Secretaria Municipal de Saúde possui há 14anos anos o Programa Capital Criança que garante o atendimento das crianças de Florianópolis desde a maternidade com acompanhamento agendado, sistematicamente durante os primeiros cinco anos de vida. 
O cuidado com a saúde das crianças em Florianópolis contribuiu com a redução importante, na última década, da taxa de mortalidade infantil, que é um indicador de qualidade de vida. Vem apresentando valores com menos de dois dígitos desde 2004, com uma diminuição de 54,3\% entre 1994 e 2011. Se estendermos o período observado até 2013, a diminuição da taxa municipal chega a $71,9 \%$ no período.

Assim, em 2013, Florianópolis atingiu marca histórica na Saúde: a taxa de mortalidade infantil no primeiro ano de vida ficou em apenas 5,2 por 1.000 nascidos vivos, uma redução de $46 \%$ em relação com 2012. É a capital com a menor taxa de mortalidade do Brasil, comparável a taxas de países como Noruega e Suécia, sendo que a prevalência de maior mortalidade, ainda está concentrada em áreas de interesse social. Esses dados são investigados e acompanhados pelo Comitê de Mortalidade Infantil que têm papel estratégico em apoiar a rede de atenção à saúde no município para reduzir os óbitos infantis evitáveis.

O município tem também, quase $100 \%$ de cobertura de equipes de Saúde da Família na Atenção Básica e esse é um fator facilitador no desenvolvimento das ações de promoção e monitoramento da saúde dos educandos de cada território adstrito às escolas.

Indicadores educacionais também demostram o nível de qualidade de vida em Florianópolis como a proporção de crianças e jovens frequentando ou tendo completado determinados ciclos de educação. No período de 2000 a 2010, a proporção de crianças de cinco a seis anos na escola cresceu $21,31 \%$. A proporção de crianças de 11 a 13 anos frequentando os anos finais do 
ensino fundamental no mesmo período, cresceu $24,29 \%$. Atualmente a taxa de evasão escolar é cerca de 1\%, na oitava série.

O ensino fundamental em Florianópolis, foco de nossa pesquisa, está dividido aproximadamente em $50 \%$ dos educandos em escolas de gestão municipal e outra metade ainda com gestão estadual e ainda, uma escola de gestão federal. O processo de municipalização, do ensino fundamental, embora recomendação do Ministério da Educação, ainda é muito lento.

Desde 2007, o Programa Saúde na Escola (PSE), vem trabalhando de forma intersetorial - saúde e educação -, para a promoção e atenção à saúde e educação integral dos educandos da cidade, inicialmente do ensino fundamental, contemplando praticamente $100 \%$ das escolas estaduais e municipais da Capital. A partir de 2013, passaram a ser comtemplados os educandos do ensino infantil, garantindo a promoção do desenvolvimento infantil, já na primeira infância, com ações intersetoriais da saúde e educação.

Uma das ações é realizar anualmente a avaliação nutricional dos educandos para monitorar o estado nutricional e propor estratégias de controle às alterações nutricionais, sendo que os dados são registrados no Sistema de Vigilância Alimentar e Nutricional do Escolar (SISVAN).

\subsection{POPULAÇÃO DE ESTUDO}

Foram coletados dados de 1082 crianças subdivididas em dois grupos de idade, seis e sete anos e de nove e dez anos, a partir das turmas do ensino fundamental das escolas municipais e estaduais da rede pública de educação de Florianópolis. 
Para o cálculo do tamanho da amostra a ser utilizada empregou-se o Software Confidence Interval Analysis (CIA) 2.1.2. Para um poder de teste de $80 \%$ e um a de $5 \%$ e considerando a presença de uma diferença entre os dois grupos de idade de pelo menos um quarto de desvio padrão na mediana de escore Z de IMC estimou-se ser necessário um número de 250 crianças em cada grupo de idade e para cada sexo.

Realizou-se uma amostragem por conglomerados, de maneira probabilística e aleatória, a partir da listagem das classes de escolares fornecida pelo Departamento de Ensino Fundamental das Secretarias Municipal e Estadual de Florianópolis. As unidades amostrais (classe) foram sorteadas aleatoriamente de maneira probabilística e sucessiva, até que o lote amostral estimado de 250 crianças estivesse completo, em cada idade, seis e sete anos e de nove e dez anos, e sexo.

\subsection{COLETA DE DADOS}

Esta avalição ocorreu no primeiro semestre do ano letivo de 2012 e foi realizada em cada unidade escolar. Nesta ocasião os sujeitos da pesquisa (crianças) foram identificados a partir das listagens de frequência das classes sorteadas nas escolas.

Os dados antropométricos das crianças foram tomados na própria escola, em dias devidamente agendados. Estes dados foram coletados com a colaboração de uma mestranda de Fisioterapia da Universidade Estadual de Santa Catarina (UDESC) e uma aluna do sexto ano do Curso de Medicina da Universidade Federal de Santa Catarina (UFSC) e pela pesquisadora, após prévio 
treinamento e capacitação segundo técnicas aceitas internacionalmente ${ }^{100}$, utilizando instrumentos padronizados para a coleta e preenchimento dos dados, sempre com a supervisão da pesquisadora.

As variáveis obtidas foram idade, sexo, peso, estatura, perímetro braquial, Prega Cutânea Tricipital (PCT), duas medidas de cintura abdominal, as razões das CC/E e CA/E, PN e pressão arterial.

Para avaliação do peso utilizou-se balança digital da marca CADENCE $^{\circledR}$ Modelo Bal150 (Cachoeira do Sul, RS - Brasil), devidamente calibrada, com capacidade para $150 \mathrm{~kg}$ e subdivisões de 100 gramas, e o registro dos valores foi feito até uma casa decimal. Os escolares foram pesados com um mínimo de roupa possível, somente com camiseta e calça, descalços e sem o uso de chapéu ou boné, sendo posicionados em pé sobre a plataforma da balança com o peso do corpo igualmente distribuído entre os pés, os braços caídos ao longo do corpo e olhando para frente ${ }^{100}$.

Para aferição da estatura utilizou-se um estadiômetro da marca WISO ${ }^{\circledR}$, fixado à parede, graduado em centímetros, sendo considerada a precisão de uma casa decimal $(\mathrm{mm})$. Os escolares foram medidos eretos, descalços, vestindo roupa leve e sem adereços nos cabelos, em posição ortostática, com a cabeça posicionada de modo que o plano de Frankfurt (o qual passa pela órbita e pelo meato auditivo externo) ficasse horizontalizado, joelhos esticados, pé juntos, braço solto ao longo do corpo e com calcanhares, panturrilha, glúteos, omoplata e dorso da cabeça da criança mantida em contato com a superfície plana da parede. Antes da leitura da medida, o escolar foi posicionado firmemente, enquanto a haste móvel do estadiômetro era deslocada até a parte superior da cabeça (vértex). A medida foi registrada no milímetro mais próximo ao observado no estadiômetro ${ }^{100}$. 
Os valores mensurados de peso e estatura foram transformados em escore z com base nos valores do referencial da OMS de $2007^{100-102}$.

Obtiveram-se a CC e CA com a criança ereta, braços relaxados ao lado do corpo, pés juntos, abdômen relaxado e foi medida com fita métrica inextensível e flexível, graduada em centímetros e milímetros, tendo como referência a cicatriz umbilical e as espinhas ilíacas póstero-superiores; foram utilizadas duas medidas, uma que passa sobre a cicatriz umbilical circunferência da cintura - e outra obtida por uma linha horizontal imaginária que passa no ponto médio entre a borda inferior da última costela e a crista ilíaca - circunferência abdominal. Considerou-se apenas uma unidade após a vírgula. Realizou-se a leitura das medidas no momento da expiração ${ }^{103-106}$.

A avaliação do perímetro braquial foi realizada com fita métrica inextensível, com espessura de $0,5 \mathrm{~cm}$ com precisão de $0,1 \mathrm{~cm}$; localizou-se e marcou-se o ponto médio do braço; foi solicitado para a criança abduzir levemente o braço para colocar a fita métrica; posicionando a fita sobre o ponto médio e com o braço relaxado verificou-se se a fita estava alinhada em um plano horizontal; aplicou-se tensão a fita, de modo que ela se ajustou firmemente em torno do braço, envolvendo sem comprimir o ponto médio do braço não dominante, entre o processo acromial e o olécrano, com a criança em posição ortostática ${ }^{107}$. O perímetro braquial foi utilizado para cálculo da massa gorda e massa muscular do braço ${ }^{100,108}$.

Para obter a prega cutânea tricipital, utilizou-se um adipômetro, modelo Lange $^{\circledR}$ de pressão constante, devidamente calibrado e com a criança ereta, como os braços relaxados ao lado do corpo, marcou-se o ponto médio entre o 
processo acromial e o olécrano. $\mathrm{O}$ antropometrista se posicionava atrás da criança, pinçava a prega cutânea verticalmente na face posterior do braço, um centímetro acima do ponto médio entre processo acromial e o olécrano, e, destacada a prega cutânea, com o calibrador na mão direita foram colocadas as hastes do adipômetro perpendiculares à prega no ponto médio do braço, mantendo o pinçamento e a prega pressionada, enquanto era realizada a leitura da medida ${ }^{84,107,109}$.

A pressão arterial foi obtida por meio de medida única de um mesmo examinador, após a criança estar em repouso por aproximadamente cinco minutos, com esfigmomanômetro aneroide para medir pressão arterial com braçadeira nos tamanhos infantil (dimensão de 15,0 x 6,5 cm), adolescente (dimensão de 16,0 x 8,0 cm) e adulto (dimensão de 21,5 x 12,0 cm), da marca Missouri Mikatos, previamente calibrado, segundo o preconizado, com a câmara de ar ocupando $40 \%$ do comprimento do braço, medido em um ponto médio entre o olécrano e acrômio, cobrindo 80 a 100\% do perímetro do braço. As medidas, quando alteradas, foram repetidas três vezes no mesmo dia ${ }^{110,111}$.

Os dados de peso do nascimento foram obtidos do banco do Sistema de Nascidos Vivos (SINASC) da Secretaria Municipal de Saúde de Florianópolis nos anos de 2001/2002 e 2004/2005 e/ou do registro na Caderneta de Saúde da Criança e Adolescente do Município de Florianópolis. Ao todo foi possível recuperar a informação do $\mathrm{PN}$ de 816 crianças, o que corresponde a 75,42\% da amostra total possível. 


\subsection{VARIÁVEIS DE ESTUDO E SUA OPERACIONALIZAÇÃO}

Os níveis pressóricos foram classificados individualmente em percentis em relação ao referencial americano, para sexo, idade e estatura, segundo o preconizado pelo National High Blood Pressure Education Program Working Groupon High Blood Pressure in Childrenand Adolescents (NHBPEP) ${ }^{107,111 .}$ Quando a medida de PA foi considerada alterada foram realizadas três medições em tempos diferentes, porém no mesmo período. Os níveis pressóricos foram considerados alterados quando superiores ao percentil 90 e elevados quando acima do percentil 95. As PAS e PAD foram descritas para sexo e idade (média, mediana e desvio padrão), ajustadas para a estatura ${ }^{107,111}$. Os valores de PAS e PAD foram analisados como variáveis contínuas e/ou discretas. A primeira (contínua) foi para calcular médias e desvios padrão e, a segunda para categorizar a PA em dois grupos: PA alterada e PA adequada. Como PA alterada foram classificados todos os casos de pré-hipertensão (valores alterados maiores que o percentil 90) e hipertensão arterial (maiores que percentil 95), analisando as suas relações com as variáveis antropométricas nutricionais e de composição corporal, bem como com o PN.

A variável $\mathrm{PN}$ foi registrada em gramas e operacionalizada tanto de forma continua quanto subdividida em categorias, em função da análise a ser realizada. Utilizou-se a nomenclatura de baixo peso ao nascer para os nascidos abaixo de $2500 \mathrm{~g}$, de peso insuficiente para os nascidos com peso maior ou igual a $2500 \mathrm{~g}$ e menor que $3000 \mathrm{~g}$, peso normal de $3000 \mathrm{~g}$ a $3999 \mathrm{~g}$ e de peso elevado para os nascidos com peso maior ou igual a $4000 \mathrm{~g}$. 
Para análise do crescimento, estado nutricional e da composição corporal na idade escolar foram utilizados, em escores $\mathrm{z}$, o peso (zP); a estatura (zE); o índice de massa corpórea (zIMC); a circunferência do braço (zCB), a circunferência da cintura (zCC); a prega cutânea tricipital (zPCT); a Área Muscular do Braço (zAMB), e a Área Gorda do Braço (zAGB). Utilizou-se também a Razão Circunferência da Cintura para Estatura (CC/E), Razão Circunferência Abdominal para Estatura (CA/E), o Percentual de Área Muscular do Braço (\%AMB) e o Percentual de Área Gorda do Braço (\%AGB).

Para a transformação destas variáveis em escore z foram utilizados dois referenciais: os da $\mathrm{OMS}^{101,109,112}$ e o de Frisancho ${ }^{113,114}$. Este último referencial foi baseado nos dados do National Health and Nutrition Examination Survey (NHANES III) dos Estados Unidos, e publicado especificamente para a avaliação antropométrica, incluindo a composição corporal ${ }^{115}$.

$\mathrm{Na}$ caracterização do estado nutricional dos escolares utilizou-se os parâmetros zP, zE e zIMC, segundo o referencial das curvas da OMS para crianças com cinco anos e mais ${ }^{100}$. As curvas da OMS são atualmente preconizadas pelo Ministério da Saúde para avaliar o crescimento infantil, já fazendo parte inclusive da caderneta da criança na atenção básica à saúde e de Florianópolis.

O escore $z$ de peso foi utilizado com a finalidade de caracterizar a curva de distribuição dos escolares em relação à distribuição das curvas de escores z de estatura e IMC.

O IMC - calculado a partir do peso em $\mathrm{kg}$ divido pelo quadrado da estatura em metros -, foi utilizado em escore z para classificação do estado nutricional 
segundo os pontos propostos pelo $\mathrm{MS}^{97}$ e $\mathrm{OMS}^{116}$ : magreza acentuada, medidas menores que -3 escore $z$; magreza, medidas iguais ou maiores que -3 escore $z e$ menores que -2 escores $z$; eutrofia, maiores ou iguais a -2 e menor que +1 escores $z$; sobrepeso, medidas iguais ou maiores que +1 e menores que +2 escores $z$; obesidade medidas iguais ou maiores que +2 e menores que +3 escores z, obesidade grave quando a criança apresentava zIMC igual ou maior que +3 escores z A composição corporal foi estimada por meio de fórmulas, embasadas em medidas antropométricas de pregas cutâneas e circunferências corporais, que, mesmo sendo métodos indiretos de avaliação, têm demonstrado resultados consistentes, fidedignos e válidos para estimativa da composição corporal na população infantil ${ }^{119}$. Esses métodos são recomendados para o uso na prática clínica e em estudos epidemiológicos pelo fácil manejo, baixo custo e inocuidade ${ }^{103}$.

No presente estudo, as curvas da referência de Frisancho ${ }^{113}$ foram adotadas, para cálculo dos escores z da Área Muscular do Braço (AMB) e Área Gorda do Braço (AGB). 
Quadro 1 - Fórmulas para cálculo da área total do braço, área muscular do braço e área gorda do braço.

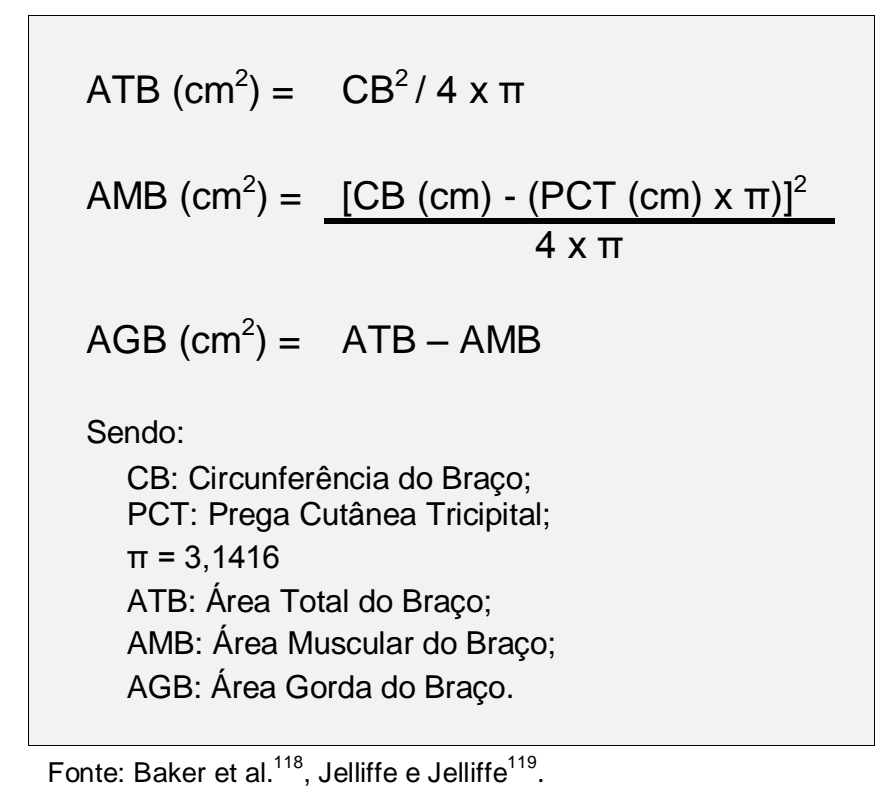

Quanto aos métodos de avaliação da composição corporal, estes assumem um modelo bicompartimental, onde o corpo como um todo é constituído por dois compartimentos: massa gorda e massa magra. A AMB é utilizada como um estimador válido da massa magra corporal e, portanto, a reserva proteica, e a AGB seria um estimador da massa gorda corporal, a reserva de gordura. Ambas podem ser usadas como marcadores de depleção de reservas gordurosas e musculares ou como uma medida de excesso de gordura, na população infantil ${ }^{120-122}$.

Para a avaliação da massa magra corporal dos escolares optou-se por utilizar a AMB. Nas analises, operacionalizou-se esta variável de forma contínua e foi calculado o percentual de Área Muscular do Braço corrigida (\%AMBc) em relação à Área Total do Braço (ATB). A correção da AMB subtraindo a área do osso do braço dos escolares foi realizada seguindo a correção proposta por Heymsfield et al. ${ }^{123}$ para adultos, porém 
proporcionalmente adaptada para a área do osso da população infantil. A variável, \%AMB, também foi operacionalizada de forma contínua.

A gordura corporal, ou massa gorda corporal foi avaliada por meio da AGB; da Circunferência do Braço (CB); da CC e da $\mathrm{PCT}^{121}$. Calculou-se os escores z da AGB, CB, CC, CA, PCT a fim de controlar a influência do sexo e da idade sobre essas variáveis. O percentual de AGB em relação ATB e a razão CC/E também foram calculados. A razão circunferência da cintura, em centímetros, pela estatura, em centímetros é outra maneira que vem sendo muito utilizada, inclusive na população infantil, para controlar a influência das variáveis sexo e idade sobre a circunferência da cintura ${ }^{97,124-127}$. As variáveis $z A G B, z C B, z C C, z P C T, \% A G B$ e razão de CC/E foram operacionalizadas na forma de variáveis contínuas.

Como não foi possível obter todas as informações para todas as crianças estudadas, algumas tabelas e gráficos irão apresentar um "n total" diferente do total da amostra incluída na pesquisa.

\subsection{ANÁLISE DOS DADOS}

Os dados foram digitados e armazenados em planilhas, utilizando-se 0 programa Microsoft Excel 2007. A checagem da qualidade da digitação das medidas antropométricas foi verificada a partir de gráficos de dispersão, e para as crianças com valores muito discrepantes os dados digitados foram revisados nas planilhas originais.

Os pontos de corte da razão CC/E equivalentes aos do escore z de IMC recomendados pelo $\mathrm{MS}^{112}$ e pela $\mathrm{OMS}^{101}$ foram calculados por regressão logística. 
Para realizar a análise estatística utilizou-se os Softwares SPSS (Statistical Package for the Social Sciences) versão 15.0, MedCalc versão 12.1.4.0 e GraphPad Prism 5 versão 5.04. Foram calculadas frequências, proporções, médias, desvios padrão, curva ROC (Receiver Operating Characteristic) e curvas de distribuição normal segundo a necessidade. As comparações foram realizadas a partir dos parâmetros de tendência central, dispersão e proporções, pelo teste $t$ de Student (Mann-Whitney para distribuições não normais), análise de variância (teste de Kruskal-Wallis para distribuições não normais), Qui-quadrado $\left(\chi^{2}\right)$, coeficiente de correlação de Pearson, Análise de Múltiplas Variáveis por regressão binária logística, Stepwise, Backward, Wald.

\subsection{ASPECTOS ÉTICOS}

A realização deste estudo obedece aos princípios éticos para pesquisas com seres humanos, conforme resolução CNS 196/96, foi aprovada pelo Comitê de Ética em Pesquisa da Faculdade de Saúde Pública da Universidade de São Paulo, conforme documento COEP n 196/96 aprovado em 15 de fevereiro de 2012 (Anexo A).

O presente estudo fez parte de uma pesquisa institucional intitulada "Perfil epidemiológico de crescimento e nutricional de escolares em Florianópolis comparando tendências de crescimento, com a referência da MGRS/OMS", desenvolvida pelo Programa Saúde na Escola (PSE) da Secretaria Municipal de Saúde de Florianópolis e coordenada pela 
pesquisadora. O referido Programa é realizado intersetorialmente pelas Secretarias de Saúde e de Educação do Município e Estadual de Educação e foi criado por Decreto Interministerial ํo 6.286 de 5/12/2007. O Programa abrange hoje, $100 \%$ (66) das escolas de Ensino Fundamental e Médio e 50\% do Ensino Infantil da Capital, atendendo a 50.000 crianças e, tem como uma de suas diretrizes, analisar o estado nutricional dos escolares e pressão arterial. A realização dessa pesquisa poderá auxiliar o PSE a nortear ações de intervenção locais, visando a melhoria da saúde dos educandos.

O Termo de Consentimento Livre e Esclarecido foi enviado para as escolas sorteadas e a própria escola, encaminhou-o para as mães ou responsáveis pelas crianças (Anexo B).

Foram excluídas do estudo, todas aquelas crianças cujos pais e ou responsáveis se negaram a participar do estudo e que estavam fora das faixas etárias do estudo e/ou apresentaram problemas mórbidos que sabidamente têm relação com o seu crescimento e/ou pressão arteriais, não relacionados diretamente à sua condição nutricional.

Durante o levantamento antropométrico e avaliação da PA, a identificação de escolares com alterações da PA e/ou nutricionais foi objeto de avaliação específica e uma vez decidida a melhor alternativa para o cuidado do escolar, este foi encaminhado aos Centros de Saúde de Florianópolis. 


\section{RESULTADOS E DISCUSSÃO}

\subsection{CARACTERIZAÇÃO DA POPULAÇÃO DO ESTUDO}

Das 1082 crianças da amostra dos dois grupos de idades, pouco mais da metade tinha idade entre seis e sete anos - Grupo 1 (G1) - e os demais estavam entre nove e dez anos de idade - Grupo 2 (G2). A proporção de sexo masculino e feminino foi aproximadamente igual entre os dois grupos de idade (Tabela 1).

Tabela 1 - Distribuição das frequências dos escolares segundo sexo e faixa etária.

\begin{tabular}{lccc}
\hline \multirow{2}{*}{$\begin{array}{c}\text { Grupos de } \\
\text { idade }\end{array}$} & \multicolumn{2}{c}{ Sexo } & \multirow{2}{*}{$\begin{array}{c}\text { Total } \\
\mathbf{n}(\%)\end{array}$} \\
\cline { 2 - 3 } & $\begin{array}{c}\text { Masculino } \\
\mathbf{n}(\%)\end{array}$ & $\begin{array}{c}\text { Feminino } \\
\mathbf{n}(\%)\end{array}$ & \\
\hline \multirow{2}{*}{$\mathrm{G} 1$} & $303(49,6)$ & $308(50,4)$ & $611(100,0)$ \\
& $(55,4)$ & $(57,6)$ & $(56,5)$ \\
$\mathrm{G} 2$ & $244(51,8)$ & $227(48,2)$ & $471(100,0)$ \\
& $(44,6)$ & $(42,4)$ & $(43,5)$ \\
Total & $\mathbf{5 4 7}(\mathbf{5 0 , 5 )}$ & $\mathbf{5 3 5 ( 4 9 , 5 )}$ & $\mathbf{1 0 8 2}(\mathbf{1 0 0 , 0 )}$ \\
& $(\mathbf{1 0 0 , 0 )}$ & $(\mathbf{1 0 0 , 0 )}$ & $(\mathbf{1 0 0 , 0 )}$ \\
\hline
\end{tabular}

A média de idade dos dois grupos foi respectivamente 6,5 anos ( $\mathrm{dp}=$ $0,31)$ e 9,6 anos $(d p=0,26)$.

Quanto ao peso de nascimento se observou que não havia diferença estaticamente significante entre as medianas dos dois grupos, $\mathrm{G} 1=3250 \mathrm{~g} \mathrm{e}$ $\mathrm{G} 2=3253 \mathrm{~g}$, e a dispersão dos pesos de nascimento foi muito semelhante entre os dois grupos (Figura 2). 
Figura 2 - Distribuição do peso de nascimento dos escolares segundo os grupos de idade.

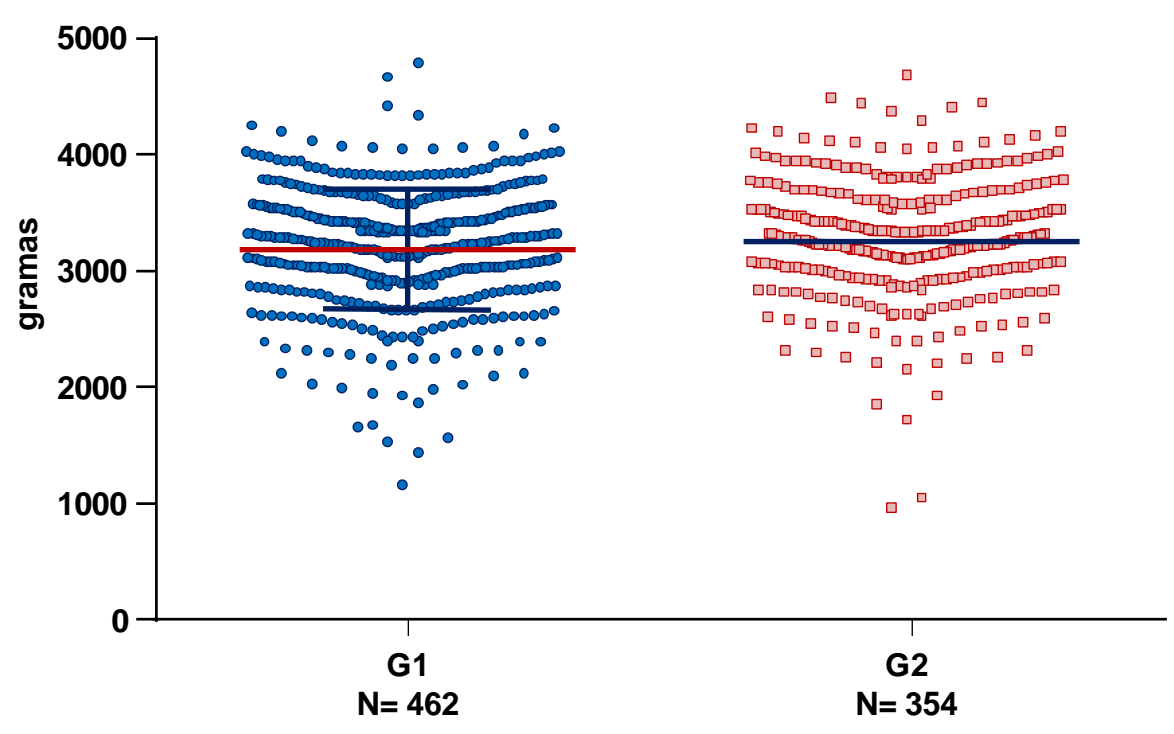

No que tange ao crescimento a Figura 3 mostra a distribuição dos escolares, independentemente de sexo e idade, segundo o seu escore z de estatura, verificando-se que o grupo como um todo teve um crescimento acima do esperado, com uma mediana de estatura para a idade deslocada em direção a valores superiores do referencial. 
Figura 3 - Curva de distribuição da frequência de escolares segundo escore z da estatura.

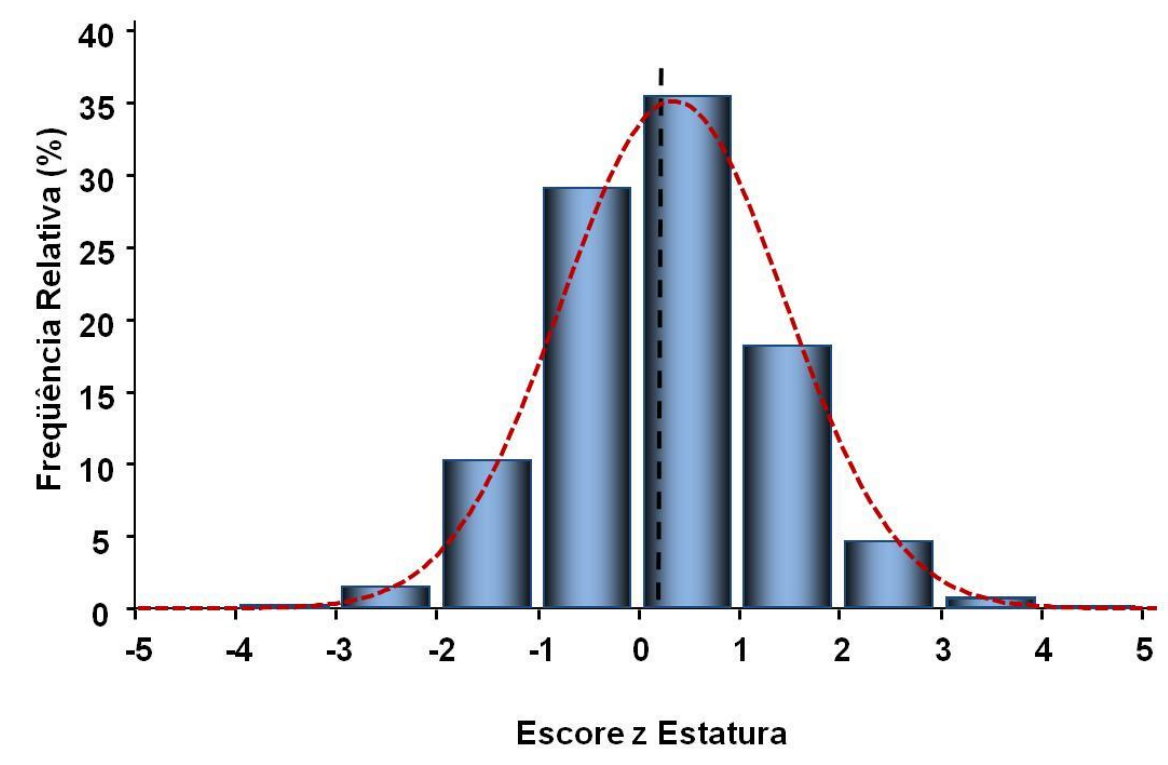

Quando se analisa a estatura por sexo, como mostra a Figura 4, verificase que meninos e meninas têm crescimento semelhante, ambos também com desvio a direita das curvas de crescimento em relação à mediana de referência de escore $z$ de estatura da OMS. Comparando o escore $z$ de estatura entre meninos e meninas verifica-se que não há diferença estatisticamente significante das médias $(p=0,6667)$. A média do escore $z$ de estatura para idade dos meninos foi $0,23 \mathrm{com} d p=1,09$ (IC 95\% 0,14 a 0,33) e das meninas a média foi 0,26 com dp $=1,09$ (IC $95 \% 0,17$ a 0,33). 
Figura 4 - Curvas de distribuição da frequência de escolares segundo escore $z$ de estatura por sexo.

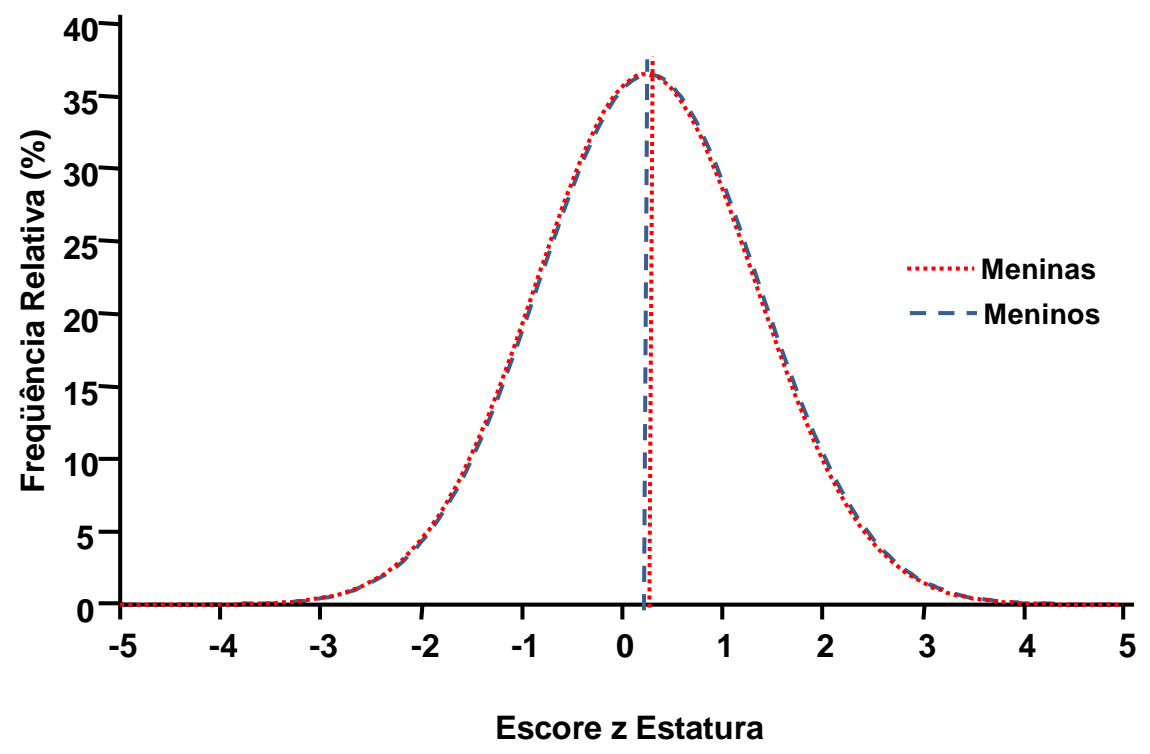

A Figura 5 mostra as curvas de distribuição da frequência de escolares segundo escore z de estatura por grupos de idade (G1 e G2). Como se observa, os dois grupos de idade tiveram um crescimento acima da mediana de referência.

Figura 5 - Curvas de distribuição da frequência de escolares segundo escore $z$ de estatura por grupos de idade.

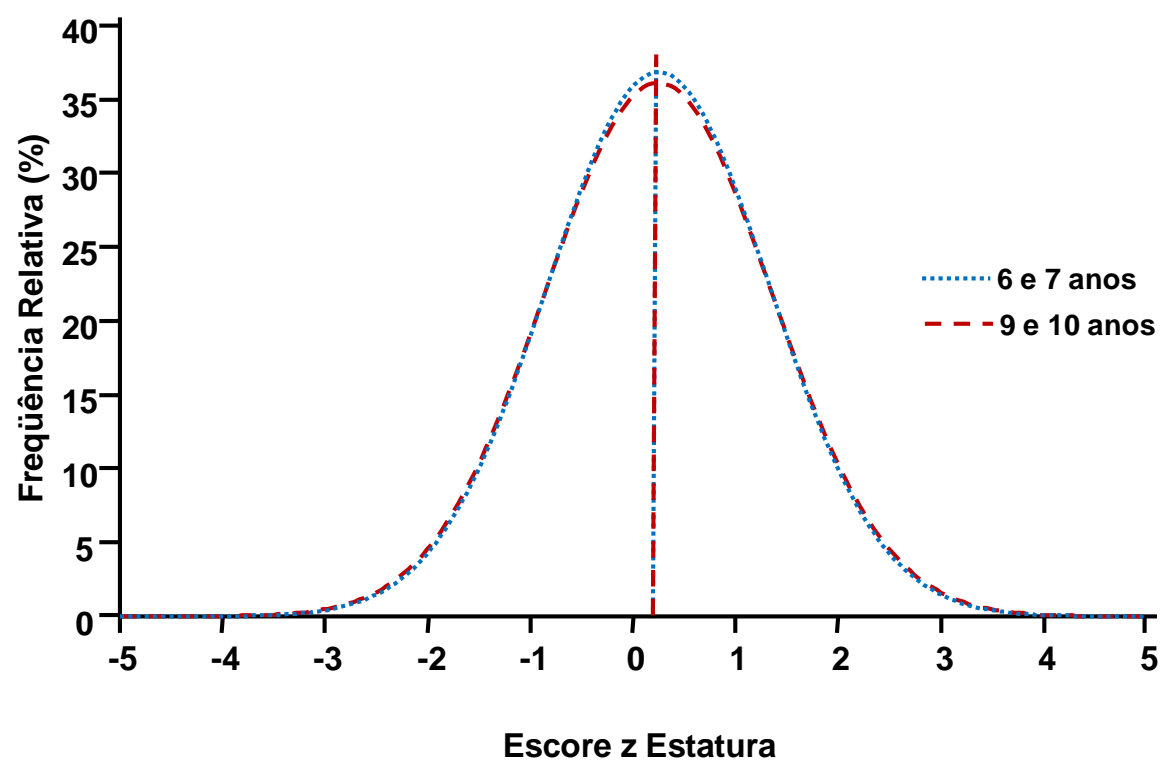


A média de escore z de estatura para idade no $\mathrm{G} 1$ foi de 0,25 , dp =1,08 (IC95\% 0,16 a 0,33) e no G2 o valor foi de 0,25, dp =1,09 (IC de 95\% 0,18 a 0,31). A diferença entre os dois grupos etários não foi estatisticamente significante $(p=0,9898)$.

A Figura 6, em relação ao escore $z$ de peso, demonstra um desvio para a direita das curvas de distribuição dos escolares evidenciando a presença de excesso de peso entre os escolares.

Figura 6 - Distribuição da frequência de escolares segundo escore $z$ de peso para idade.

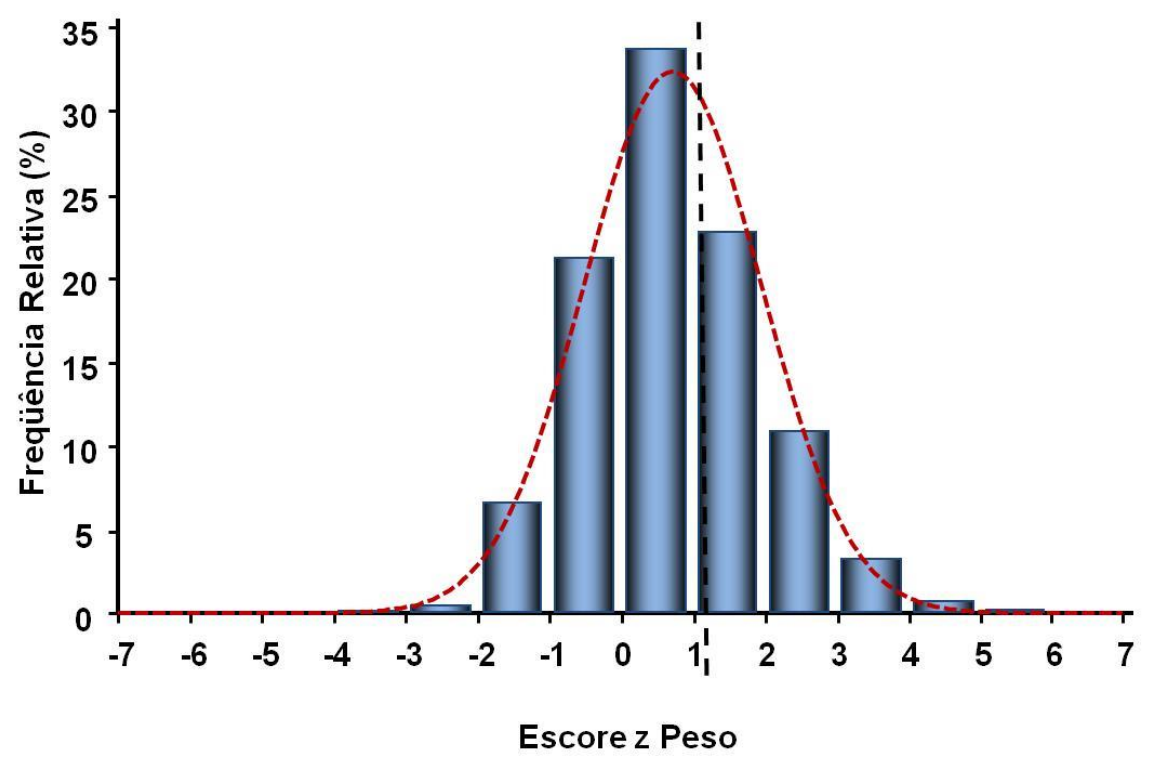

A diferença das médias de escore $z$ de peso por sexo foi estatisticamente significante $(p=0,047)$, sendo que a média dos meninos foi $0,79(\mathrm{dp}=1,26)$ e das meninas a média foi de $0,64(\mathrm{dp}=1,19)$ como mostra a Figura 7.

Como se observa nas Figuras 7 e 8 além das médias serem superiores às medianas do referencial, a curva de distribuição como um todo dos valores 
observados, encontra-se desviada para o lado direito do gráfico, isto é, em direção aos valores mais elevados do referencial, principalmente no que tange à distribuição dos pesos dos escolares do sexo masculino.

Figura 7 - Curvas de distribuição da frequência de escolares segundo escore $z$ de peso por sexo.

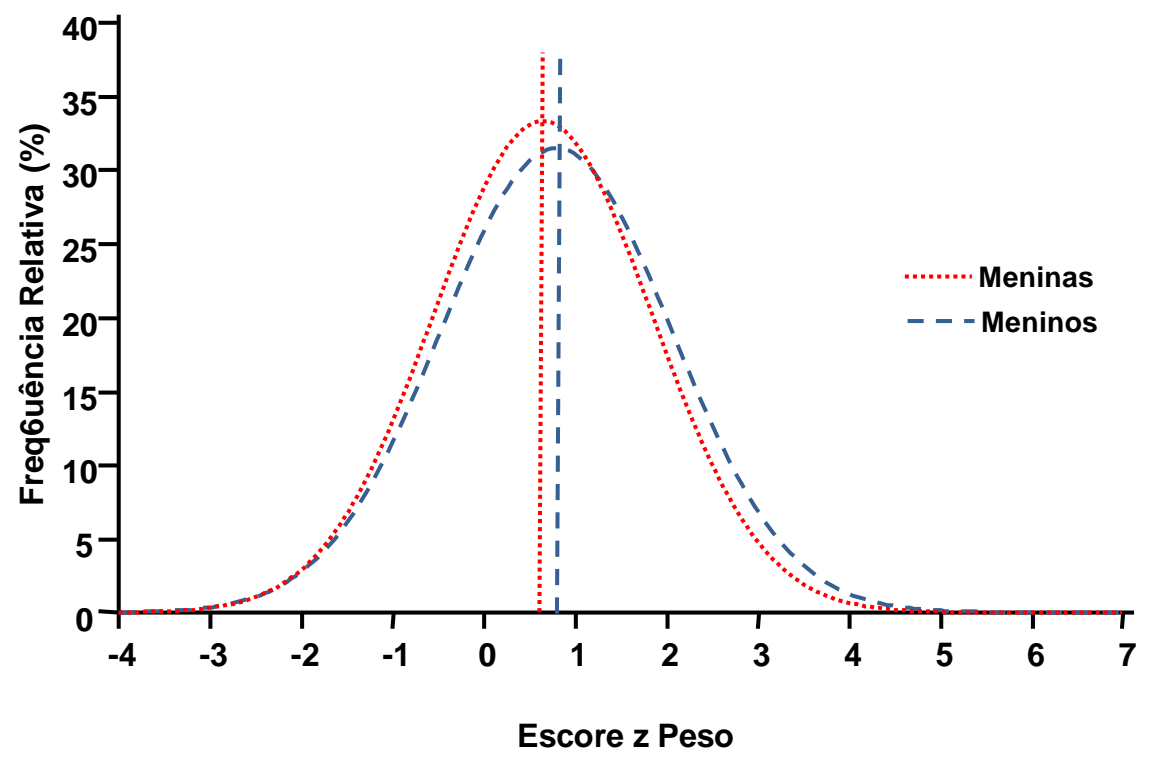

Figura 8 - Curvas de distribuição da frequência de escolares segundo escore $z$ de peso por idade.

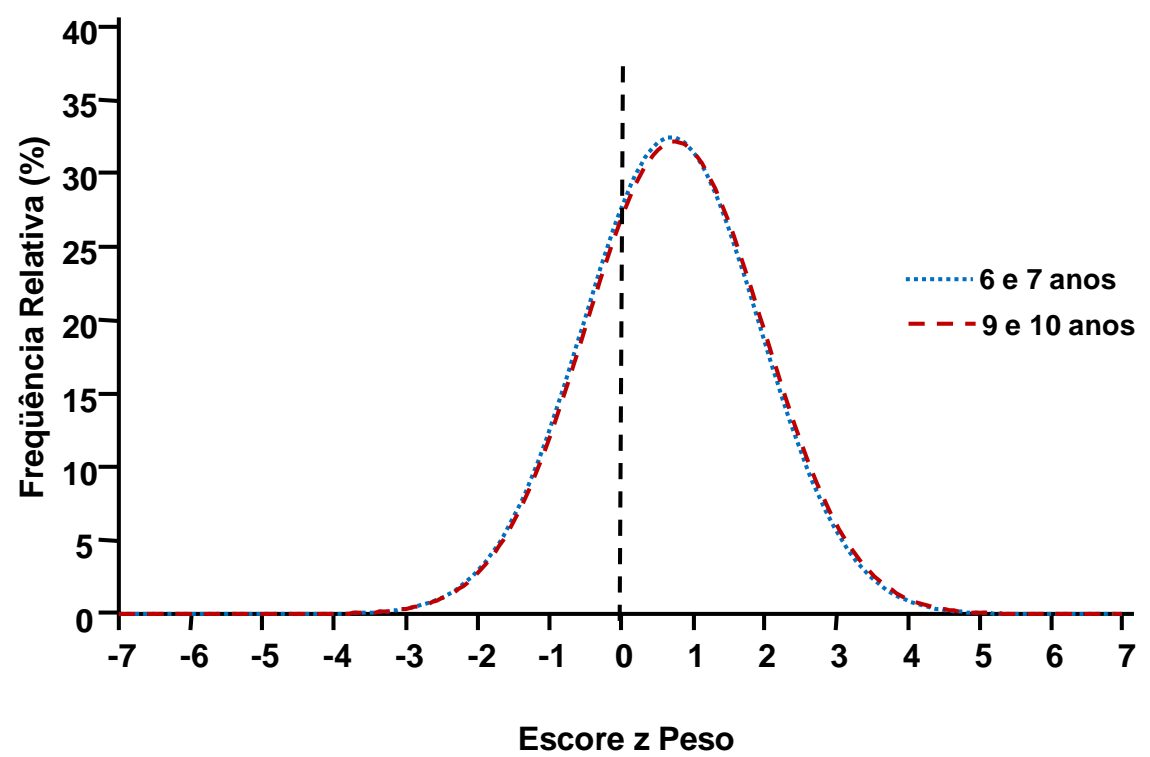


A Figura 9, das curvas de distribuição dos escolares segundo escore z de IMC, mostra também, um desvio para a direita, com uma média de escore z positiva de 0,78 e um dp = 1,32 (IC95\% 0,69 a 0,85), o que é compatível com o valor dos escores $z$ de altura e peso para idade, observados na amostra.

Figura 9 - Curvas de distribuição da frequência de escolares segundo escore $\mathrm{z}$ de IMC.

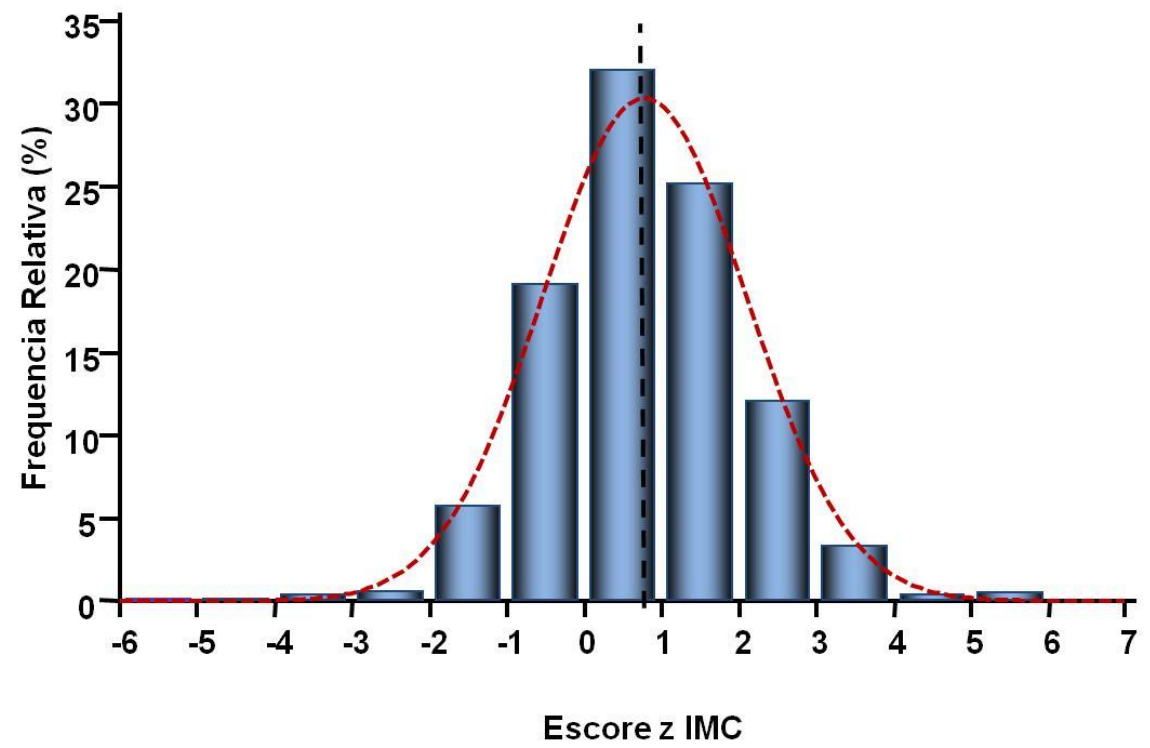

A Figura 10 mostra as frequências de escolares segundo a classificação do estado nutricional pelo IMC, de acordo com a proposta da OMS e do MS, e evidencia que $42,5 \%$ das crianças já estavam com excesso de peso, chamando principalmente a atenção que 4,4\% já eram portadores de obesidade grave. Quanto à magreza ou magreza acentuada a prevalência observada foi de 1,7\%. Essa proporção é inferior à esperada na distribuição de referência para as populações supostamente normais, o que pode significar que entre os escolares de Florianópolis pode haver desnutrição, mas que esta condição, por sua frequência, não é mais um importante problema de saúde pública. 
Figura 10 - Distribuição dos escolares segundo estado nutricional com base no escore z de Índice de Massa Corporal dos escolares.

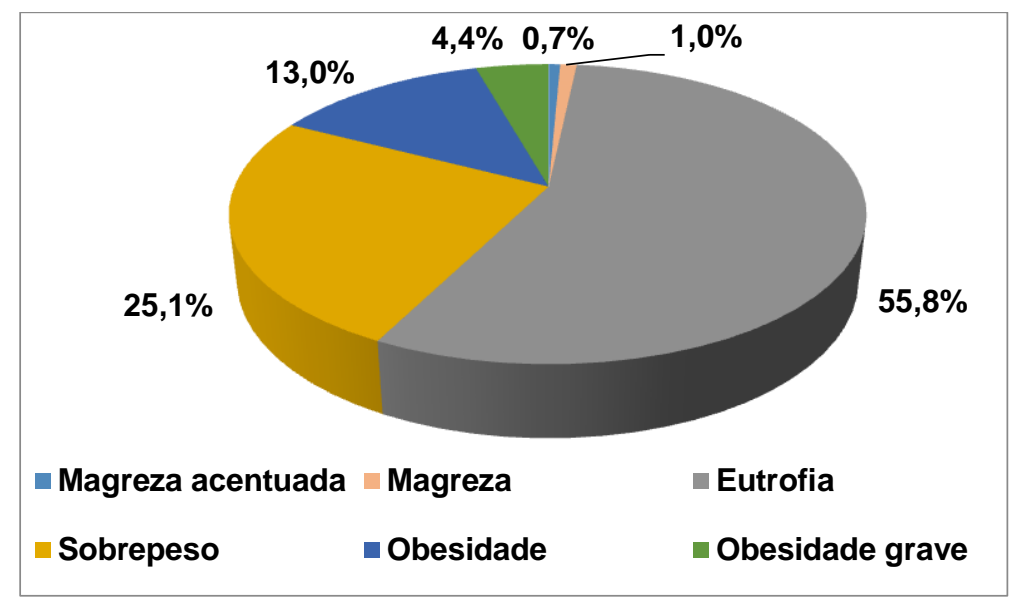

A Tabela 2 mostra as prevalências dos diferentes diagnósticos de estado nutricional dos escolares, conforme o sexo. Como se verifica a prevalência de obesidade grave era 2,1 vezes maior entre os meninos.

Tabela 2 - Distribuição dos escolares segundo o diagnóstico nutricional e sexo.

\begin{tabular}{lccccc}
\hline \multirow{2}{*}{ Estado Nutricional } & \multicolumn{2}{c}{ Meninas } & \multicolumn{2}{c}{ Meninos } & Total \\
\cline { 2 - 5 } & $\mathbf{N}$ & $\mathbf{( \% )}$ & $\mathbf{N}$ & $(\%)$ & $\mathbf{N}(\%)$ \\
\hline Magreza acentuada & 3 & $(0,6)$ & 4 & $(0,7)$ & $7(0,7)$ \\
Magreza & 7 & $(1,3)$ & 5 & $(0,9)$ & $12(1,0)$ \\
Eutrofia & 301 & $(56,3)$ & 296 & $(54,1)$ & $597(55,8)$ \\
Sobrepeso & 137 & $(25,6)$ & 134 & $(24,5)$ & $271(25,1)$ \\
Obesidade & 63 & $(11,8)$ & 69 & $(12,6)$ & $132(13,0)$ \\
Obesidade Grave* & 18 & $(3,4)$ & 39 & $(7,1)$ & $57(4,4)$ \\
\hline TOTAL & 535 & $(100,0)$ & 547 & $(100,0)$ & $1082(100,0)$ \\
\hline${ }^{*} \mathrm{p}<0,05$ & & & & &
\end{tabular}

No grupo de crianças como um todo se observou que as médias dos escores $z$ foram respectivamente $0,72(d p=1,30)$ para o peso/idade, 0,25 (dp $=1,09)$ para estatura/idade e 0,78 $(\mathrm{dp}=1,32)$ para 0 IMC. Esses valores revelam diferença significante $(p<0,0001)$ quando comparadas com os valores 
de seus respectivos referenciais.

As Tabelas 3 e 4, a seguir, mostram que as médias de escores $z$ de peso, estatura e IMC não apresentam diferenças entre os dois grupos de idade, entretanto, segundo o sexo, verificou-se que os meninos apresentavam um peso proporcionalmente maior para a idade enquanto a média de IMC era maior nas meninas.

Tabela 3 - Medidas de tendência central e dispersão das características antropométricas dos escolares segundo grupos de idades.

\begin{tabular}{|c|c|c|c|}
\hline \multirow{3}{*}{$\begin{array}{c}\text { Parâmetros } \\
\text { antropométricos } \\
\text { em escore z }\end{array}$} & \multicolumn{2}{|c|}{ Grupos etários } & \multirow{3}{*}{$\begin{array}{c}\mathrm{p} \\
\text { (entre grupos) }\end{array}$} \\
\hline & G1 & G2 & \\
\hline & $\bar{x}(d p)$ & $\bar{x}(d p)$ & \\
\hline Peso & $0,69(1,23)$ & $0,74(1,23)$ & 0,5075 \\
\hline Estatura & $0,25(1,08)$ & $0,25(1,11)$ & 0,9898 \\
\hline IMC & $0,76(1,31)$ & $0,80(1,33)$ & 0,6209 \\
\hline
\end{tabular}

x: média; dp: desvio padrão; IMC: Índice de Massa Corpórea.

Tabela 4 - Medidas de tendência central e dispersão das características antropométricas dos escolares segundo sexo.

\begin{tabular}{lccc}
\hline \multicolumn{1}{c}{ Parâmetros } & \multicolumn{2}{c}{ Sexo } & \multirow{2}{*}{$\mathbf{p}$} \\
\cline { 2 - 3 } $\begin{array}{c}\text { antropométricos } \\
\text { em escore z }\end{array}$ & $\overline{\mathbf{X}}(\mathbf{d p})$ & $\mathbf{F}$ & \\
\hline Peso/idade & $0,79(1,26)$ & $0,64(1,19)$ & $\mathbf{0 , 0 0 4 7 ^ { * }}$ \\
Estatura/idade & $0,23(1,09)$ & $0,26(1,09)$ & 0,6667 \\
IMC & $0,41(1,24)$ & $0,45(1,19)$ & $0,0009^{\star}$ \\
\hline
\end{tabular}

x: média; dp: desvio padrão; IMC: Índice de Massa Corpórea.

*t de Student: significante.

A estatura para idade não evidenciou uma diferença estatisticamente significante entre meninos e meninas.

Quanto à distribuição corporal de gordura, a Figura 11 mostra um desvio da curva de distribuição do escore z da CC comparada à mediana de 
referência de acordo com o referencial de Frisancho ${ }^{114}$, indicando que os escolares de Florianópolis provavelmente têm um maior acúmulo de gordura na região abdominal. A média de escore z observada para a CC foi de 0,49 ( $\mathrm{dp}=$ 0,98), com um IC de $95 \%$ variando de 0,43 a 0,54 .

Figura 11 - Curva de distribuição da frequência de escolares segundo o escore $z$ da circunferência da cintura.

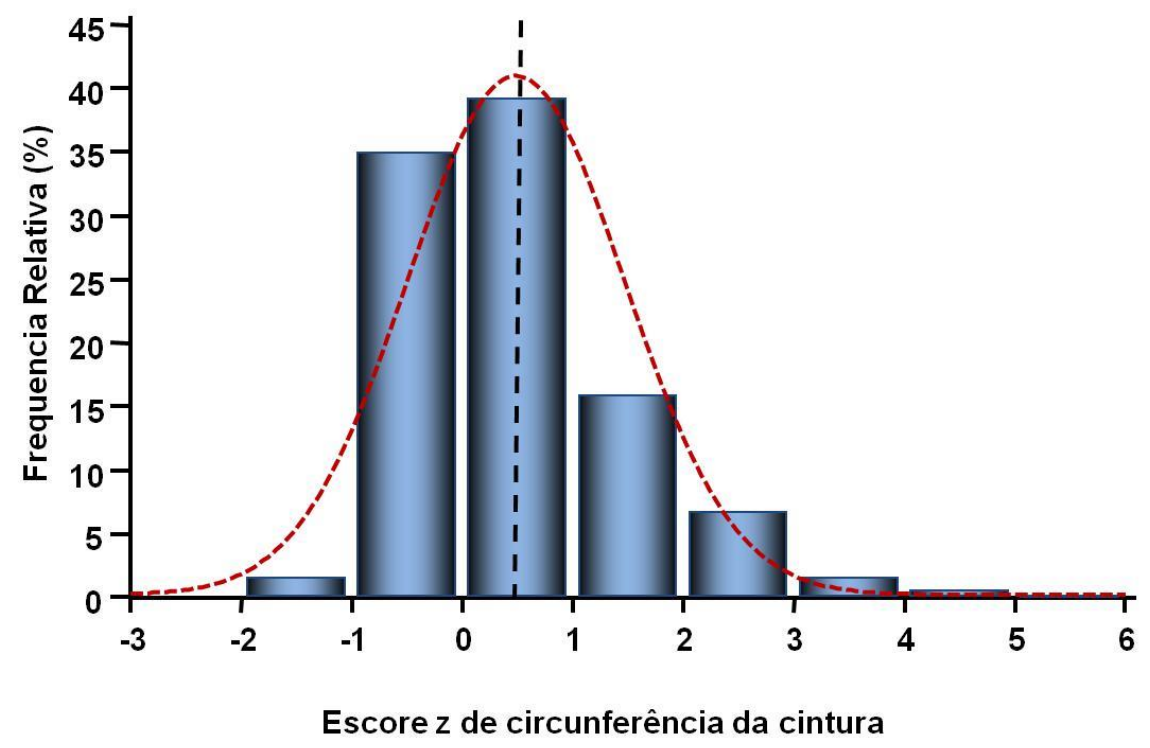

Utilizando-se outros índices de composição corporal, a Tabela 5 mostra as medidas de tendência central comparando os dois grupos de idade. Verificase diferença estatisticamente significante entre as duas gerações dos escolares quanto ao escore $z$ de $A M B$ e AGB. É interessante notar que o grupo mais velho apresenta uma menor área muscular do braço simultaneamente a uma maior área gorda, na mesma região do braço. 
Tabela 5 - Médias dos indicadores de composição corporal dos escolares, segundo os grupos de idades.

\begin{tabular}{cccc}
\hline $\begin{array}{c}\text { Composição corporal } \\
\text { em escore } \mathbf{z}\end{array}$ & $\mathbf{G}$ 1 & $\mathbf{G 2}$ & $\mathbf{P}$ \\
\hline CC & $0,47(0,98)$ & $0,51(0,98)$ & 0,5105 \\
CA & $0,33(0,93)$ & $0,29(0,94)$ & 0,5044 \\
AMB & $-0,04(1,25)$ & $-0,23(1,26)$ & $\mathbf{0 , 0 0 1 3 6 ^ { * }}$ \\
AGB & $0,18(1,17)$ & $0,33(1,19)$ & $\mathbf{0 , 0 0 3 7 6 8 ^ { * }}$ \\
\hline
\end{tabular}

x: média; dp: desvio padrão; CC: circunferência de cintura; CA: circunferência abdominal; AMB: Área Muscular do Braço; AGB: Área Gorda do Braço.

*Significante estatisticamente.

Quando se compara estes parâmetros entre meninos e meninas, a Tabela 6 mostra diferença apenas quanto à $A G B$, que é maior entre meninos.

Tabela 6 - Médias de indicadores de composição corporal dos escolares, segundo o sexo.

\begin{tabular}{cccc}
\hline $\begin{array}{c}\text { Composição corporal } \\
\text { em escore } \mathbf{z}\end{array}$ & $\begin{array}{c}\mathbf{M} \\
\mathbf{x}(\mathbf{d p})\end{array}$ & $\mathbf{\overline { \mathbf { x } }} \mathbf{( \mathbf { d p } )}$ & $\mathbf{P}$ \\
\hline CC & $0,51(0,99)$ & $0,46(0,97)$ & 0,3509 \\
CA & $0,33(0,93)$ & $0,29(0,94)$ & 0,5044 \\
AMB & $0,14(1,29)$ & $0,29(0,94)$ & 0,05844 \\
AGB & $0,39(1,30)$ & $0,11(1,04)$ & $\mathbf{0 , 0 0 0 1}^{*}$ \\
\hline
\end{tabular}

x: média; dp: desvio padrão; CC: circunferência de cintura; CA: circunferência abdominal;

AMB: Área Muscular do Braço; AGB: Área Gorda do Braço.

*Significante estatisticamente.

Na Tabela 7, observa-se que a mediana da PCT apresentava diferença estatisticamente significante em função da idade, sendo a PCT maior nos mais velhos. Quanto ao sexo não se observou diferença. 
Tabela 7 - Medianas e dispersão dos valores da prega cutânea tricipital (PCT) e da relação da cintura abdominal pela estatura (CA/E) dos escolares, segundo grupos de idade e sexo.

\begin{tabular}{|c|c|c|c|c|}
\hline $\begin{array}{c}\text { Composição corporal } \\
\text { em escore z }\end{array}$ & G1 & G2 & $\mathbf{M}$ & $\mathbf{F}$ \\
\hline Me da $\mathrm{PCT}^{\star \star}$ & $-0,18$ & 0,13 & $-0,11$ & $-0,02$ \\
\hline Mínimo & $-1,29$ & $-1,90$ & $-1,23$ & $-1,90$ \\
\hline Máximo & 5,50 & 6,57 & 6,57 & 4,85 \\
\hline$P$ & \multicolumn{2}{|c|}{$<0,0001^{*}$} & \multicolumn{2}{|c|}{0,792} \\
\hline Me CA/E ${ }^{\star *}$ & 0,47 & 0,47 & 0,47 & 0,47 \\
\hline Mínimo & 0,37 & 0,35 & 0,35 & 0,37 \\
\hline Máximo & 0,69 & 0,68 & 0,69 & 0,64 \\
\hline$P$ & \multicolumn{2}{|c|}{0,923} & \multicolumn{2}{|c|}{0,357} \\
\hline
\end{tabular}

Me=mediana; *Significante estatisticamente; ${ }^{* \star T e s t e ~ d e ~ M a n n ~ W h i t n e y . ~}$

Na mesma tabela verifica-se que não houve diferença na mediana da razão $\mathrm{CA} / \mathrm{E}$ tanto em função do sexo quanto da idade. A média da razão $\mathrm{CA} / \mathrm{E}$ observada no conjunto de todos os escolares foi de $0,478(\mathrm{dp}=0,052)$ com um intervalo de confiança de $95 \%$ de 0,476 a 0,482 .

Publicação recente sugere que uma medida da razão da CA/E igual ou superior a 0,5 indica a existência de obesidade central. Este valor $(0,5)$ é o correspondente ao percentil 85 da amostra estudada, independentemente da idade e $\operatorname{sexo}^{128}$.

Em nosso estudo, também não se observou diferenças em função da idade ou sexo para um valor da mediana da razão da CA/E, que foi 0,47. Este valor corresponde ao percentil 75 , na distribuição de valores da pesquisa citada anteriormente ${ }^{128}$.

As medidas de composição corporal utilizadas no estudo anterior ${ }^{128}$ - CC e CA -, bem como relatado por outros autores são consideradas preditoras de risco de doença cardiovascular e metabólica, também em crianças, demonstrando serem melhores marcadores da quantidade de tecido adiposo 
visceral do que o IMC. Estas medidas também são consideradas como indicadores mais sensíveis de resistência à insulina, de alteração de pressão arterial, de colesterol sérico e dos níveis de triglicerídeos ${ }^{75,125,129}$.

Em nosso estudo, na comparação da $A M B$ e da $A G B$ entre os dois grupos de idade (Tabela 5), observou-se uma diferença estatisticamente significante $(p=0,00136$ e $p=0,003768$ respectivamente), sugerindo que essas medidas podem ser relevantes como indicadores de composição corporal, tanto quanto a CC e CA. Apesar disso, as dificuldades para a realização das medidas dos indicadores $A M B$ e $A G B$ e para a sua interpretação, fazem com que as mesmas tenham menor praticidade do que a CC ou CA, para a avaliação de crianças na rotina assistencial.

\subsection{PRESSÃO ARTERIAL}

No que tange a pressão arterial, a média da pressão arterial sistólica dos escolares como um todo foi de $97,2 \mathrm{mmHg}$, dp $=10,7$ (IC95\% 96,5 a 97,8 $\mathrm{mmHg}$ ) e a média da diastólica foi $61,6 \mathrm{mmHg}, \mathrm{dp}=8,2$, (IC95\% 61,1 a 62,1 $\mathrm{mmHg}$ ), valores muito próximos aos propostos pelo referencial ${ }^{130}$.

Apesar disto, observou-se uma elevada prevalência de alterações da PA, sendo que no total 148 crianças (13,7\% dos escolares) apresentavam alguma elevação, predominando o aumento da PAS, que foi observada em 103 crianças (9,5\%). Quanto à PAD 79 escolares (7,3\%) também apresentavam elevação.

Pela Tabela 8 observa-se que na amostra para a PAS a proporção de crianças com hipertensão foi maior do que daquelas com pré-hipertensão, o mesmo não ocorrendo quanto à pressão diastólica. 
Tabela 8 - Distribuição dos escolares conforme a classificação de sua alteração de Pressão Arterial Sistólica (PAS) ou Diastólica (PAD).

\begin{tabular}{lcc}
\hline Pressão arterial & $\begin{array}{c}\text { PAS } \\
\text { n (\%) }\end{array}$ & $\begin{array}{c}\text { PAD } \\
\text { n (\%) }\end{array}$ \\
\hline Pré-hipertensos & $36(34,6)^{\star}$ & $38(48,1)^{\star *}$ \\
Hipertensos & $68(65,4)^{\star}$ & $41(51,9)^{\star *}$ \\
Total & $\mathbf{1 0 4 ( \mathbf { 1 0 0 , 0 ) }}$ & $\mathbf{7 9 ( \mathbf { 1 0 0 , 0 ) }}$ \\
\hline
\end{tabular}

${ }^{*} \mathrm{p}=0,018$ (significante estatisticamente). ${ }^{* \star} \mathrm{p}=0,08891$ (NS).

A Tabela 9 mostra que apesar do número absoluto de crianças com alteração de pressão ser aparentemente maior entre as meninas, não há diferença estatisticamente significante na prevalência de alteração de pressão arterial segundo o sexo.

Tabela 9 - Distribuição das frequências de escolares conforme classificação de Pressão Arterial dos escolares por sexo.

\begin{tabular}{lcc}
\hline Pressão arterial & $\begin{array}{c}\text { Masculino } \\
\mathbf{n}(\%)\end{array}$ & $\begin{array}{c}\text { Feminino } \\
\mathbf{n}(\%)\end{array}$ \\
\hline Normal & $478(87,4)$ & $456(85,2)$ \\
PA alterada & $69(12,6)$ & $79(14,8)$ \\
Total & $\mathbf{5 4 7 ( 1 0 0 , 0 )}$ & $\mathbf{5 3 5 ( 1 0 0 , 0 )}$ \\
\hline
\end{tabular}

Teste Exato de Fischer: $\mathrm{p}=0,331$ (NS).

Quanto à faixa etária, observou-se uma prevalência de pressão alterada (pré-hipertensão ou hipertensão arterial) maior entre os escolares do G2, mais velhos, em comparação aos do G1. Isto indica a possibilidade de que haja um aumento de problemas de PA com o passar da idade, ou que o referencial utilizado, talvez não seja tão adequado para a nossa população, dependendo da faixa etária avaliada (Tabela 10). 
Tabela 10 - Distribuição das frequências de escolares conforme classificação de PAS e PAD alteradas dos escolares, por grupos etários.

\begin{tabular}{lcc}
\hline Pressão arterial & G1 & G2 \\
& $\mathbf{n}(\%)$ & n (\%) \\
\hline Pré-hipertensos & $546(89,36)$ & $388(82,38)$ \\
Hipertensos & $65(10,64)$ & $83(17,62)$ \\
Total & $\mathbf{6 1 1 ( 1 0 0 , 0 0 )}$ & $\mathbf{4 7 1}(\mathbf{1 0 0 , 0 )}$ \\
\hline
\end{tabular}

Teste Exato de Fischer: $\mathrm{p}=0,0012(\mathrm{~S})$.

Risco relativo $=1,66(\mathrm{IC}=1,23$ a 2,24$)$

No G2 o risco relativo de apresentar PA alterada foi 1,66 vezes maior quando comparado ao G1. O IC de $95 \%(1,23$ a 2,24) mostra que o risco atribuível de aumento da pressão arterial com o decorrer da idade (entre os seis e os dez anos de idade) na melhor das hipóteses é de $23 \%$ e na pior das hipóteses de 124\%.

A análise isolada da PAS ou da PAD revelou basicamente a mesma tendência que o grupo como um todo, isto é, não evidenciando diferença entre meninos e meninas, mas apresentando uma maior proporção de alterações no grupo de escolares de maior idade.

Estas diferenças de PA em relação à idade, com maior prevalência nas crianças mais velhas, já tem sido descritas na literatura inclusive, fenômeno esse que poderia estar relacionado ao início do desenvolvimento puberal ${ }^{131,132}$. Alguns autores ${ }^{133,134}$ mostram uma associação maior de RCV na idade adulta, nas crianças púberes que tem alterações de PA em comparação com as pré- púberes (em torno de nove anos de idade). Quando, além de PA elevada o IMC também era elevado estudos mostram que essas crianças desenvolvem placas de ateroma já na segunda década de vida ${ }^{20,132}$. 


\subsubsection{Pressão Arterial e Peso de Nascimento}

Apesar de ter sido possível recuperar a informação de PN apenas de 816 crianças, como há resultados controversos na literatura quanto a associação de alteração de PN entre crescimento fetal, alterações metabólicas e HAS na idade adulta ${ }^{35,43,44,135}$ optou-se por verificar se havia nessas crianças alguma correlação entre PAS, PAD e o PN.

Tanto para a PAD quanto a PAS não se encontrou relação com o PN. Os coeficientes de correlação de Pearson com o PN foram praticamente iguais a 0,0 e, obviamente, não significantes $(p=0,8673$ para $P A D, p=0,6692$ para PAS).

\subsubsection{Pressão Arterial e Idade}

Apesar da análise direta da correlação entre idade e PA não ser favorecida pelo fato da amostra aqui estudada ser composta por dois subgrupos de idade distintos, que possuem uma gama de variação de idade intragrupo muito restrita, cumpre salientar que quando se analisou a proporção de alterações da PA por subgrupo de idade se observou diferenças estatisticamente significantes, com uma maior prevalência no G2, de crianças mais velhas, o que indica que é possível que exista uma elevação de PA em função da idade (Tabela 10).

O fato de em nosso estudo a amostra ter incluído crianças na faixa etária de nove e dez anos - portanto pré-puberes - poderia explicar a prevalência de alterações de PA que foi observada. 
Apesar de realizados em adolescentes, estudos tem evidenciado correlação importante entre a PAS e PAD e a idade ${ }^{59,136}$, o que corrobora as alterações da PA em função da idade aqui encontradas..

\subsubsection{Pressão Arterial e Estatura}

Na Figura 12, quando se analisam os escolares como um todo, observase uma tendência estatisticamente significante de aumento da PAS em função do escore $z$ de estatura, sendo que quanto mais alta a criança maior tende ser sua PAS. O Coeficiente de Correlação de Pearson foi de 0,1860 com IC95\% de 0,1278 a 0,2429 , apesar deste valor de coeficiente ser relativamente pequeno, a correlação pode ser considerada importante, pois já é aceito que a PA é uma variável biológica cujos valores normalmente são modulados por múltiplos fatores.

Figura 12 - Relação da Pressão arterial sistólica (PAS) dos escolares com escore $z$ de estatura (HAZ).

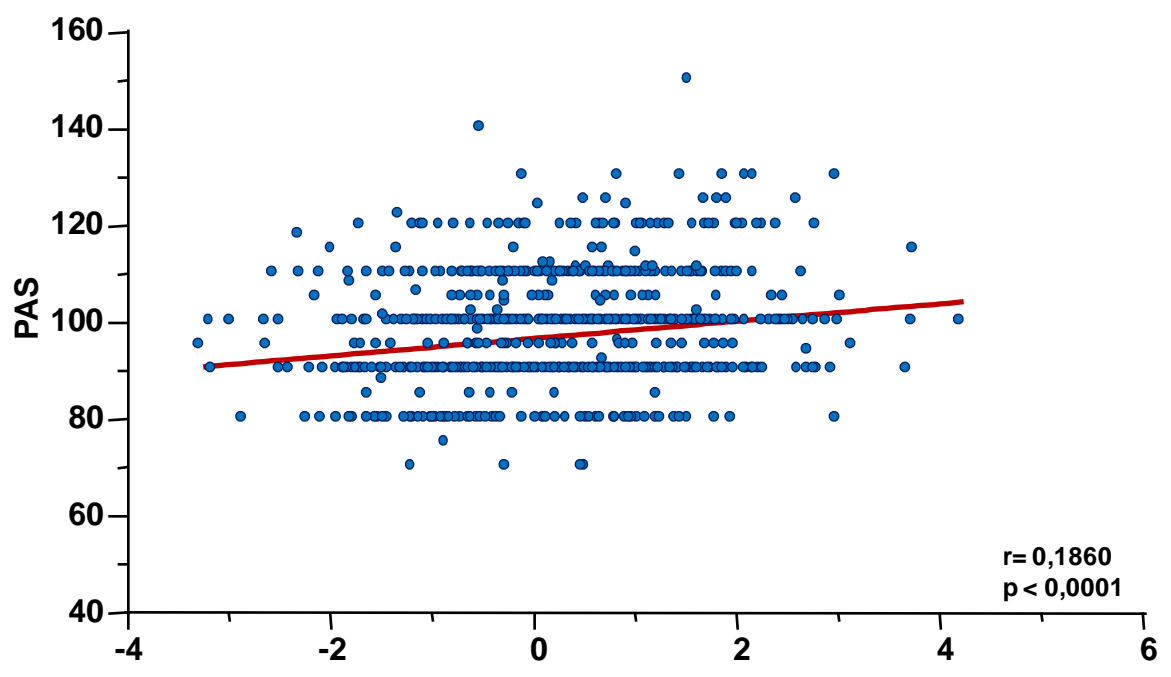

HAZ 
Na Figura 13 observou-se para a PAD, o mesmo comportamento da PAS, com tendência a ser mais elevada nas crianças mais altas. O Coeficiente de Correlação de Pearson entre PAD e o escore $z$ de estatura foi de 0,1763 (IC95\% 0,1179 a 0,2335) também significante $(p<0,0001)$, valendo para o mesmo as considerações já feitas no caso da PAS.

Figura 13 - Relação da Pressão arterial diastólica (PAD) dos escolares com escore $z$ de estatura (HAZ).

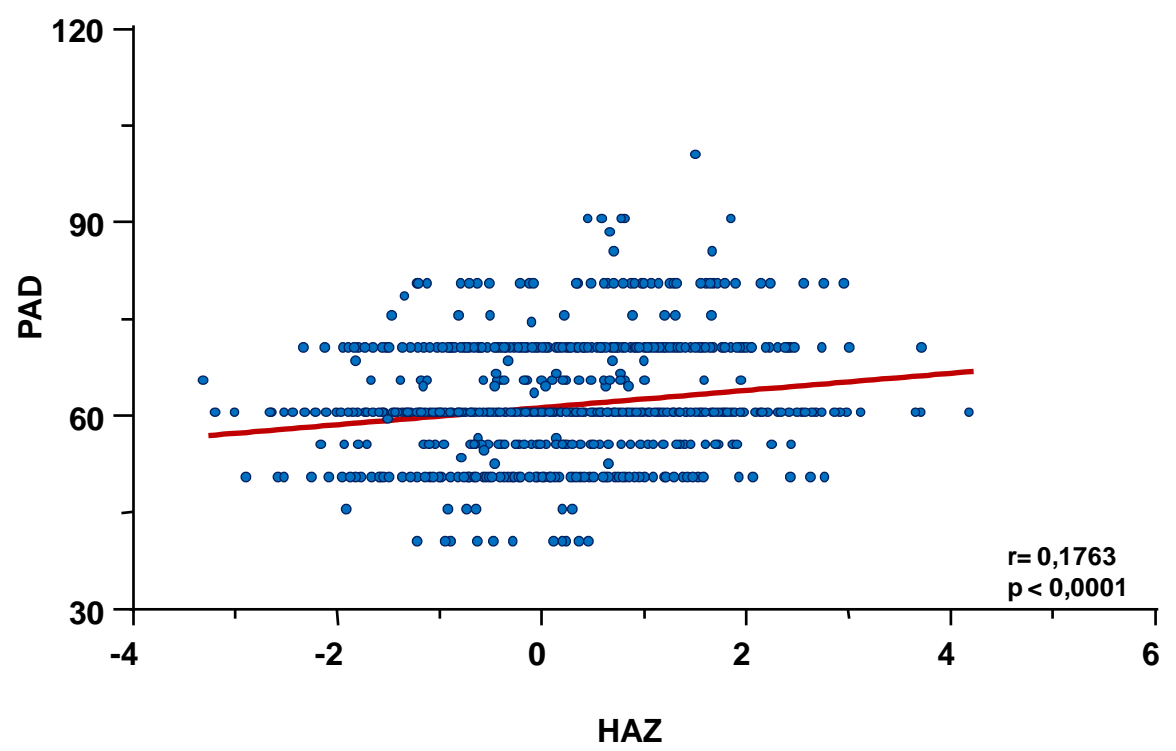

Quando se analisam estas correlações no grupo de escolares mais jovens (Figuras 14 e 15), observa-se que há correlação ( $r=0,1779$, IC95\% de 0,09996 a 0,2536) da PAS com o escore $z$ de estatura, estatisticamente significante $(p<0,0001)$. O mesmo ocorre quando se analisa a PAD, cujo Coeficiente de Correlação com a estatura foi de $r=0,1741$, IC95\% de 0,09612 a 0,2500, também estatisticamente significante $(p<0,0001)$. 
Figura 14 - Relação da Pressão arterial sistólica (PAS) dos escolares do G1 com escore $z$ de estatura (HAZ 6-7).

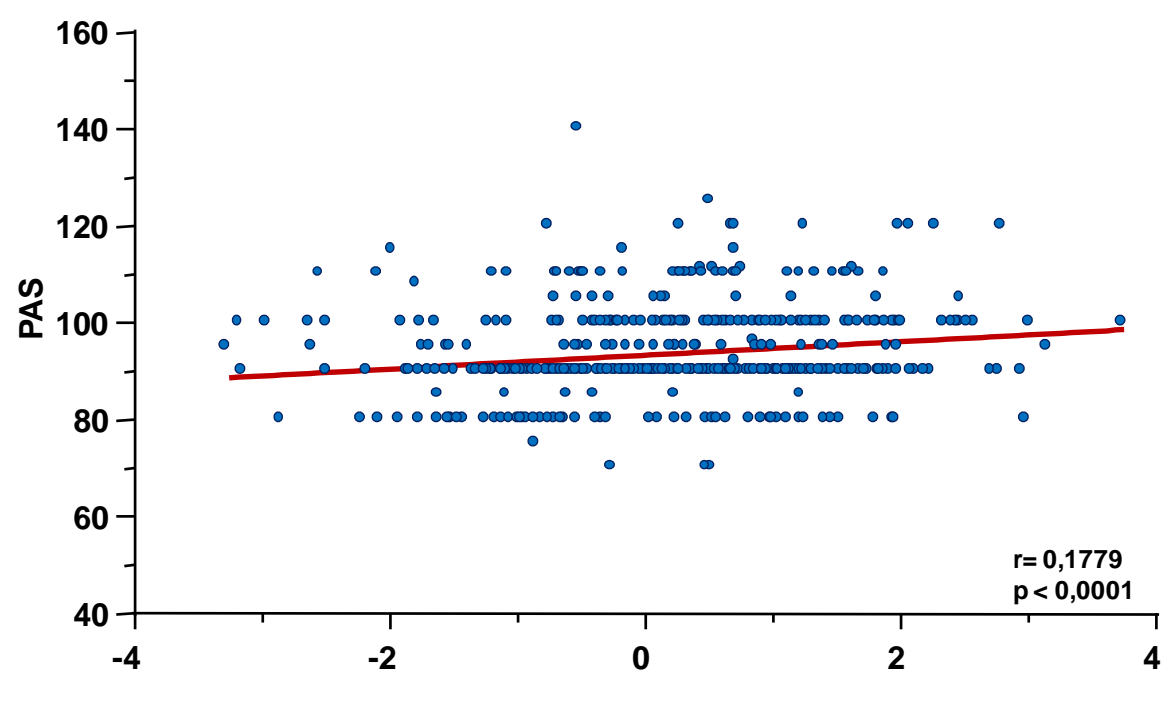

HAZ 6-7

Figura 15 - Relação da Pressão arterial diastólica (PAD) dos escolares do G1 com escore $z$ de estatura (HAZ 6-7).

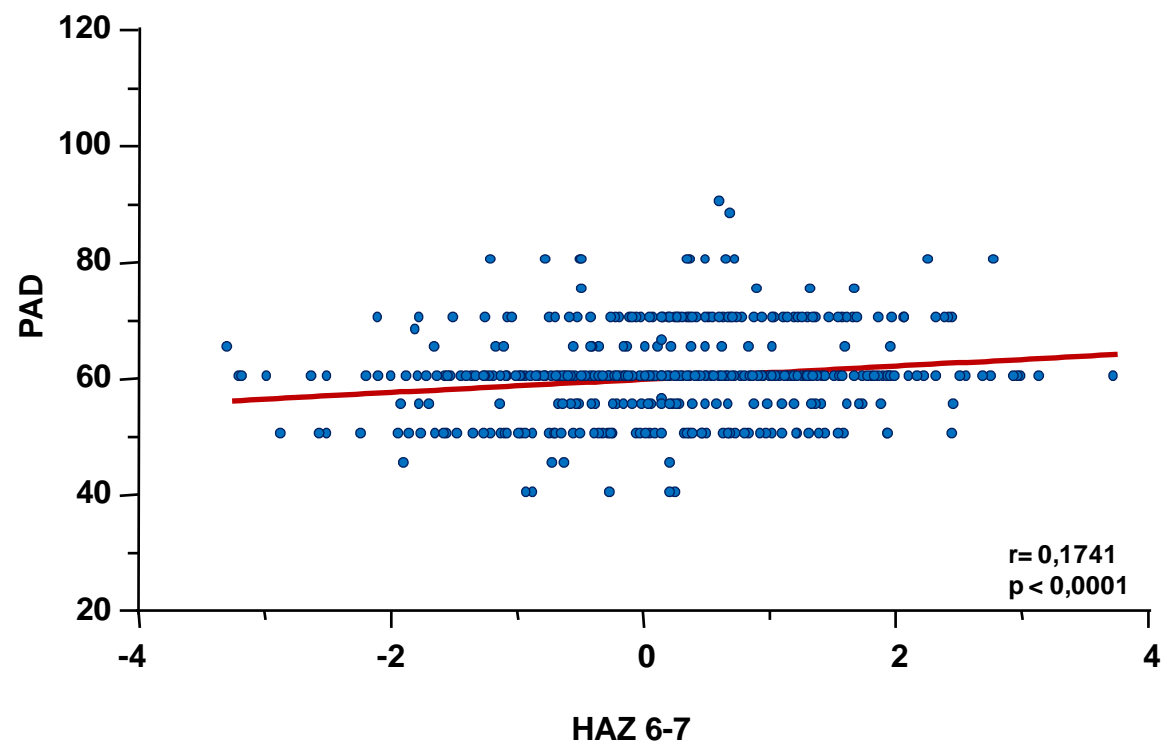

$\mathrm{Na}$ avaliação da variação da PAS em função do escore z de estatura

(Figura 16) entre os escolares mais velhos (G2), a correlação ( $r=0,2248$, IC95\% de 0,1373 a 3089) também se mostrou significante ( $p<0,0001)$. Embora o coeficiente pareça sugerir uma relação um pouco mais forte do que a 
observada no grupo das crianças mais jovens, a diferença entre os coeficientes de correlação observados nos dois grupos não se mostrou estatisticamente significante.

Figura 16 - Relação da Pressão arterial sistólica (PAS) dos escolares do G2 com escore $z$ de estatura (HAZ 9-10).

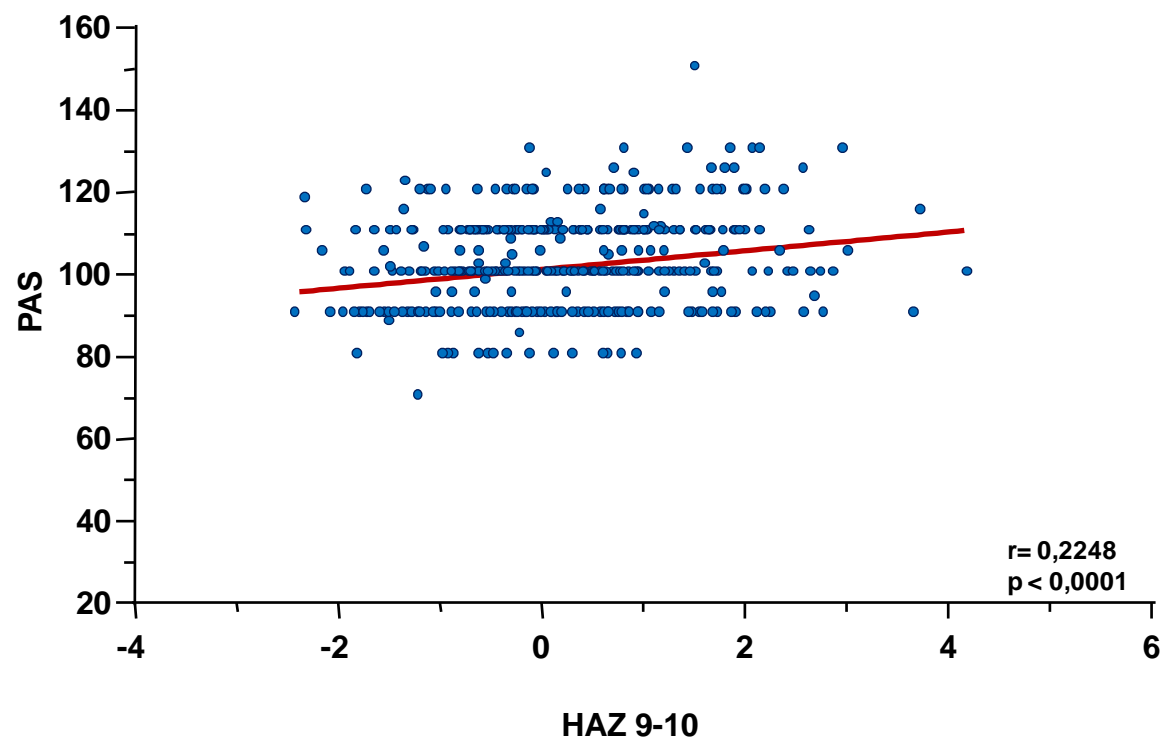

A análise da Figura 17, do valor do Coeficiente de Correlação de Pearson entre a PAD e o escore z de estatura no G1 (Figura 15).

O G2 mostrou tendência semelhante quanto à PAS nos mesmos grupos de idade, G2 r=0,1876 (IC95\% 0,09888 a 0,2733) e G1 $r=0,1741$ (IC95\% $0,00961$ a 0,2500$)$ e que também foram significantes $(p<0,0001)$. 
Figura 17 - Relação da Pressão arterial diastólica (PAD) dos escolares com escore z de estatura do G2 (HAZ 9-10).

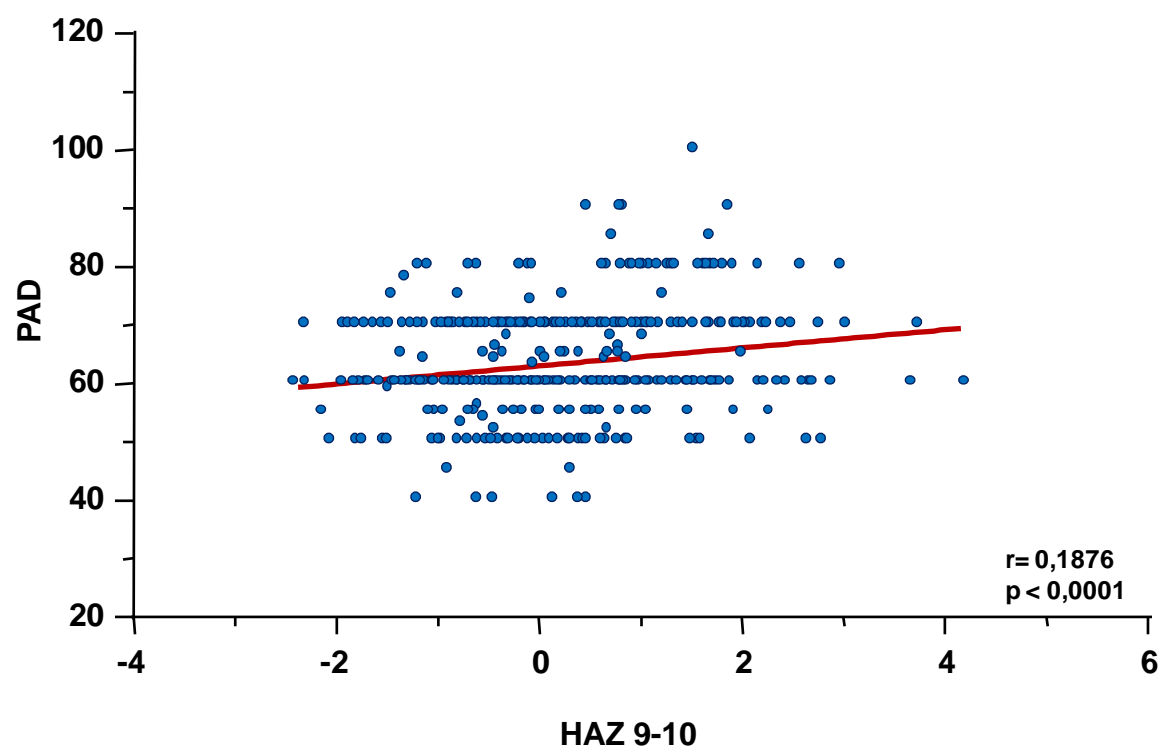

Quanto ao sexo, nas meninas, independentemente do grupo de idade, houve correlação da PAS com o escore $z$ de estatura (Figura 18). O Coeficiente $(r)$ foi de 0,1545 (IC95\% de 0,07059 a 0,2362), com um $p=0,0003$.

Figura 18 - Relação da Pressão arterial sistólica (PAS) dos escolares com escore $z$ de estatura do sexo feminino (HAZ F).

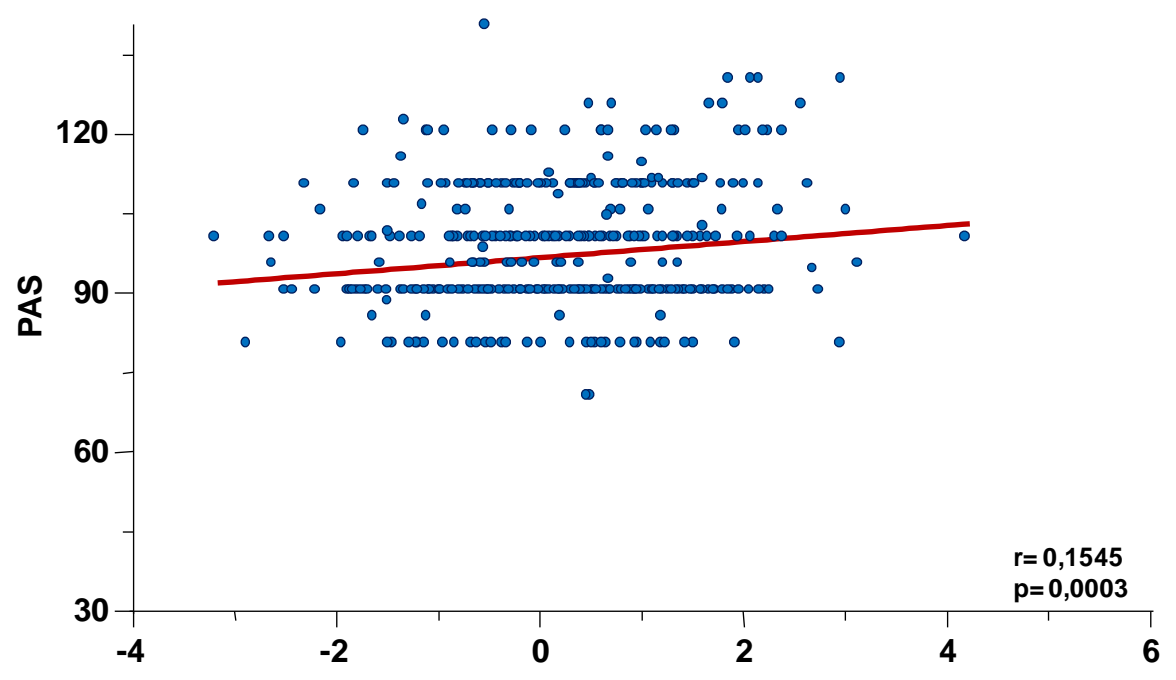

HAZ F 
A mesma tendência se observa, considerando sempre somente sexo feminino, ao se correlacionar PAD com escore $z$ de estatura (Figura 19). O Coeficiente de Correlação é de 0,1330 (IC95\% de 0,04872 a 0,2153) e, também significante $(p=0,0021)$.

Figura 19 - Relação da Pressão arterial diastólica (PAD) dos escolares com escore $z$ de estatura do sexo feminino (HAZ F).

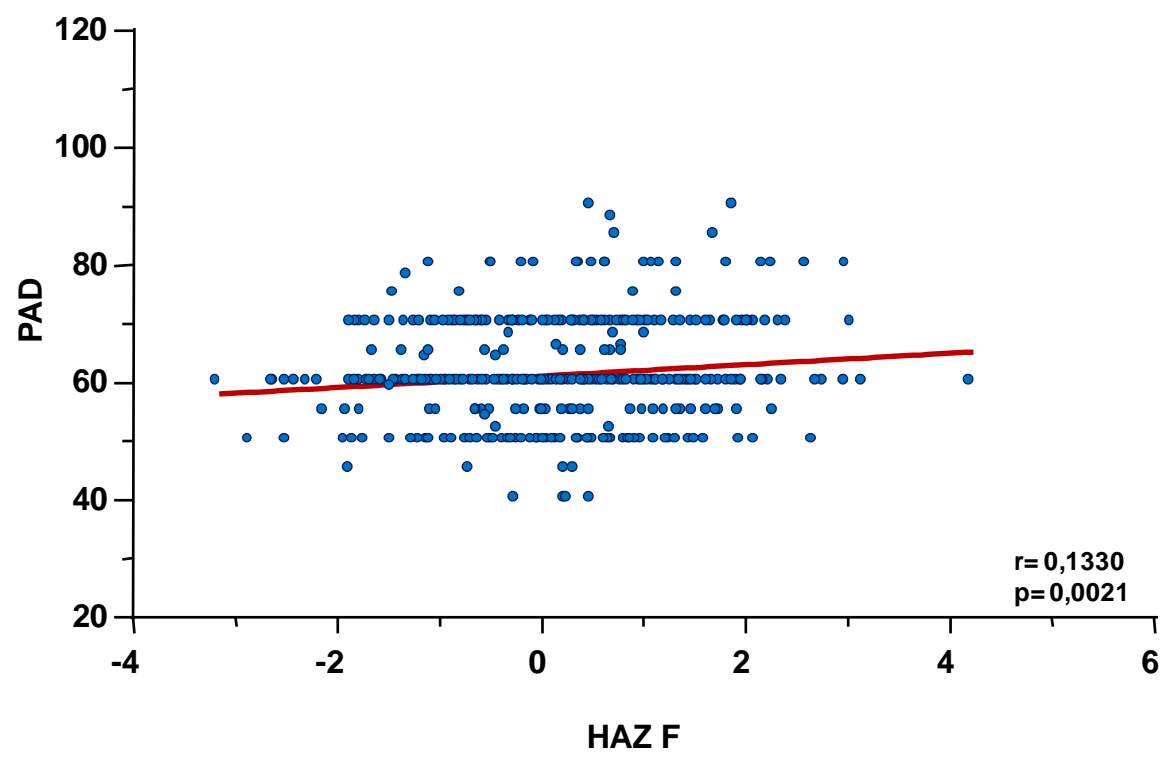

As Figuras 20 e 21 demonstram as correlações da PAS e PAD com escore $z$ de estatura nos educandos do sexo masculino e para ambas evidenciou-se correlação significante. Para a PAS o coeficiente de correlação foi 0,2160 com IC95\% de 0,1346 a 0,2946 ( $p<0,0001$ ), enquanto para a PAD verificou-se um coeficiente de 0,2167 com IC95\% de 0,1353 a 0,2952, também estatisticamente significante $(p<0,0001)$. 
Figura 20 - Relação da Pressão arterial sistólica (PAS) dos escolares com escore $z$ de estatura do sexo masculino (HAZ M).

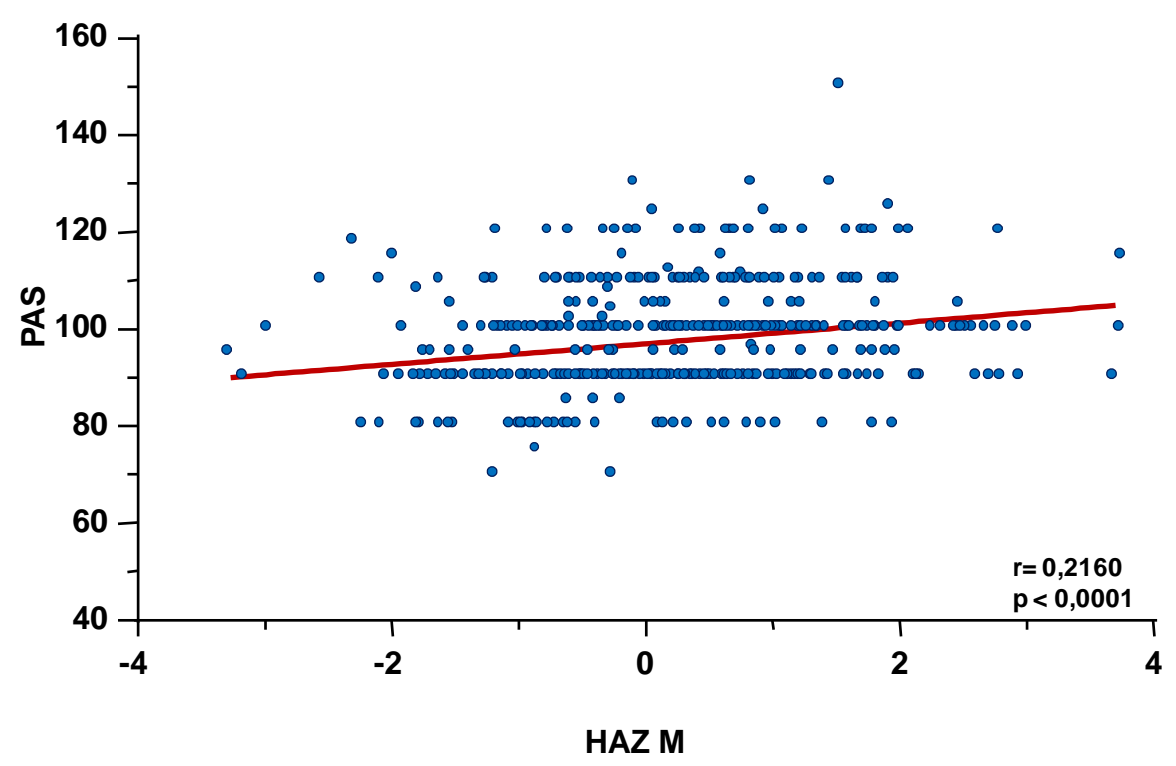

Figura 21 - Relação da Pressão arterial diastólica (PAD) dos escolares com escore $z$ de estatura do sexo masculino (HAZ M).

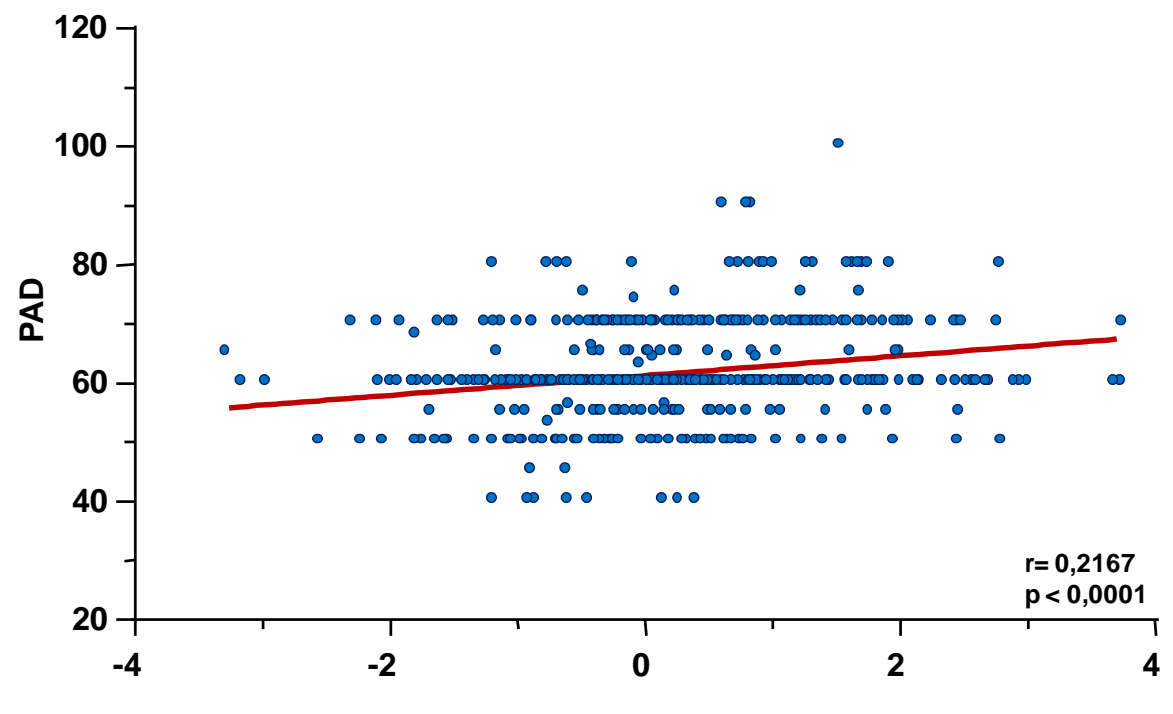

HAZ M

No presente estudo, o comportamento das PAS e PAD, correlacionandose de maneira direta e significante estatisticamente com os valores de $z$ escore de estatura, não mostrou diferenças de tendência quando a análise foi 
estratificada por grupos de idade ou por grupos de sexo. Apesar disso, os coeficientes de correlação não se mostraram muito elevados, variando conforme o grupo entre 0,13 e 0,22 .

Como os grupos de idade não apresentaram diferenças no crescimento estatural alcançado ( $z E / l ~ G 1=0,25$ e zE/l G25 $=0,17 ; p=0,9898$ ), bem como quando a estatura foi analisada segundo o sexo $(z E / / M=0,23$ e $z E / l F=0,26$; $p=0,6667$ ), mas intragrupo observou-se relação entre os níveis de pressão e o escore $z$ de estatura, fica evidente que há mesmo uma influência específica do processo de crescimento na definição da PA da criança.

Em concordância com nosso estudo, uma pesquisa que correlacionou a elevação da PA com o crescimento e o desenvolvimento puberal observou uma relação muito estreita entre as taxas máximas de elevação da PA e o aumento do peso e da altura, sugerindo também que o crescimento como um todo poderia influenciar os aumentos de $\mathrm{PA}^{137}$.

A análise entre essas alterações de PA e crescimento, principalmente entre as crianças mais velhas, pode eventualmente, ser consequência da tendência secular de crescimento que vem sendo observada nas últimas décadas, já que os valores de referência de PA propostos pela Task Force ${ }^{7}$ se referem a uma geração de crianças, cujas avaliações de pressão e estatura foram feitas há cerca de 40 anos. Se outros estudos confirmarem ou reforçarem essa possibilidade, talvez, venha a ser necessária, uma revisão ou até mesmo, a realização de um novo referencial de PA em função da idade e da estatura para as crianças até dez anos de idade. 


\subsubsection{Pressão Arterial e Estado Nutricional}

Nas Figuras 22 e 23 evidenciam-se as correlações da PAS e PAD com estado nutricional dos escolares de acordo com seu escore z de IMC. Quanto a PAS observou-se uma correlação estatisticamente significante ( $p<0,0001$ ), com um $r=0,2784$ (IC95\% de 0,2225 a 0,3325) evidenciando que PAS aumenta à medida que se eleva o IMC da criança.

Resultado semelhante ocorreu com a PAD, que apresenta uma tendência de aumento em função do zIMC, com um $r=0,2044$ (IC95\% de $0,1466$ a 0,2608$), p<0,0001$.

Figura 22- Relação da Pressão arterial sistólica (PAS) dos escolares e zIMC.

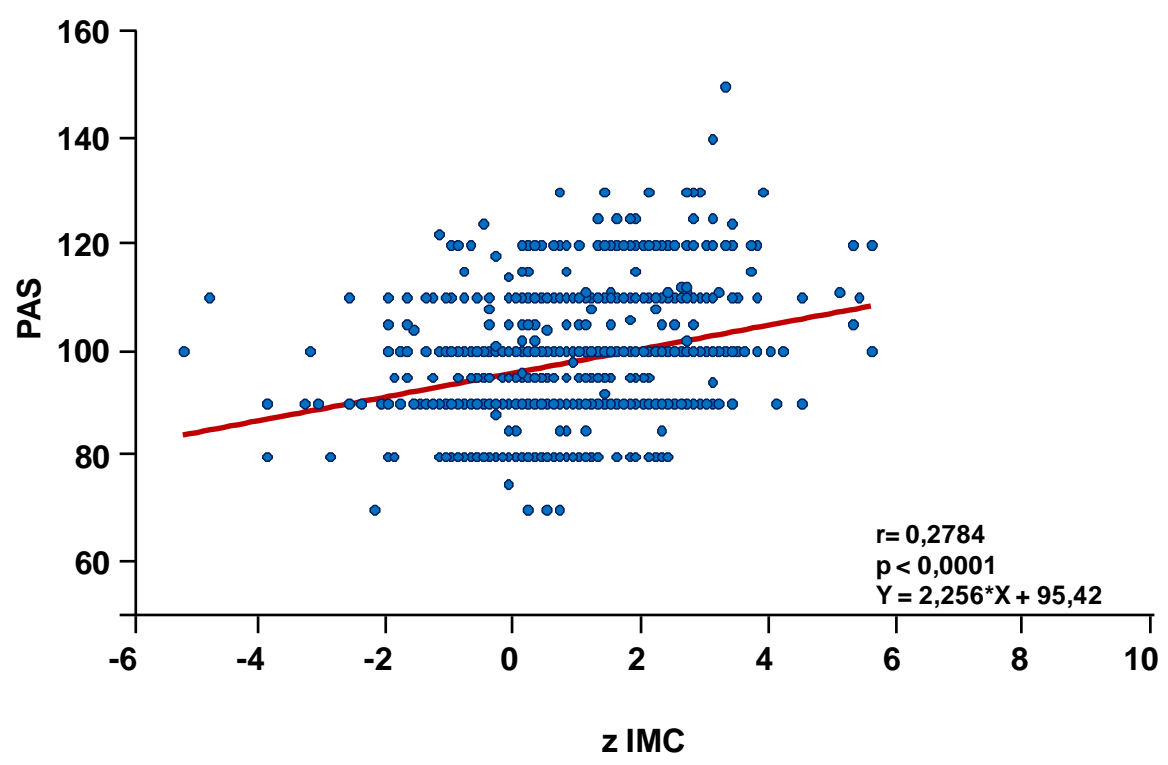


Figura 23 - Relação da Pressão arterial diastólica (PAD) dos escolares e zIMC (OMS).

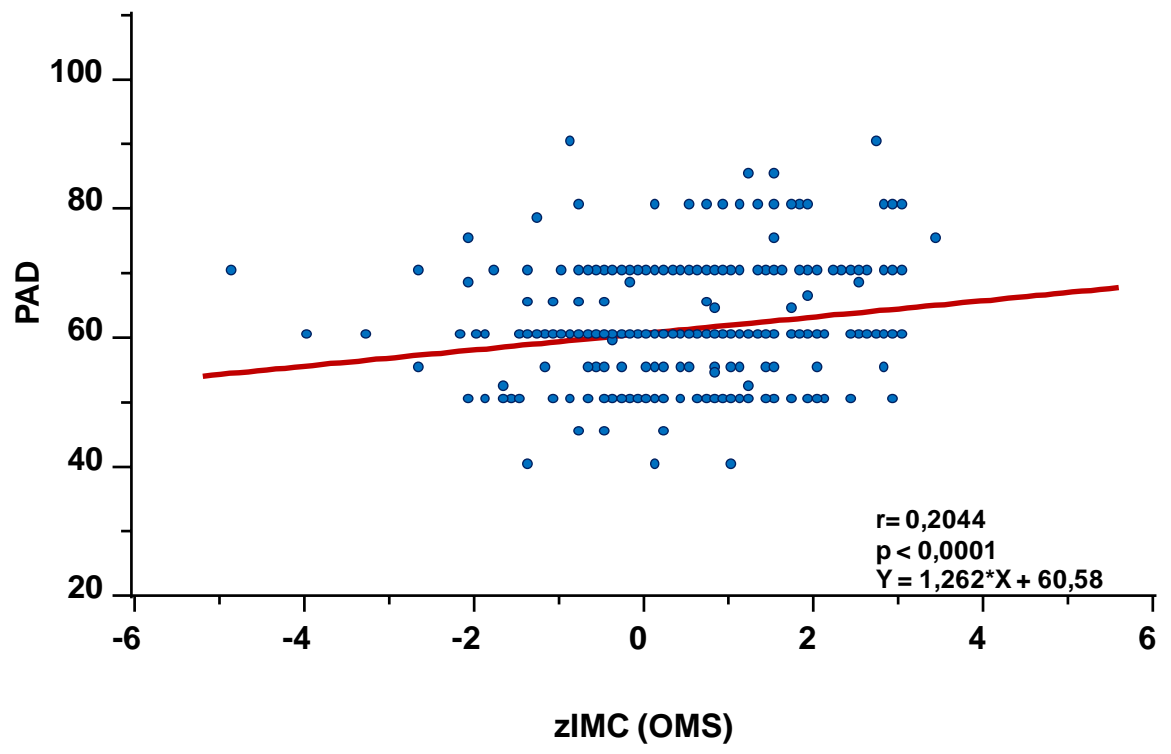

Várias pesquisas ${ }^{6,138-142}$, analisaram a associação do excesso de peso com elevação da PA. Entre essas, um estudo chinês ${ }^{142}$, com crianças e adolescentes de sete a 18 anos de idade mostrou que nos obesos havia um risco muito elevado de desenvolvimento de hipertensão.

Estudos em diversos países tem evidenciado correlação entre sobrepeso, obesidade e elevação da PA $\mathrm{A}^{4,97,116,129,133,141,143,144 .}$

Um destes estudos ${ }^{143}$ observou especificamente que para cada aumento de escore $z$ de IMC de uma unidade, na infância, ocorria um acréscimo na pressão arterial média sistólica de 0,2 a 1,0 $\mathrm{mmHg}$ para os meninos e de 0,2 a $0,8 \mathrm{mmHg}$ para as meninas, corroborando com outros estudos ${ }^{116,133}$ que evidenciaram os efeitos das elevações do IMC e de pressão arterial na infância como preditores de hipertensão e síndrome metabólica na idade adulta. Esses autores concluem que, para permanecerem livres de hipertensão ou de síndrome metabólica (com ou sem hipertensão), as pressões sanguíneas na infância deveriam permanecer abaixo do percentil 50 para idade e sexo. 
Estudo que explorou associações étnicas específicas entre medidas de tamanho corporal e avaliou IMC, razão da CA/E e as suas relações com PA (PAS e PAD) em crianças com idades compreendidas entre cinco e seis anos de idade, observou que o IMC era o marcador mais fortemente associado com a PA em todos os grupos étnicos ${ }^{80}$. Nenhuma das medidas de tamanho corporal mostrou capacidade discriminatória superior, e o valor preditivo dessas foi baixo, o que sugere que, com essa idade, outros fatores, como pais obesos, por exemplo, poderiam ser indicadores mais importantes para o aumento da PA. Em diferentes estudos, entre as várias medidas de tamanho corporal, o IMC pareceu ser o determinante mais confiável da PA em qualquer grupo étnico, embora com baixa capacidade preditiva para detecção de elevação da $P A^{6,116,145-147}$.

Já outros trabalhos longitudinais, avaliados numa metanálise ${ }^{117}$, mostraram a existência de correlações entre a infância e o IMC, com hipertensão na idade adulta, e essa associação foi mais elevada quando se considerou crianças mais velhas (maiores de oito anos) com excesso de peso e que possuíam pais obesos, reforçando que o IMC pode ser de fato um marcador útil de risco de hipertensão arterial ${ }^{92,148}$.

No Brasil, estudo de prevalência de hipertensão arterial em crianças e adolescentes obesos mostrou valores elevados de PA entre crianças e adolescentes, porém não evidenciou diferença quanto aos grupos etários ${ }^{146}$. Entretanto, outros autores enfatizam que entre adolescentes obesos a metade já apresentavam alteração de $\mathrm{PA}^{, 149,150}$.

Em nosso estudo, a associação das PAS e PAD com o IMC foi estatisticamente significantes, com resultados semelhantes para ambas. 
Apesar disso, análise de pesquisas longitudinais em escolares verificou que enquanto a prevalência de obesidade praticamente triplicou a prevalência de alteração da PA não se modificou na mesma proporção. Esses dados apontam para a necessidade de que mais pesquisas envolvendo outros possíveis fatores de risco de elevação da PA precisam continuar sendo realizadas $^{17,59}$.

\subsubsection{Pressão Arterial e Composição Corporal}

A seguir se apresentam as análise da PAS e PAD em função da composição corporal, a partir de suas relações com zCC, zCA, CC/E, CA/E, zAMB, zAGB e zPCT do grupo como um todo.

De uma maneira geral, os dados evidenciaram associação entre alterações das medidas de composição corporal com a elevação da pressão arterial sistólica e diastólica, todas estatisticamente significantes.

A análise isolada entre CC também revelou correlação com a PAS, $r=$ 0,4645 e IC 95\% 0,4164 a 0,5100, com a PAD $r=0,3352$ e IC95\% 0,2812 a 0,3871, ambas significantes (Figuras de 24 a 27). Quando a CC é analisada em escore z essas correlações, apesar de apresentarem menores Coeficientes de Pearson, se mantêm significantes estatisticamente. (Figuras de 24 a 27). 
Figura 24 - Relação da Pressão arterial sistólica dos escolares (PAS) e Circunferência da cintura (CC) em centímetros.

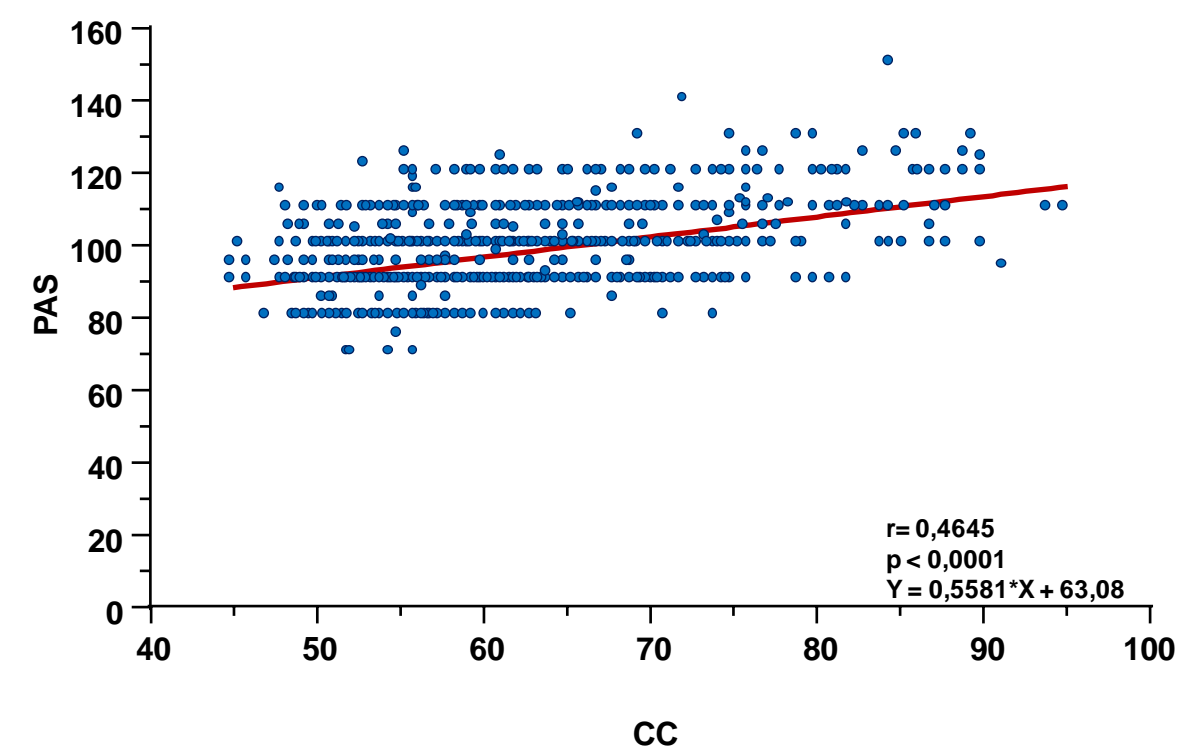

Figura 25 - Relação da Pressão arterial diastólica (PAD) dos escolares e Circunferência de Cintura (CC) em centímetros.

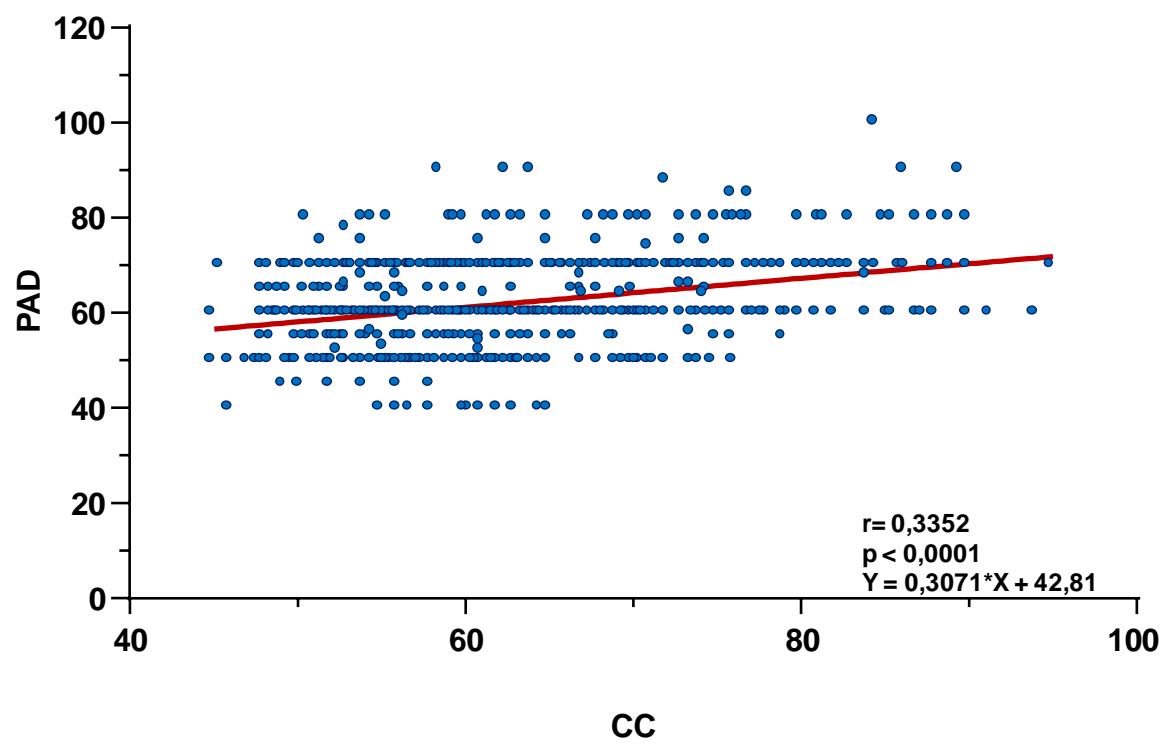


Figura 26 - Relação da Pressão arterial sistólica (PAS) dos escolares e escore $z$ de Circunferência de cintura (zCC).

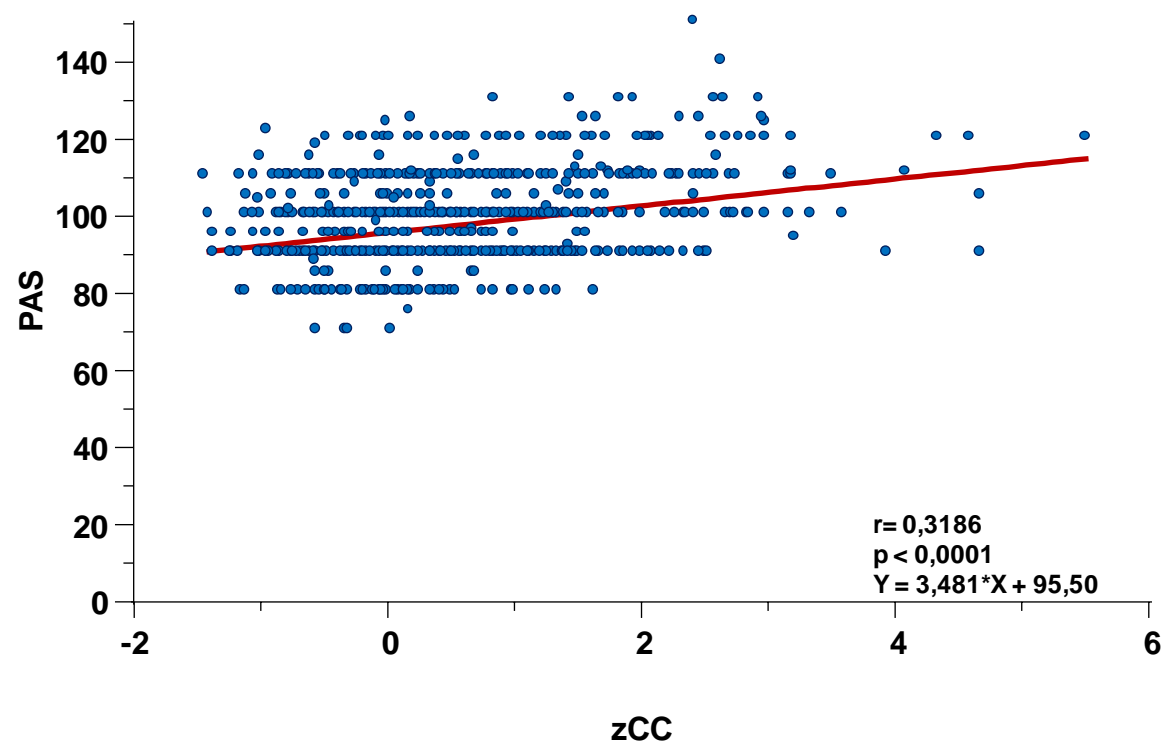

Figura 27 - Relação da Pressão arterial diastólica (PAD) dos escolares e escore $z$ de Circunferência de cintura (zCC).

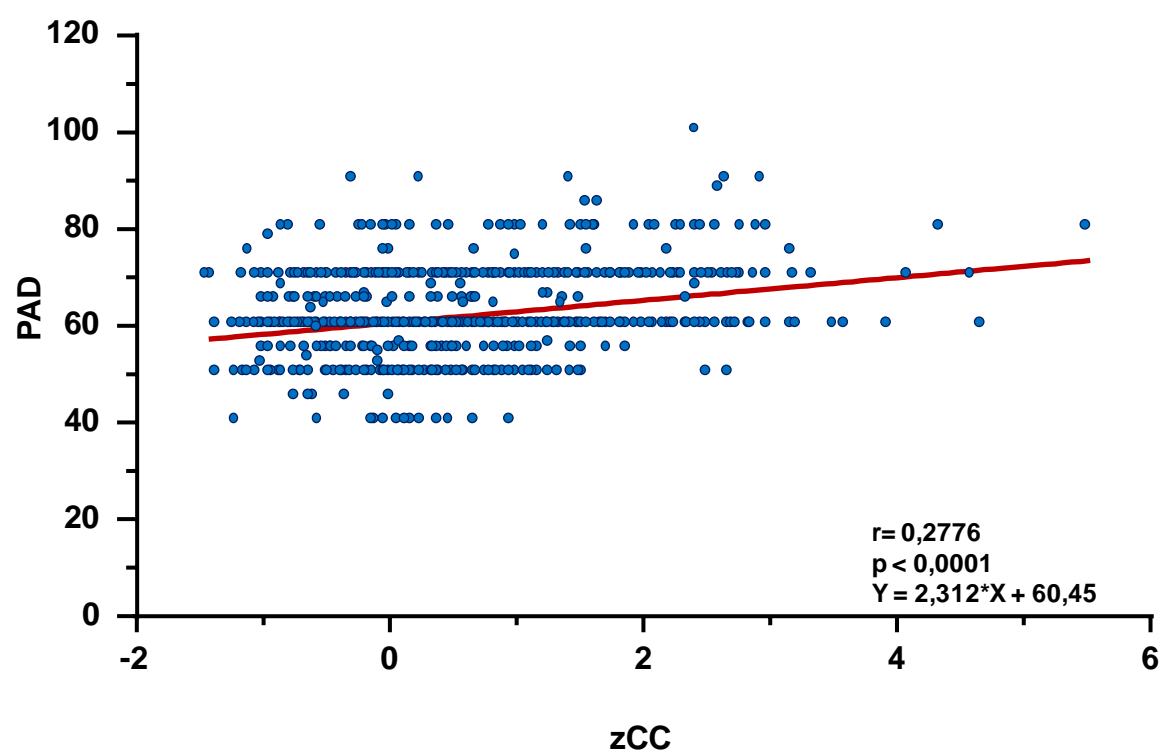

Quanto à análise das relações da CA com as alterações da PAS e PAD também se observa correlação significante, com r = 0,2732 (IC95\% 0,2172 a 0,3275) e $r=0,2379$ (IC95\% 0,1809 a 0,2934), respectivamente.

Diversos estudos, inclusive em nosso meio, tem mostrado associação entre o aumento da CC e alterações da PA em diferentes faixas etárias ${ }^{104,106,136,140,141,151 .}$ 
Um destes, que investigou a relação entre CC, combinando o IMC e pressão arterial elevada em crianças jovens (seis a sete anos idade), observou que a CC poderia aumentar a predição de elevação da pressão arterial. Considerando que medição da pressão arterial requer maior habilidade do operador e é passível de ser falsamente elevada e, que a CC é significativamente correlacionada com a pressão sanguínea, o estudo sugere o uso da medição de CC como ferramenta de triagem para a pressão arterial elevada em crianças ${ }^{89}$.

Entretanto, em outro estudo, com crianças obesas de sete a 14 anos de idade, não se constatou associação entre $C C$ e valores elevados de $\mathrm{PA}^{24}$. Essa aparente discrepância de resultado, além de mostrar a necessidade de realizar mais pesquisas destas relações, pode ser decorrente do fato que os autores que não encontraram essa correlação se limitaram a uma amostra de crianças obesas e não de uma população em geral.

A análise das retas de regressão da PAS e da PAD, em função da CC resultou respectivamente nas seguintes equações: PAS $=0,5581 \times C C+63,0$ e $\operatorname{PAD}=0,3071 \times C C+42,8$

Esses valores indicam que se não houvesse outros fatores intervenientes na determinação de PA, para cada centímetro de aumento na CC haveria um aumento de $0,6 \mathrm{mmHg}$ na PAS e 0,3 $\mathrm{mmHg}$ na PAD, valores estes, bastantes expressivos, considerando a possível variabilidade da CC que se observa em crianças.

A análise da razão da CC/E com os níveis de PAS mostrou um coeficiente de correlação de Pearson de 0,2804 (IC95\% 0,2246 a 0,3345) significante $(p<0,0001)$, como se verifica na Figura 28. 
Figura 28 - Relação da Pressão arterial sistólica (PAS) com a razão da circunferência cintura pela estatura (CC/E) em escolares.

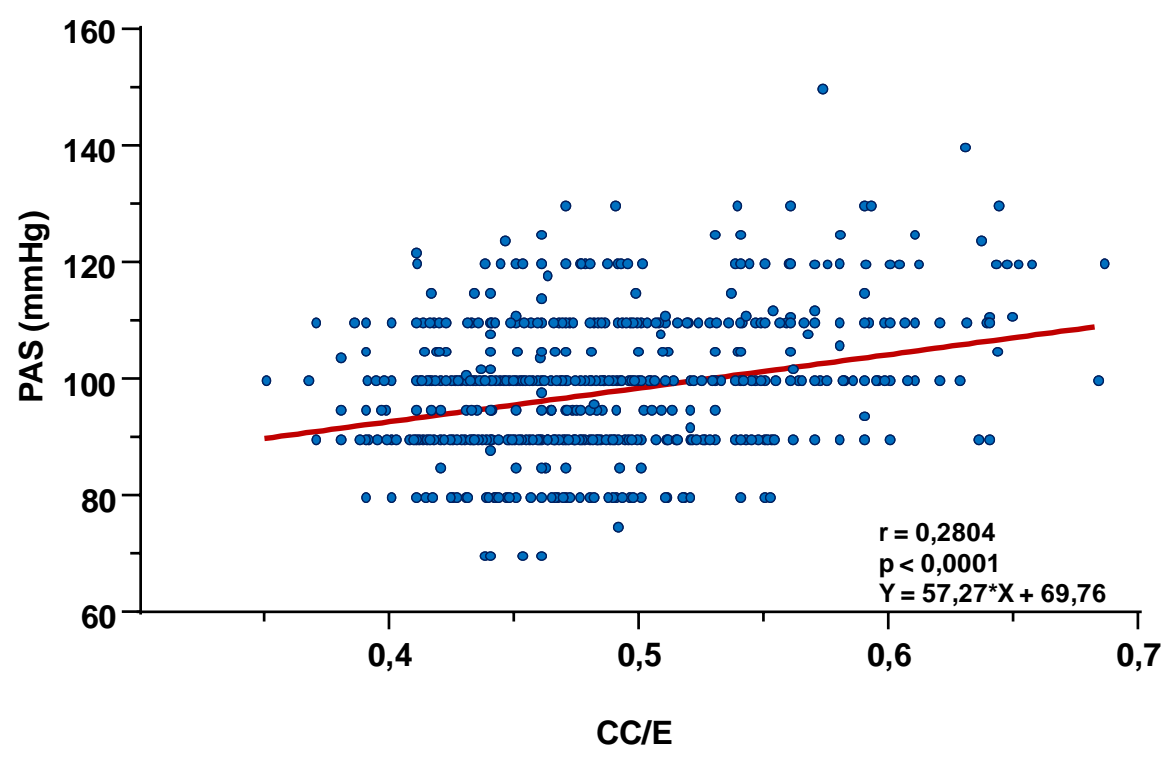

Já a análise da Figura 29 mostra uma correlação também, entre a CC/E com a PAD, com um $r=0,2330$ (IC95\% de 0,1759 a 0,2886) e $p<0,0001$ também significantes.

Figura 29 - Relação da Pressão arterial diastólica (PAD) e razão da circunferência da cintura pela estatura (CC/E).

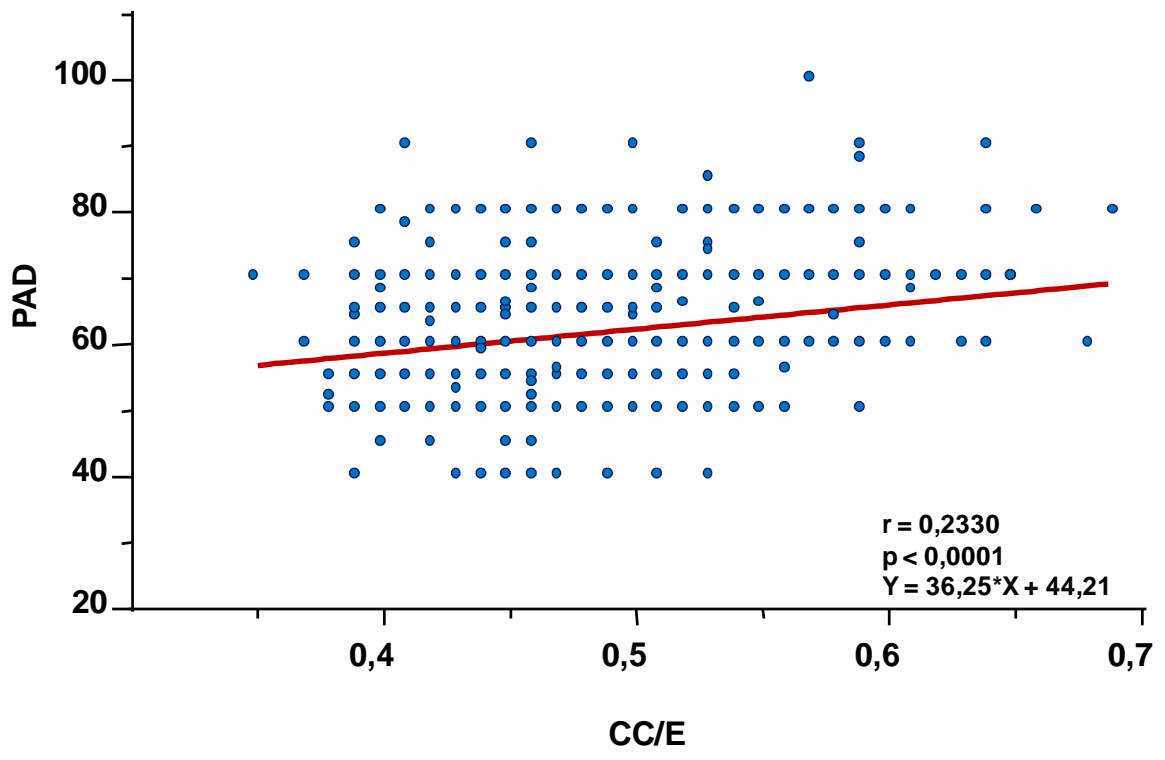


$\mathrm{Na}$ Figura 30, agora analisando a relação CA/E e PAS, encontrou-se correlação entre as mesmas, $r=0,2168$ (IC95\% de 0,1593 a 0,2729) e p < 0,0001.

Figura 30 - Relação da Pressão arterial sistólica (PAS) e razão da circunferência abdominal pela estatura (CA/E).

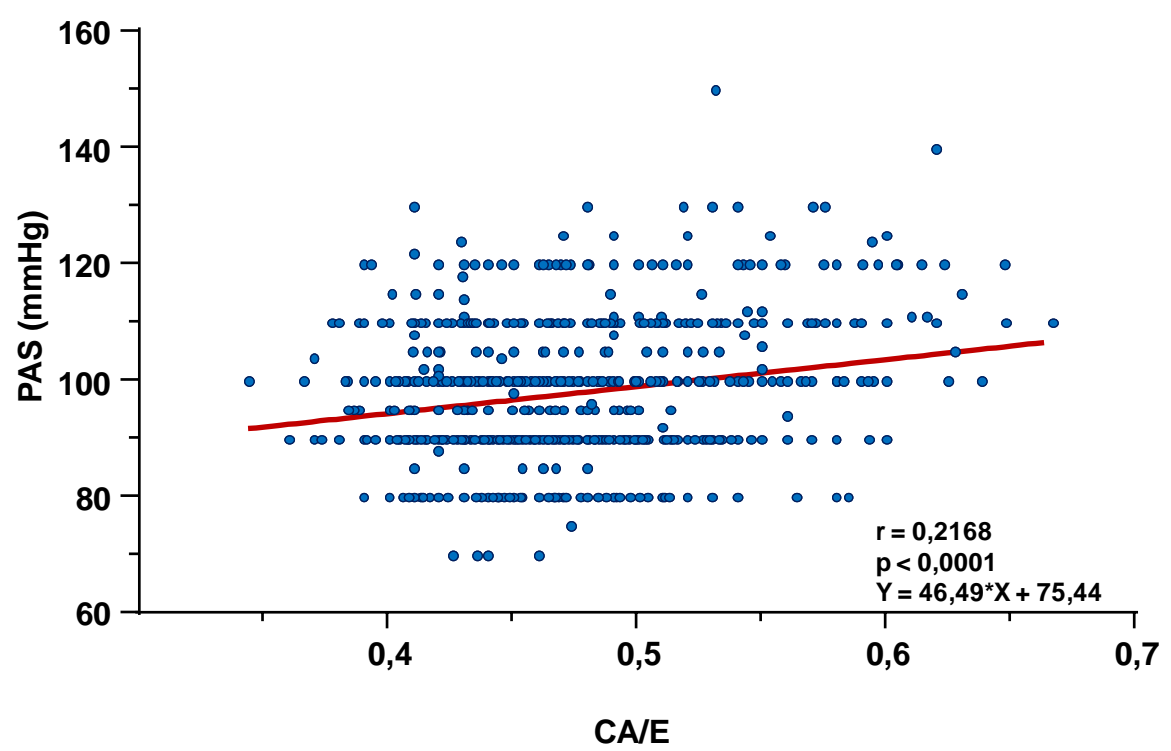

Do mesmo modo que para PAS, a CA/E mostrou correlação com a PAD, $r=0,1811$ e IC95\% de 0,1228 a 0,2381 e p < 0,0001 (Figura 31).

Figura 31 - Relação da Pressão arterial diastólica (PAD) e razão da circunferência abdominal pela estatura (CA/E).

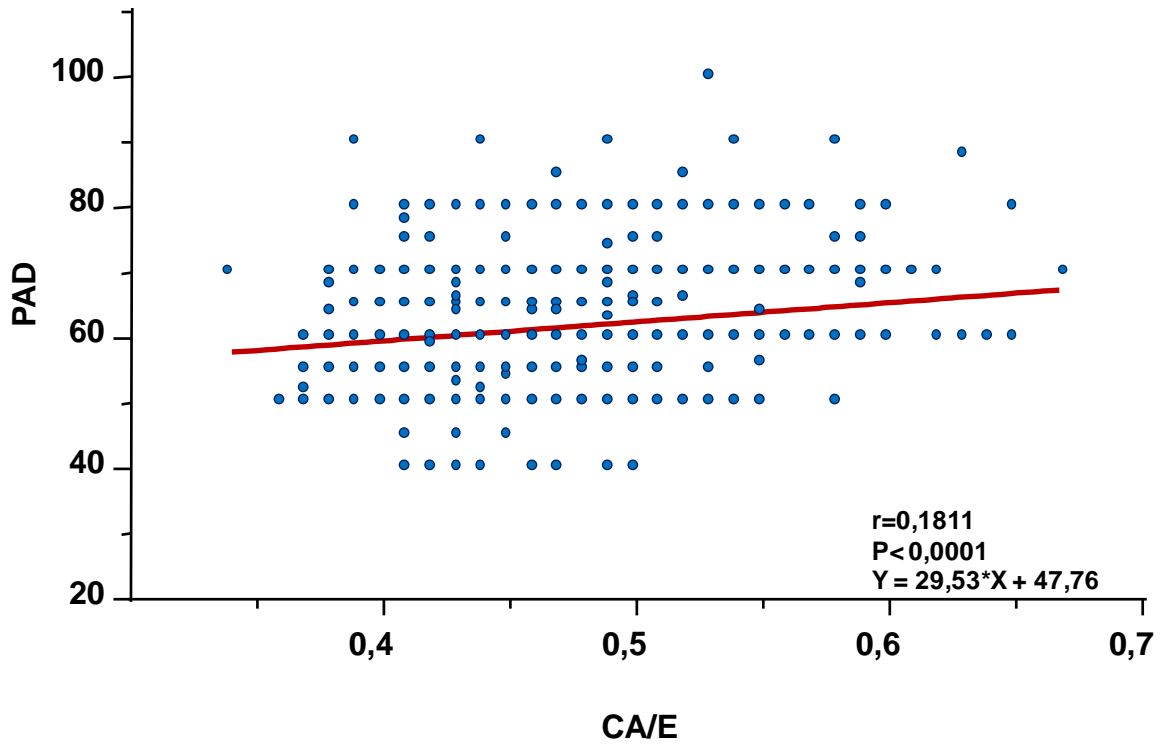


Assim, embora se tenha mostrado correlação estatisticamente significante tanto da PAS quanto da PAD com as razões da CA/E e CC/E numa população de escolares, o que se nota é que os coeficientes de correlação da razão da CC/E parecem tender a serem um pouco maiores que os da CA/E, embora não tenham evidenciado diferença na análise estatística.

Vários estudos ${ }^{95,97,125,128,141,152,153}$, demonstram a importância da razão da CA/E como indicador de desenvolvimento de HAS. Desses, uma pesquisa que analisou quais índices de composição corporal entre CC, IMC e CA/E é melhor preditor de alterações da PA e metabólicas mostrou que CC é melhor que o IMC e que é significativamente mais eficiente para prever a resistência à insulina, as alterações de PA, de colesterol sérico e os níveis de triglicerídeos. Já, a razão CA/E apresentou uma tendência de se elevar de acordo com o com o grau de obesidade das crianças, prevendo com maior grau de independência, o risco de obesidade central ${ }^{142}$.

Diversos pesquisadores sugerem que o uso da razão da CA/E possua maior facilidade de execução, podendo ser uma alternativa para avaliar a adiposidade central em crianças, especialmente na prática dos cuidados primários de saúde. Por ser um índice de proporcionalidade, da quantidade de acúmulo de gordura corporal superior em relação à altura, seus valores durante a infância são influenciados pelo crescimento, portanto, pela idade e sexo ${ }^{54,95,128,154-157}$.

Já a redução significativa na média da razão da $C A / E$ da infância à adolescência reflete a desproporcionalidade das velocidades de crescimento em altura e da CC com a idade. Espera-se que a razão da CA/E se estabilize em torno de 18 anos de idade, quando o crescimento em altura cessa e ocorre 
estabilização dos valores médios de CA/E nos mais velhos, particularmente em meninos. A razão da $\mathrm{CA} / \mathrm{E}$ só aumentaria quando o excesso de gordura se acumular na parte superior do corpo. Analisando a evolução da CC, o mesmo estudo, verificou que as meninas apresentavam valores mais baixos da CC do que os meninos para qualquer altura e, que essas diferenças eram mais importantes aos nove anos de idade ${ }^{97}$.

Essas tendências não foram confirmadas nos nossos dados, já que as diferenças em função do sexo e idade, não se mostraram estatisticamente significantes na nossa amostra.

Outros estudos $^{139,158,159}$, agora em adolescentes também mostraram que a razão da $\mathrm{CA} / \mathrm{E}$ é tão sensível quanto o $\mathrm{IMC}$ no rastreamento de risco cardiometabólico e que teria muitas vantagens por ser de simples execução, com baixo custo e capaz de detectar risco cardiometabólico, inclusive em adolescentes magros ${ }^{6}$.

Metanálise de dados de 88 mil indivíduos adultos mostrou que a CA/E foi o melhor marcador para discriminar o $\mathrm{RCV}$. Os autores recomendam o seu uso em levantamentos epidemiológicos de grande porte, pois além de discriminar melhor o risco é um indicador facilmente determinável ${ }^{117}$.

Outros estudos, um deles realizado em três cidades brasileiras envolvendo escolares e adolescentes mostrou que a razão da CC/E pode ser o marcador mais apropriado de adiposidade central, não necessitando de sexo e idade para sua estimativa. Nestas populações a razão da CC/E de 0,44 se mostrou útil para indicar alterações no perfil lipídico e avaliar depósitos de gordura abdominal $^{160,161}$. 
Ashwell e Hsieh ${ }^{162}$ resumem nos seguintes pontos a validade de utilização da CA/E: mais sensível do que o IMC para prever riscos à saúde; mais barato, mais fácil de medir e calcular que o IMC; um ponto de corte de 0,5 é valido para indicar RCV em ambos os sexos e diferentes grupos étnicos e, por último, os seus valores permitem triar, na prática, indivíduos em situação de risco.

Quanto à avaliação da composição corporal Jellife e Jellife ${ }^{119}$, na década de sessenta já recomendava o uso do perímetro braquial para avaliar AMB em crianças desnutridas. Estudos mais recentes recomendam o uso dos indicadores AMB, AGB para avaliar composição corporal, também, em crianças obesas assim como nas desnutridas ${ }^{114,115,163-166}$.

Em nosso estudo, a análise da relação da PAS com z de AMB (Figura 32) demonstrou haver uma correlação $r=0,1726$ (IC 95\% 0,1142 a 0,2298) e p $<0,0001$. Também a relação da PAD com z de AMB (Figura 33) demonstrou também haver correlação com $r=0,2337$ (IC 95\% 0,1765 a 0,2892) e $p<0,0001$. 
Figura 32 - Relação da Pressão arterial sistólica (PAS) dos escolares e z de Área Magra do Braço (zAMB).

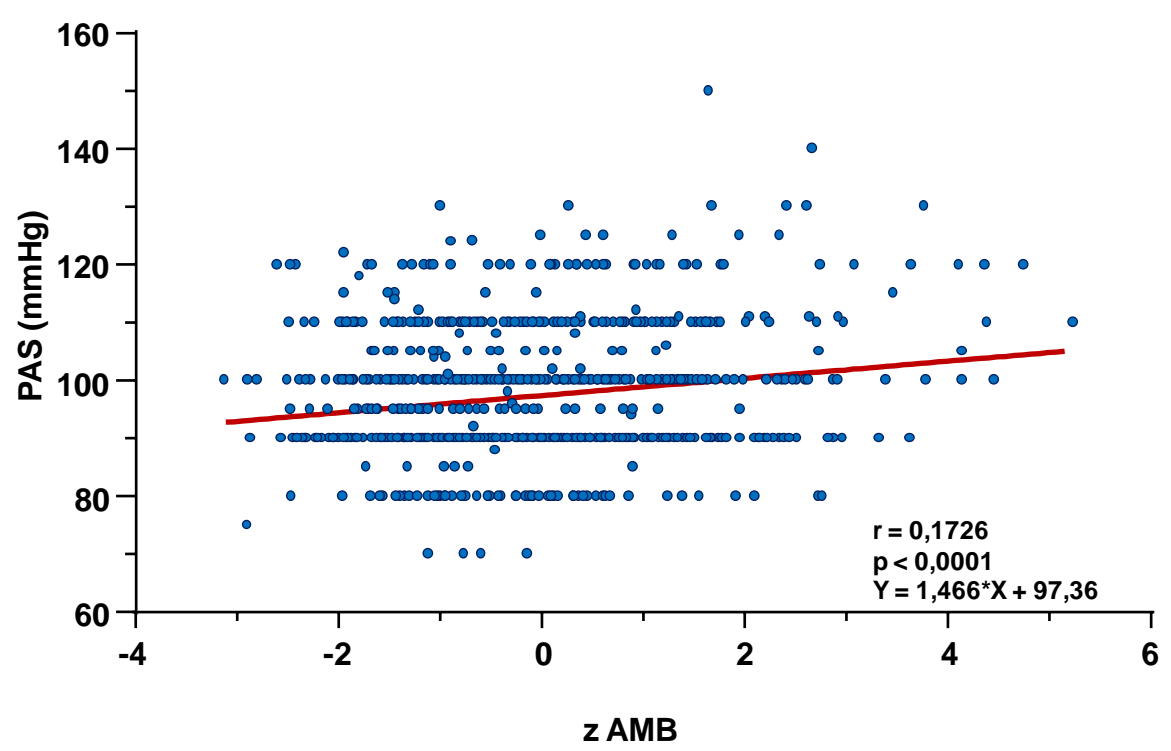

Figura 33 - Relação da Pressão arterial diastólica (PAD) dos escolares e z de Área Magra do Braço (zAMB).

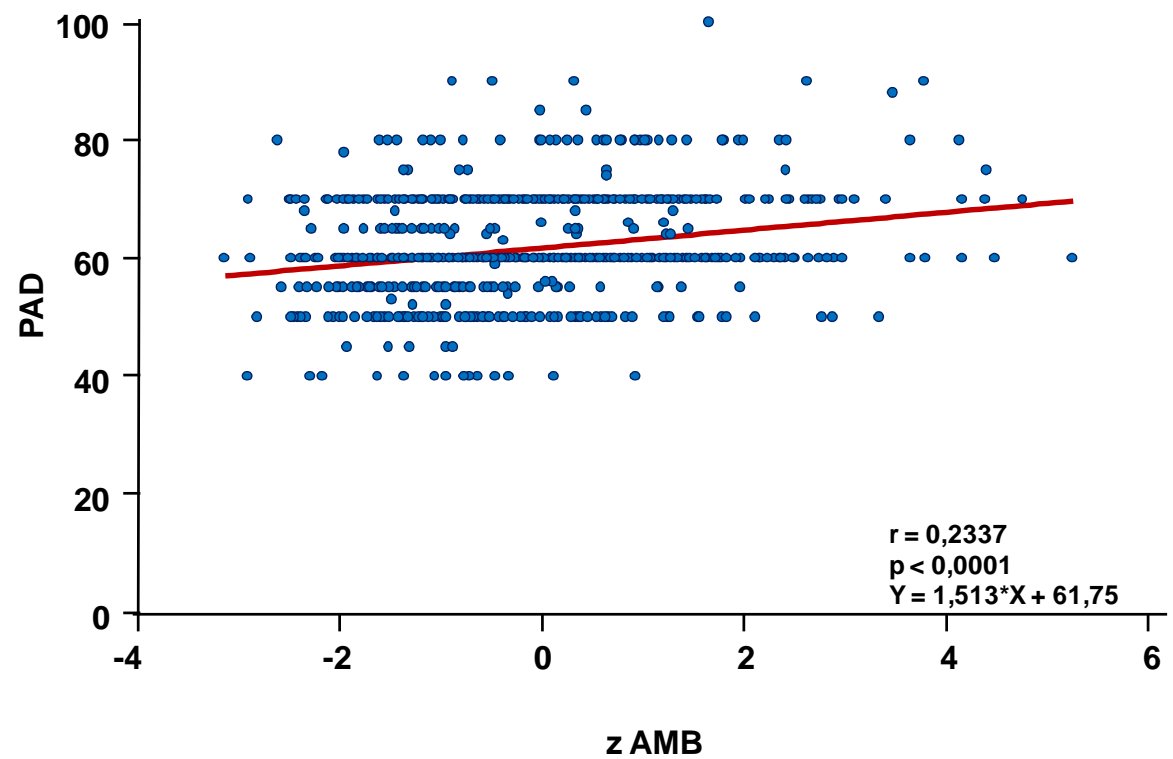

Já para o escore z de AGB e sua correlação com a PAS (Figura 34) observou-se que o Coeficiente de Pearson foi 0,3141, (IC 95\% 0,2593 a $0,3668)$ e $p<0,0001$, enquanto a correlação de PAD e zAGB apresentou um Coeficiente de 0,2173 (IC 95\% 0,1598 a 0,2734) e p < 0,0001. 
Figura 34 - Relação da Pressão arterial sistólica (PAS) e escore z de Área Gorda do Braço (zAGB).

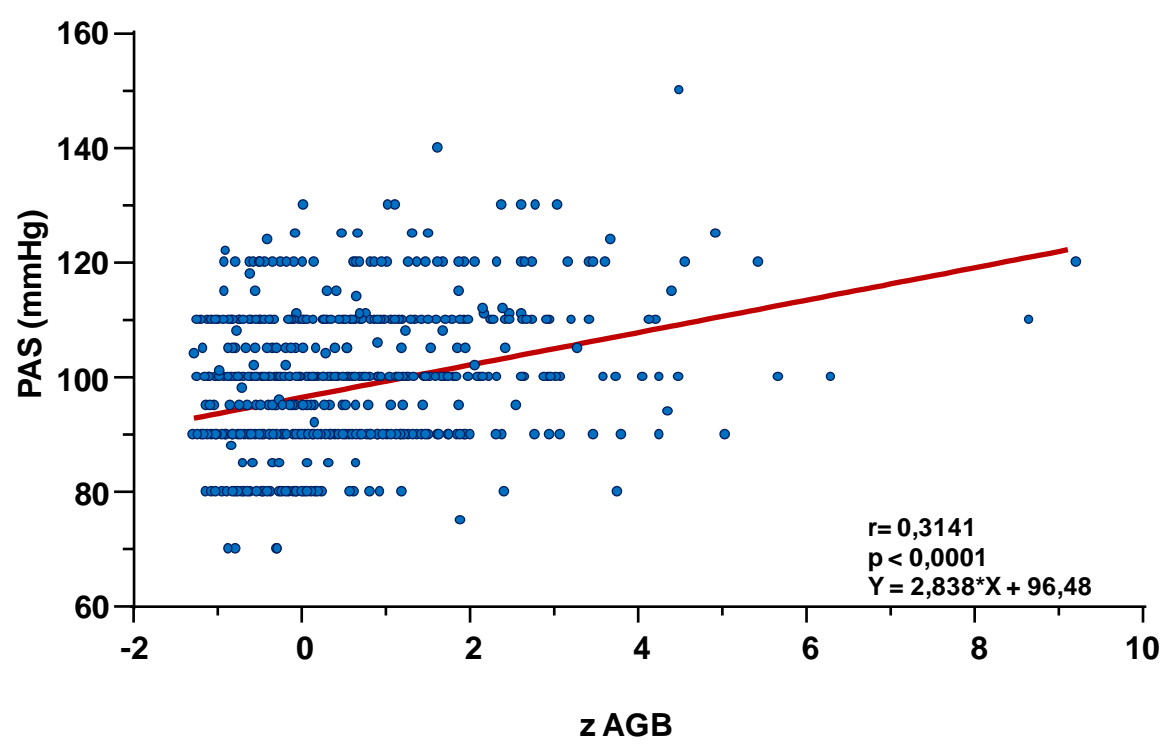

Figura 35 - Relação da Pressão arterial diastólica (PAD) e escore z de Área Gorda do Braço (AGB).

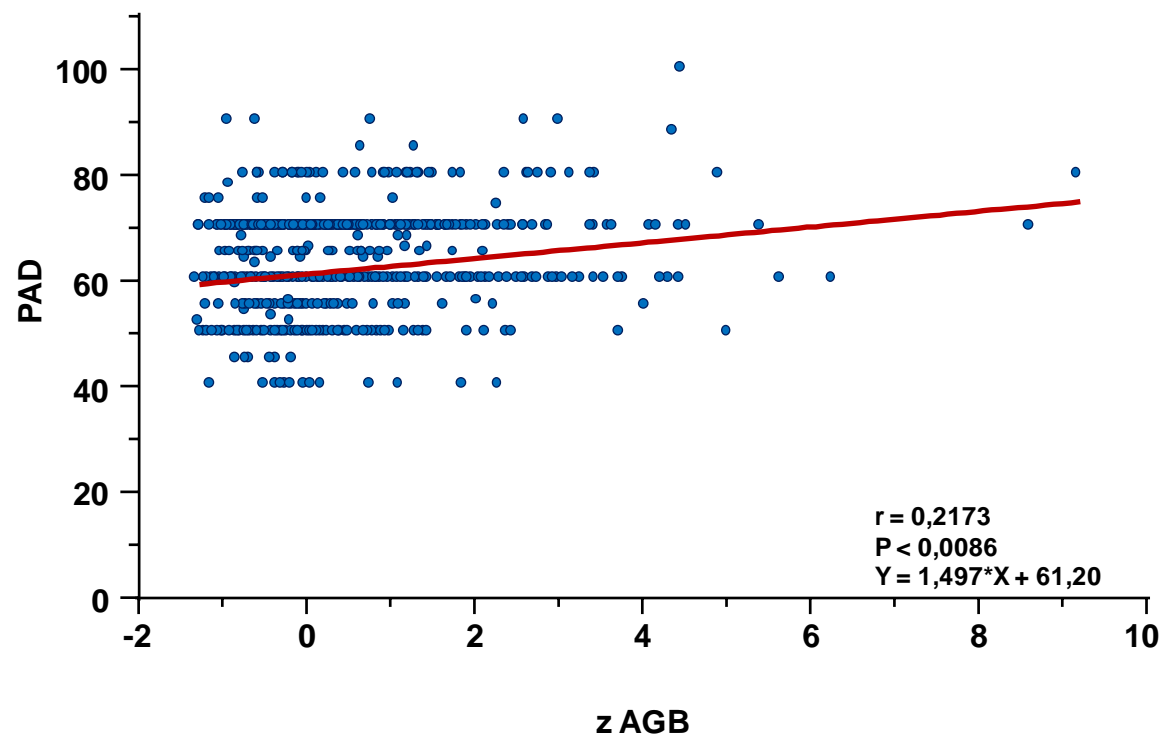

$\mathrm{Na}$ análise (Figura 36) que relaciona a PAS e o zPCT, se observa que há uma correlação, $r=0,3089$, com 95\% de IC 0,2540 a 0,3618, $p<0,0001$. 
Figura 36 - Relação da Pressão Arterial Sistólica (PAS) dos escolares com escore $z$ de Prega cutânea Tricipital (zPCT).

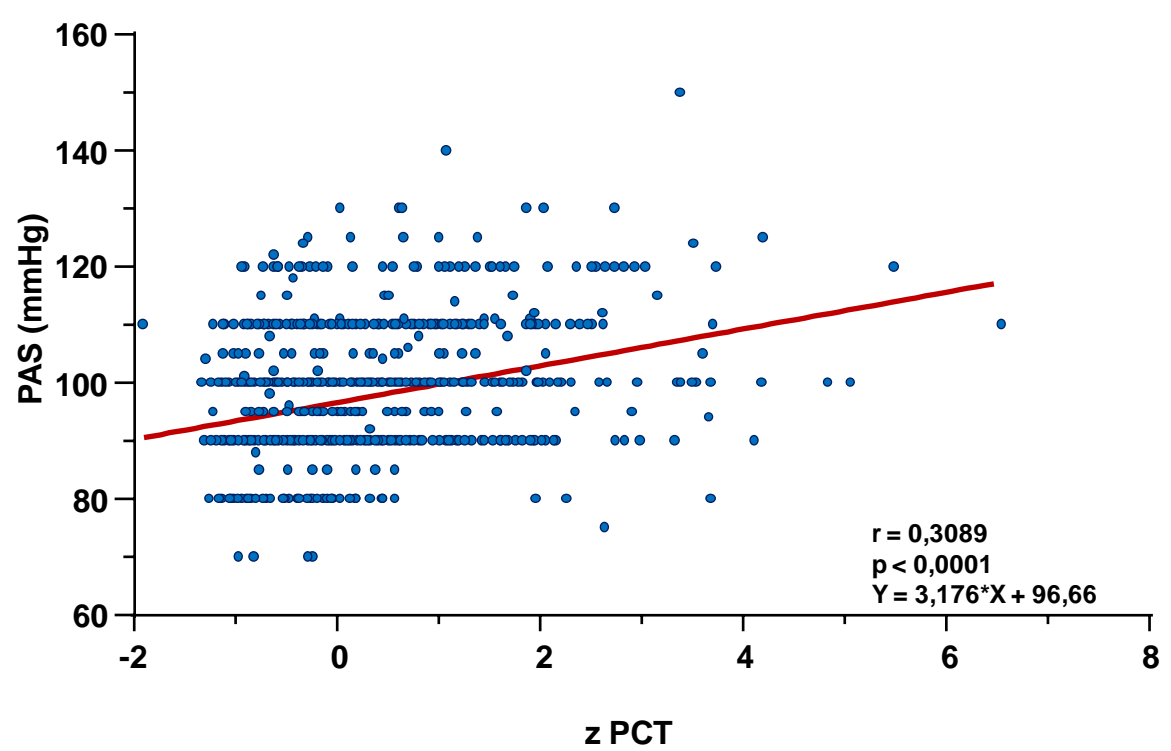

A Figura 37 apresenta a relação da PAD com zPCT na qual se observa um coeficiente de correlação $r=0,178,95 \%$ IC 1205 a 0,2359 e $p<0,0001$.

Figura 37 - Relação da Pressão arterial diastólica (PAD) dos escolares com escore $z$ de Prega cutânea Tricipital (zPCT).

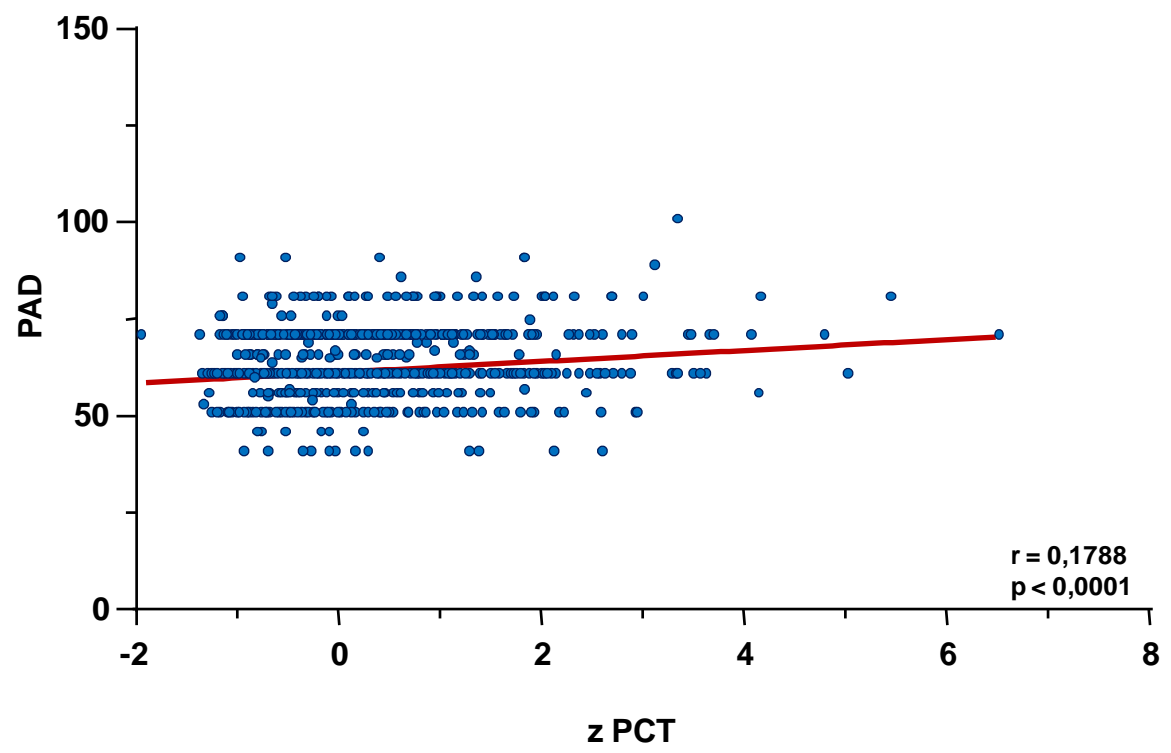


Estudo em crianças e adolescentes mostrou que o risco de hipertensão arterial era quase duas vezes maior nas crianças com percentil de PCT elevada $^{62}$, corroborando os resultados aqui observados com escore $z$ de PCT.

Também, num estudo na China, com crianças e adolescentes, numa região de elevada prevalência de alterações de PA se observou que esta se elevava na medida em que aumentavam os valores de PCT e PCS ${ }^{167}$.

Para a área muscular do braço, quando expressa em porcentagem, e o valor da PAS, como se verifica na Figura 38, detectou-se uma correlação inversa entre com um $r$ de $-0,2732$, um IC95\% de $-0,3274$ a $-0,2171$ e $p=<$ 0,0001 .

Figura 38 - Relação entre a Pressão arterial sistólica (PAS) e porcentagem da área muscular do braço (\%AMB).

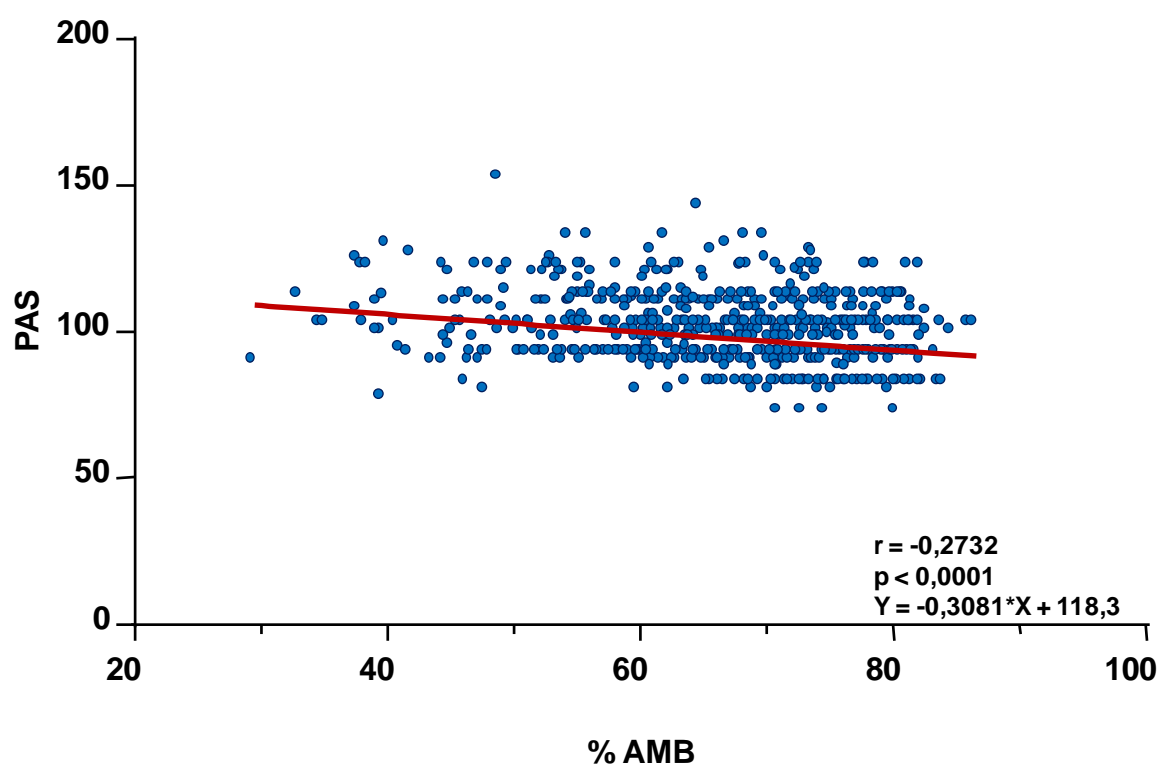


Na Figura 39 também se demonstrou uma correlação inversa entre a porcentagem de área muscular do braço e o valor da PAD, com um Coeficiente de Pearson de - 0,1062, um IC95\% de - 0,1647 a -0,04687 e $p=0,0005$.

Figura 39 - Relação entre a Pressão arterial diastólica (PAD) e porcentagem da área muscular do braço (\%AMB).

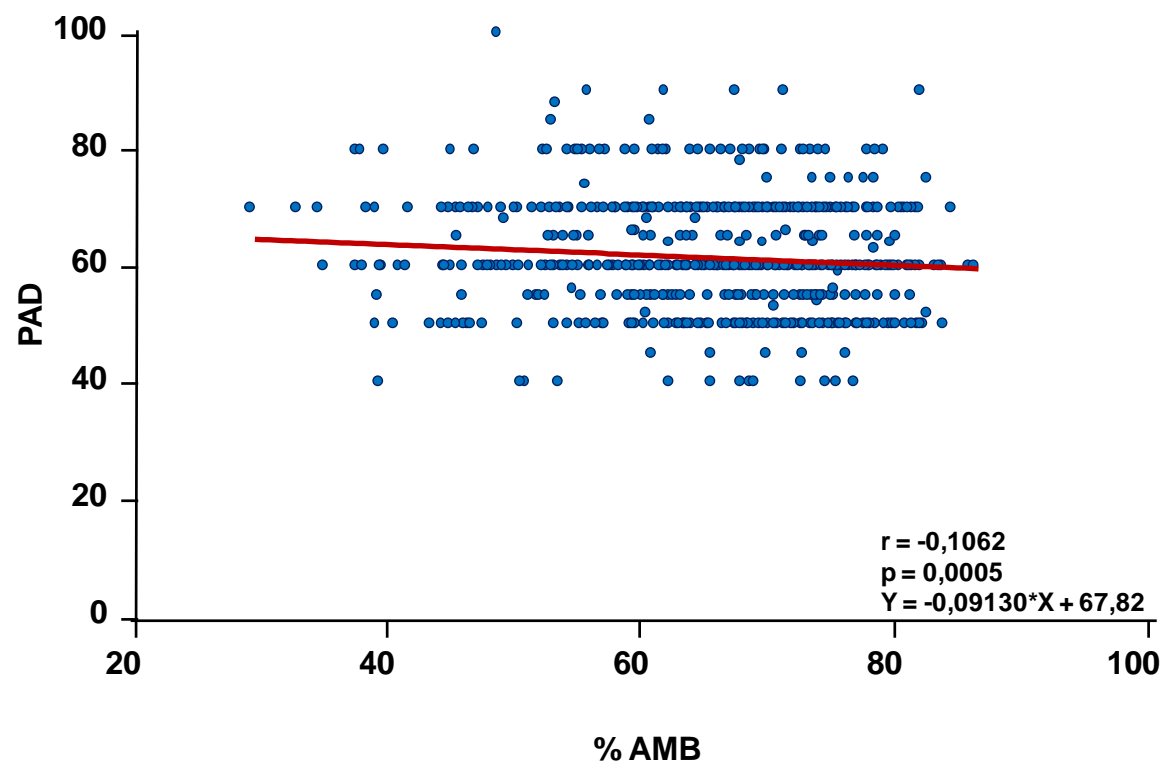

A aparente contradição das correlações dos níveis pressóricos com o escore $z$ da $A M B$ e a \% da $A M B$, indica que tanto um aumento da $A M B$ quanto uma alteração da sua proporção em relação à $A G B$ estariam relacionados a alterações de PA. Essa tendência de correlação indireta entra a AMB e maiores níveis de PA tende a ser, possivelmente, ainda mais grave, quando a AMB, independentemente de seus valores absolutos, tende a ser uma menor proporção da área do total do braço, em decorrência, obviamente de um aumento desproporcionalmente maior da AGB.

Estes achados indicam a necessidade de se realizar novos estudos tentando avaliar se um aumento excessivo de massa magra, em valor absoluto, 
pode ser indicativo de uma condição de RCV, de maneira semelhante ao que é determinado pelo excesso de massa gorda corpórea.

Partindo-se das análises anteriormente apresentadas e considerando ainda variáveis citadas na literatura como relacionadas com a HAS e as variáveis disponíveis no banco de dados realizou-se uma Análise de múltiplas variáveis por Regressão Binária Logística Stepwise Backward de Wald. Nesta análise considerou-se como variável dependente a elevação de PA (sistólica e/ou diastólica) e como variáveis independentes: a idade e sexo da criança, o seu peso de nascimento, a sua razão de circunferência da cintura para a estatura e o escore z de área gorda do braço.

Como se observa na Tabela 11, a idade é uma das variáveis que se confirma como associada a um maior risco de HAS (OR $=1,215)$, entretanto por suas características de não ser passível de modificação, sua operacionalização na prática como determinante de risco na assistência primária é de pequena utilidade.

Tabela 11 - Regressão Binária Logística Stepwise Backward de Wald

\begin{tabular}{lcccccc}
\hline Variável & Beta & $\begin{array}{c}\text { Erro } \\
\text { Padrão }\end{array}$ & Significância & Exp(B) & $\begin{array}{c}\text { Limite } \\
\text { inferior do } \\
\text { IC95\% }\end{array}$ & $\begin{array}{c}\text { Limite } \\
\text { superior do } \\
\text { IC95\% }\end{array}$ \\
\hline zAGB & 0,020 & 0,109 & 0,856 & 1,02 & 0,82 & 1,26 \\
PN & 0,000 & 0,000 & 0,492 & 1,00 & 1,00 & 1,00 \\
Sexo & 0,165 & 0,0217 & 0,446 & 1,18 & 0,77 & 1,80 \\
Idade* $^{*}$ & 0,195 & 0,069 & 0,005 & 1,22 & 1,06 & 1,39 \\
CC/E $^{*}$ & 10,160 & 1,906 & 0,000 & 25842,37 & 616,08 & 1083995,14 \\
Constante & $-8,445$ & 1,098 & 0,000 & 0,00 & & \\
\hline
\end{tabular}

zAGB: escore z da área gorda do braço; PN: peso de nascimento; CC/E: razão circunferência da cintura pela estatura.

*Significantes 
A outra variável CC/E mostra um OR extremamente elevado e por sua facilidade de coleta parece ser de fato uma variável bastante útil para a triagem de crianças em idade escolar que podem já estar apresentando hipertensão arterial, principalmente na assistência básica como rotina de atenção, quando nem sempre a medida da PA pode ser efetuada de maneira universal ${ }^{116,132,140}$. Partindo-se desse pressuposto analisou-se o desempenho da CC/E como instrumento de triagem de uma possível HAS em escolares por intermédio da Curva ROC (Reciever Operator Characteristics). Nesta análise, (Figura 40) a área sob a curva estimada foi de 0,68 (IC95\% 0,66 a 0,72), estatisticamente significante $(p<0,0001)$, indicando a viabilidade de sua utilização como marcador de risco.

Figura 40 - Área Sob a Curva ROC da CC/E

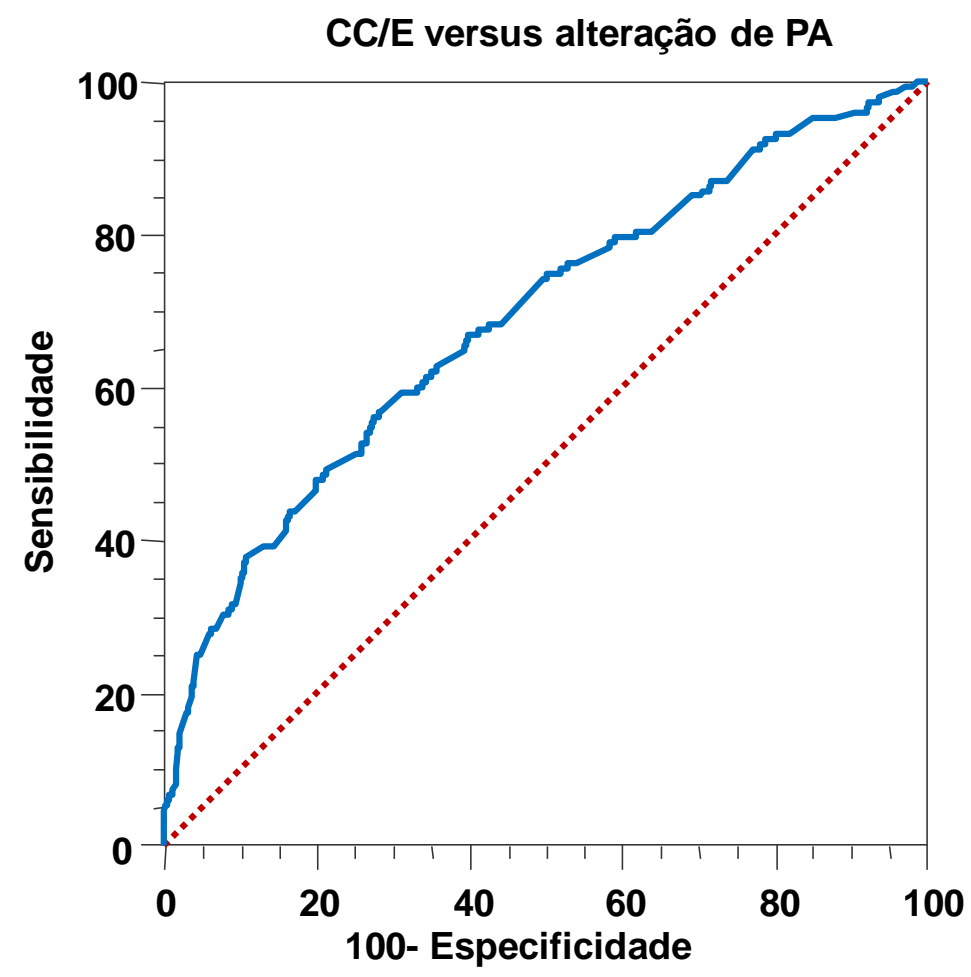


A partir da curva ROC o ponto de corte que expressa simultaneamente os melhores níveis de associação entre sensibilidade e especificidade corresponde a uma razão da CC/E acima de 0,49 (sensibilidade de 56,1\% e especificidade de 72,6\%), como se observa na Tabela 12.

Na mesma tabela, se verifica que um valor acima do ponto de corte de, 0,40 apresenta uma elevada sensibilidade $(98,7 \%)$, porém com baixa especificidade $(4,0 \%)$. Já o ponto de corte acima de 0,63 confere uma elevada especificidade $(99,3 \%)$, porém com uma baixíssima sensibilidade $(6,1 \%)$.

Como se observa, o ponto de corte poderá ser deslocado dentro destes limites dependendo do objetivo de sua utilização, ou seja, de triagem quando se requer uma maior sensibilidade ou de quase diagnóstico quando se deseja uma maior especificidade.

Estes valores são semelhantes aos obtidos na análise pela curva ROC do indicador zIMC, nesta mesma amostra, que revelou uma área sob a curva 0,67 , indistinguível estatisticamente da área da curva ROC para a CC/E.

Ainda em relação, ao zIMC o ponto de corte de melhor sensibilidade associada à melhor especificidade foi $>1,5$ zIMC com uma sensibilidade de $50,7 \%$ (IC de 42,3 a 59,0 ) e uma especificidade de $77,7 \%$ com (IC de 74,9 a $80,4)$.

Esse comportamento quase idêntico como instrumento de triagem de risco de hipertensão arterial entre os dois indicadores reforça a validade da utilização da CC/E como um marcador de risco de HAS, em escolares, inclusive em decorrência da maior facilidade operacional para a sua realização. 
Tabela 12 - Ponto de Corte, Sensibilidade e Especificidade da Razão da CC/E

\begin{tabular}{ccccc}
\hline $\begin{array}{c}\text { Ponto de } \\
\text { Corte }\end{array}$ & Sensibilidade & $\begin{array}{c}\text { IC95\% da } \\
\text { Sensibilidade }\end{array}$ & Especificidade & $\begin{array}{c}\text { IC95\% da } \\
\text { Especificidade }\end{array}$ \\
\hline $\mathbf{> 0 , 4 0}$ & 98,7 & $95,2-99,8$ & 4,0 & $2,8-5,4$ \\
$\mathbf{> 0 , 4 3}$ & 93,2 & $87,9-96,7$ & 17,9 & $15,5-20,5$ \\
$\mathbf{> 0 , 4 6}$ & 76,4 & $68,7-82,9$ & 45,8 & $42,6-49,1$ \\
$\mathbf{> 0 , 4 9}$ & 56,1 & $47,7-64,2$ & 72,5 & $69,5-75,3$ \\
$\mathbf{> 0 , 5 2}$ & 39,2 & $31,3-47,5$ & 85,6 & $83,1-87,7$ \\
$\mathbf{> 0 , 5 9}$ & 14,9 & $9,6-21,6$ & 97,8 & $96,6-98,6$ \\
$\mathbf{> 0 , 6 3}$ & 6,1 & $2,8-11,2$ & 99,3 & $98,5-99,7$ \\
\hline
\end{tabular}

A seguir realizou-se análise de regressão linear entre CC/E e os diferentes níveis de PAS que as crianças apresentavam, obtendo-se a seguinte equação de definição de reta:

$$
\mathrm{PAS}=57,43 \times \text { CC_E }+69,68
$$

da mesma maneira para a PAD a equação que define a reta de regressão encontrada foi:

$$
\text { PAD }=36,25 \times \text { CC_E }+44,21
$$

Estas equações indicam que para uma elevação de um décimo de unidade da razão da CC/E se produziria aproximadamente um aumento de 5,7 $\mathrm{mmHg}$ na PAS e de $3,6 \mathrm{mmHg}$ na PAD.

Como se verifica esses valores mostram que mesmo pequenas variações na razão da CC/E podem resultar em grandes variações na PA de crianças em idade escolar. 


\section{CONCLUSÕES}

Nas escolas públicas da cidade de Florianópolis as crianças em idade escolar apresentam:

a) Prevalência elevada, 13,7\%, de pré-hipertensão e hipertensão arterial com tendência a ser mais elevada com a idade, independentemente do peso de nascimento.

b) Crescimento adequado que, em termos médios, é maior do que o proposto pelo referencial da OMS, independentemente do peso de nascimento.

c) Prevalência elevada, $42,5 \%$, de sobrepeso, obesidade e obesidade grave, A prevalência de obesidade grave é maior, proporcionalmente, entre os meninos $(7,1 \%)$ e não mostra relação com o peso de nascimento.

d) Maiores níveis de PA quanto maior o crescimento estatural alcançado, independentemente do peso de nascimento.

e) Correlação direta entre níveis de pressão arterial e valores de escores z de índice de massa corpórea, de escore z de AMB e menores proporções (\%) de área muscular do braço em relação à quantidade de massa gorda.

f) A razão de circunferência da cintura para a estatura como marcador indicativo de elevação de PA para ambos os sexos e nas diferentes idades. 


\section{CONSIDERAÇÕES FINAIS}

Embora não esteja previsto entre os objetivos de uma tese elaborar considerações que vão além das conclusões, os resultados aqui observados impõem levantar a hipótese de que há de fato a necessidade de se institucionalizar, na assistência básica à saúde, a vigilância da pressão arterial de escolares e, possivelmente até antes desta idade, mesmo que a sua avaliação precisa só seja realizada após uma triagem prévia por indicadores antropométricos, como, por exemplo, a avaliação da razão circunferência da cintura pela estatura, que é de operacionalização relativamente simples em crianças destas faixas etárias. 


\section{REFERÊNCIAS ${ }^{1}$}

1. Sorof J, Daniels S. Obesity hypertension in children: a problem of epidemic proportions. Hypertension. 2002; 40(4):441-7.

2. Souza MGB, Rivera IR, Silva MAM, Carvalho ACC. Relação da obesidade com a pressão arterial elevada em crianças e adolescentes. Arq Bras Cardiol. 2010; 94(6):714-9.

3. Schimdt MI, Duncan BB, Silva GA, Menezes AM, Monteiro CA, Barreto SM, Chor D, Menezes PR. Series Health in Brazil 4 Chronic noncommunicable diseases in Brazil: burden and current challenger. Published online May 9, 2011. DOI:10.1016/S0140-6736(11)60135-9. Disponível em: <http://download.thelancet.com/flatcontentassets/pdfs/bra zil/brazilpor4.pdf>. Acesso em: 13 abr 2013.

4. Butte NF, Garza C, Onis M. Evaluation of the feasibility of international growth standards for school-ages children and adolescents. J Nutri. 2007; 137(1):153-7.

5. Instituto Brasileiro de Geografia e Estatística. Estudo nacional de despesa familiar (ENDEF). Rio de Janeiro: IBGE; 1976. Disponível em: >http://biblioteca.ibge.gov.br/visualizacao/monografias/GEBIS\%20\%20RJ/ConsumoAlimentar/v1\%20t1\%20-\%20Parte\%204\%20\%20DF,\%20RO,\%20AC,\%20AM,\%20RR,\%20PA,\%20AM,\%20GO\%20e\% 20MT.pdf.>. Acesso em: 10 abr 2012.

6. Kollias A. Hypertension in children and adolescents. World J Hypertens. 2011. 23; 1(1):15-9.

7. Moyer VA; U.S. Preventive Services Task Force Screening for primary hypertension in children and adolescents: U.S. Preventive Services Task Force recommendation statement. Ann Intern Med. 2013 Nov 5; 159(9):613-9.

\footnotetext{
${ }^{1}$ Esta tese está de acordo com as referências segundo as normas do International Committee of Medical Journals Editors (Vancouver), em vigor no momento desta publicação.
} 
8. Story M, Stevens J, Himes J, Stone E, Rock BH, Ethelbah B, Davis S. Obesity in American-Indian children: prevalence, consequences, and prevention. Prev Med. 2003; 37(6 Pt 2):S3-12.

9. Freedman DS, Goodman A, Contreras OA, DasMahapatra P, Srinivasan $\mathrm{SR}$, Berenson GS. Secular trends in BMI and blood pressure among children and adolescents: the Bogalusa Heart Study. Pediatrics. 2012; 130(1):e159-66.

10. Muntner P, He J, Cutler JA, Wildman RP, Whelton PK. Trends in Blood Pressure Among Children and Adolescents. JAMA. 2004;291(17):2107-13.

11. Chiolero AM, Paradis G, Madeleine G, Hanely JA, Paccaud F, Bovet P. Discordant secular trends in elevated blood pressure and obesity in children and adolescents in a rapidly developing country. Circulation. 2009, 119(4):558-65.

12. Grijalva-Eternod CS, Lawlor DA, Wells JCK. Testing a capacity-load model for hypertension: disentangling early and late growth effects on childhood blood pressure in a prospective birth cohort. PLOS One. 2013; 8(2):e56078.

13. Samuels J. The Increasing Burden of Pediatric Hypertension American Heart Association Hypertension, 2012. Disponível em: <http://hyper.ahajournals. org/content/early/2012/06/18>. Acesso em: 20 mai 2013.

14. Martorell R. Khan LK, Hughes ML, Grummer-Strawn LM. Overweight and obesity in preschool children from developing countries. Int J Obes Relat Metab Disord. 2000;24(8):959-67.

15. Moreira NF, Muraro AP, Brito FSB, Gonçalves-Silva RMV, Sichieri R, Ferreira MG. Obesidade: principal fator de risco para hipertensão arterial sistêmica em adolescentes brasileiros participantes de um estudo de coorte. Arq Bras Endocrinol Metab. 2013; 57(7):520-6. 
16. Fredriks AM, Buuren S, Feekes EM, Verloove-Vanhoric SP, Wit JM. Are age references for waist circumference, hip circumference and waist-hip ratio in Dutch children useful in clinical practice? Eur $J$ Pediatr. 2005; 164(4):216-22.

17. Chiolero A, Bovet P, Paradis G, Paccaud F. Has blood pressure increased in children in response to the obesity epidemic? Pediatrics. 2007; 119(3):544-53.

18. Rodrigues LG, Pombo N, Koifman S. Prevalência de alterações metabólicas em crianças e adolescentes com sobrepeso e obesidade: uma revisão sistemática. Rev Paul Pediatr. 2011; 29(2):277-88.

19. Angelopoulos PD, Milionis HJ, G Moschonis G, Manios Y. Relations between obesity and hypertension: preliminary data from a cross-sectional study in primary schoolchildren: the children study. Eur J Clin Nutr. 2006; 60(10):1226-34.

20. Falaschetti $M$, Hingorani $A D$, Jones $A$, Charakida $M$, Finer $N$, Whincup $P$, Lawlor DA, Davey Smith G, Sattar N, Deanfield JE. Adiposity and cardiovascular risk factors in a large contemporary population of prepubertal children. Eur Heart J. 2010; 31(24):3063-72.

21. Maire B, Lioret S, Gartner A, Delpeuch F. Transition nutritionnelle et maladies chroniques non transmissibles liées àl'alimentation dans les pays en développement. John Libbey Eurotext. 2002; 12(1):45-55. Disponível em: <www.jle.com/fr/print/e-docs/00/03/5B/7B/article.phtml>. Acesso em: 10 jun 2012.

22. Thompson DR, Obarzanek E, Franko DL, Barton BA, Morrison J, Biro FM, Daniels SR, Striegel-Moore RH. Childhood overweight and cardiovascular disease risk factors: The National Heart, Lung, and Blood Institute Growth and Health Study. J Pediatr. 2007;150(1):18-25. 
23. Rezende DF, Scarpelli RAB, Souza GF, Costa JO, Scarpelli AMB, Scarpelli PA, Carbvalho GB, D'Agostini HM, Pedrosa JC. Prevalência da hipertensão arterial sistêmica em escolares de 7 a 14 anos do Município de Barbacena, Minas Gerais, em 1999. Arq Bras Cardiol. 2003; 81(4): 375-80.

24. Noronha JAFN, Ramos ALC, Ramos ALC, Ramos AT, Cardoso MAA, Carvalho DF, Medeiros CCM. High blood pressure in overweight children and adolescents. J Hum Growth Dev. 2012; 22(2):196-201.

25. Strauss RS, Pollack HA. Epidemic increase in childhood overweight, 1986 -1998. JAMA. 2001; 286(22):2845-8.

26. Kelly T, Yang W, Chen CS, Reynolds K, He J. Global burden of obesity in 2005 and projections to 2030. Int J Obes (Lond). 2008, 32(9):1431-7.

27. de Oliveira CL, Mello MT, Cintra IP, Fisberg Mauro. Obesidade e síndrome metabólica na infância e adolescência. Ver Nutr. Campinas. 2004; 17(2):237-245.

28. Gigante DP, Victora CG, Araujo CLP, Barros FC. Tendências no perfil nutricional das crianças nascidas em 1993 em Pelotas, Rio Grande do Sul, Brasil: análises longitudinais. Cad Saúde Pública. 2003; 19(1 Suppl):S141-S7.

29. Dehghan M, Akhtar-Danesh N, Merchant AT. Childhood obesity, prevalence and prevention. Nutr J. 2005; 4:24.

30. Ogden CL, Carroll MD, Curtin LR, McDowell MA, Tabak CJ, Flegal KM. Prevalence of overweight and obesity in the United States, 1999 -2004. JAMA. 2006; 295(13):1549-55.

31. Raj M, Kumar K.R. Obesity in children e adolescentes. Indian J Med Res 2010; 132:598-607. 
32. Instituto Brasileiro de Geografia e Estatística. Pesquisa de orçamentos familiares 2008-2009. Antropometria e análise do estado nutricional de crianças, adolescentes e adultos no Brasil. Rio de Janeiro: IBGE; 2010. Disponível em: <http://www.ibge.gov.br/home/estatistica/populacao/condic aodevida/pof/2008_2009_encaa/pof_20082009_encaa.pdf [2012 Abr 19]>. Acesso em: 30 jun 2012.

33. Instituto Brasileiro de Geografia e Estatística. Censos Demográficos 2010. Brasil. Rio de Janeiro; 2011. Disponível em: <http://www.ibge.gov.br/ home/estatistica/populacao/censo2010/default.shtm [2012 Abr 19]>. Acesso em: 10 jul 2012.

34. Sayer AA, Syddall HE, Dennison EM, Gilbody HJ, Duggleby SL, Cooper C, Barker DJ, Phillips DI. Birth weight, weight at $1 \mathrm{y}$ of age, and body composition in older men: findings from the Hertfordshire Cohort Study. Am J Clin Nutr. 2004; 80(1):199-203.

35. Barker DJ, Fall $\mathrm{CH}$. Fetal and infant origins of cardiovascular disease. Arch Dis Child. 1993; 68(6):797-9.

36. Gale CR, Martyn CN, Kellingray S, Eastell R, Cooper C. Intrauterine programming of adult body composition. J Clin Endocrinol Metab. 2001; 86(1):267-72.

37. Gardner DSL, Hosking J, Metcalf BS, Jeffery AN, Voss LD, Wilkin TJ. Contribution of early weight gain to childhood overweight and metabolic health: a longitudinal study (EarlyBird 36). Pediatrics. 2009; 123(1):e67e73.

38. Monteiro POA, Victora CG, Barros FC, Monteiro LMA. Birth size, early childhood growth, and adolescent obesity in a Brazilian birth cohort. Int $\mathrm{J}$ Obes Relat Metab Disord. 2003; 27(10):1274-82. 
39. Sarni ROS, Souza FIS, Pitta TS, Fernandez AP, Hix S, Fonseca FA. Baixo peso ao nascer: influência na pressão arterial, composição corporal e antropometria. Arq Med ABC. 2005; 30(2):76-82.

40. Murphy MJ, Metcalf BS, Jeffery AN, Voss LD, Wilkin TJ. Does lean rather than fat mass provide the link between birth weight, $\mathrm{BMI}$, and metabolic risk? EarlyBird 23. Pediatr Diabetes. 2006; 7(4):211-4.

41. Martins EB, Carvalho MS. Relationship between birth weight and weight excess in childhood: a systematic review. Cad. Saúde Pública. 2006; 22(11):2281-300.

42. González DA, Nazmi A, Victora CG Growth from birth to adulthood and abdominal obesity in a Brazilian birth cohort. Int J Obes. 2010; 34(1):195202.

43. Barker DJ, Winter PD, Osmond C, Margetts B, Simmonds SJ. Weight in infancy and death from ischaemic heart disease. Lancet. 1989; 2(8663):577-80.

44. Barker DJ, Bull AR, Osmond C, Simmonds SJ. Fetal and placental size and risk of hypertension in adult life. BMJ. 1990; 301(6746):259-62.

45. Cole TJ. Modeling postnatal exposures and their interactions with birth size. J Nutr. 2004:134(4): 201-4.

46. Corvalán C, Gregory CO, Ramirez-Zea M, Martorell R, Stein AD. Size at birth, infant, early and later childhood growth and adult body composition: a prospective study in a stunted population. Int $J$ Epidemiol. 2007;36(3):550-7.

47. McCarthy A, Hughes R, Tilling K, Davies D, Davey Smith G, Ben-Shlomo $Y$. Birth weight, postnatal, infant, and childhood growth and obesity in young adulthood: evidence from the Barry Caerphilly Growth Study. Am J Clin Nutr. 2007; 86(4):907-13. 
48. Weiss R, Dziura J, Burgert TS, Tamborlane WV, Taksali SE, Yeckel CW, Allen K, Lopes M, Savoye M, Morrison J, Sherwin RS, Caprio S. Obesity and the metabolic syndrome in children and adolescents. $N$ Engl J Med. 2004; 350(23):2362-74.

49. Wilcox AJ: On the importance-and the unimportance-of birth weight. Int $J$ Epidemiol. 2001; 30(6):1233-41.

50. Eriksson J, Forsen T, Tuomilechto J, Osmand C, Barker D. Size at birth, childhood growth and obesity in adult life. Int $J$ Obes Relat Metab Disord. 2001; 25(5):735-40.

51. Eriksson J, Forsen T, Tuomilechto J, Osmand C, Barker D. Early growth and coronary heart disease in later life: longitudinal study. BMJ. 2001; 322(7292):949-53.

52. Nascimento VG, Bertoli CJ, Leone C. Ratio of weight to height gain: a useful tool for identifying children at risk of becoming overweight or obese at preschool age. Clinics. 2011; 66(7):1223-6.

53. Lawlor DA, Ebrahim S, Smith GD. Is there a sex difference in the association between birth weight and systolic blood pressure in later life? Findings from a meta-regression analysis. Am J Epidemiol. 2002; 156(12):1100-4.

54. Neyzi O, Saka HN, Kurtoğlu S. Anthropometric studies on the turkish population - A historical review. J Clin Res Pediatr Endocrinol. 2013; $5(1): 1-12$.

55. Önnerfält J, Erlandsson LK, Orban K, Broberg M, Helgason C, ThorngrenJerneck K. A family-based intervention targeting parents of preschool children with overweight and obesity:conceptual framework and study design of LOOPS- Lund overweight and obesity preschool study. BMC Public Health. 2012, 12:879. 
56. Quaioti TCB e Almeida SS. Determinantes psicobiológicos do comportamento alimentar: uma ênfase em fatores ambientais que contribuem para a obesidade. Psicol USP. 2006; 17(4):193-211.

57. Hirschler V, Roque MI, Calcagno ML, Gonzalez C, C Aranda. Materna circunferência da cintura e da previsão de síndrome metabólica infantil. Arch Pediatr Adolesc Med. 2007; 161(12):1205-10.

58. Matijasevich A, Santos IS, Menezes AMB, Barros AJD, Gigante DP, Horta $\mathrm{BL}$, Barros FC, Victora CG. Trends in socioeconomic inequalities in anthropometric status in a population undergoing the nutritional transition: data from 1982, 1993 and 2004 Pelotas Birth Cohort studies. BMC Public Health. 2012;12:511.

59. Durrani AM, Fatima W. Determinants of blood pressure distribution in school children. Eur J Public Health. 2012; 22(3):369-73.

60. Gigante DP, Barros FC, Post C LA, Olinto MTA. Prevalência de obesidade em adultos e seus fatores de risco. Rev Saúde Pública.1997; 31(3): 23646.

61. Monteiro CA, Conde LW. Tendência secular da desnutrição e da obesidade na infância na cidade de São Paulo (1974-1996). Rev Saúde Pública. 2000; 34(6 Supl):52-61.

62. Monser DC et al. Anthropometric measures and blood pressure in school children. J Pediatr (Rio J). 2013; 89(3):243-9.

63. Hollar D, Messiah SE, Lopez-Mitnik G, Hollar TL, Almon M, Agatston AS. Healthier options for public schoolchildren program improves weight and blood pressure in 6- to 13-year-olds. J Am Diet Assoc. 2010; 110(2):261-7.

64. Jiang J, Xia X, Greiner T, Wu G, Lian G, Rosenqvist U. The effects of a 3year obesity intervention in schoolchildren in Beijing. Child Care Health Dev. 2007; 33(5):641-6. 
65. Pérez-Morales ME, Bacardí-Gascón M, Jiménez-Cruz A, ArmendárizAnguiano A. Randomized controlled school based interventions to prevent childhood obesity: systematic review from 2006 to 2009. Arch Latinoam Nutr. 2009; 59(3):253-9.

66. Silveira JAC, Taddei JAAC, Guerra PH, Nobre MRC. Effectiveness of school-based nutrition education intervention to prevent and reduce excessive weight gain in children and adolescents: a systematic review. $J$ Pediatr(Rio J). 2011; 87(5):382-92.

67. Ogden CL, Carrol MD, Kit BK, Flegal KM. Prevalence of obesity and trends in body mass index among us children and adolescents, 19992010. JAMA. 2012; 307(5):483-90.

68. Sorof JM, Turner J, Martin DS, Garcia K, Garami Z, Alexandrov AV, Wan F, Portman RJ. Cardiovascular risk factors and sequelae in hypertensive children identified by referral versus school-based screening. Hypertension. 2004; 43(2):214-8.

69. Christofaro DGD, Ritti-Dias RM, Fernandes RA, Polito MD, andrade SM, Cardoso JR, Oliveira AR. Detecção de hipertensão arterial em adolescentes através de marcadores gerais e adiposidade abdominal. Arq Bras Cardiol. 2011; 96(6): 465-470.

70. Freedman DS, Dietz WH, Srinivasan SR, Berenson GS. The relation of overweight to cardiovascular risk factors among children and adolescents: The Bogalusa heart study. Pediatrics. 1999; 103(6):1175-82.

71. Freedman DS, Khan LK, Dietz WH, Srinivasan SR, Berenson GS. Relationship of childhood obesity to coronary heart disease risk factors in adulthood: The Bogalusa heart study. Pediatrics. 2001; 108(3):712-8.

72. Huxley R, Mendis S, Zheleznyakov E, Reddy S, Chan J: Body mass index, waist circumference and waist:hip ratio as predictors of cardiovascular risk-a review of the literature. Eur J Clin Nutr. 2010, 64(1):16-22. 
73. Klein S, Allison DB, Heymsfield SB, Kelley DE, Leibel RL, Nonas C, Kahn R. Waist circumference and cardiometabolic risk: a consensus statement from Shaping America's Health: Association for Weight Management and Obesity Prevention; NAASO, The Obesity Society; the American Society for Nutrition; and the American Diabetes Association. Am J Clin Nutr. 2007;85(5):1197-202.

74. Rosa MLG, Mesquita ET, Rocha ERR, Fonseca VM. Índice de Massa Corporal e Circunferência da Cintura como Marcadores de Hipertensão Arterial em Adolescentes. Arq Bras Cardiol. 2007; 88(5):573-8.

75. Victora CG, Sibbritt D, Horta BL, Lima RC, Cole T, Wells J. Weight gain in childhood and body composition at 18 years of age in Brazilian males. Acta Paediatr. 2007; 96(2):296-300.

76. Hirschler V, Aranda C, Calcagno ML, Maccalini, G, Jadzinsky, M. Waist circumference identify children with the metabolic syndrome? Arch Pediatr Adolesc Med. 2005; 159(8):740-4.

77. Janssen I, Katzmarzyk PT, Ross R. Body mass index, waist circumference, and health risk: evidence in support of current National Institutes of Health guidelines. Arch Intern Med. 2002; 162(18):2074-79.

78. Janssen $\mathrm{Y}$, Katzmarzyk PT, Ross R. Waist circumference and not body mass index explain obesity-related health risk. Am J Clin Nutr. 2004; 79(3):379-84, 2004.

79. Simons-Morton DG, Donato $\mathrm{K}$, Loria CM, Pratt CA, Ershow AG, Morrissette MA, Czajkowski S, Arteaga SS, Obarzanek E. Obesity research and programs at the National Heart, Lung, and Blood Institute. $J$ Am Coll Cardiol. 2010; 55(9):917-20.

80. Hoog MLA, van Eijsden M, Stronks K, Gemke RJ, Vrijkotte TG. Association between body size and blood pressure in children from different ethnic origins. Cardiovasc Diabetol. 2012, 11:136. 
81. Instituto Brasileiro de Geografia e Estatística. Pesquisa de orçamento familiar. IBGE. 2012. Disponível em: <http://www.ibge.gov.br>. Acesso em: 10 dez 2012.

82. Jaworski M, Kułaga Z, Płudowski P, Grajda A, Gurzkowska B, Napieralska E, Swiąder A, Pan H, Litwin M; Olaf Study Group. Population-based centile curves for triceps, subscapular and abdominal skinfold thicknesses in Polish children and adolescents - the OLAF study. Eur J Pediatr. 2012; 171(8):1215-21.

83. Junaibi AA, Abdulle A, Sabri S, Hag-Ali M, Nagelkerke N. The prevalence and potential determinants of obesity among school children and adolescents in Abu Dhabi, United Arab Emirates. Int J Obes (Lond). 2013; 37(1):68-74.

84. Must A, Dallal GE, Dietz WH. Reference data for obesity: 85th and 95th percentiles of mass index (wt/ht2) and triceps skinfold thickness. 1991; 53(4):839-46.

85. Srinivasan SR, Wang R, Chen W, Wei CY, Xu J, Berenson GS. Utility of Waist-to-Height Ratio in detecting central obesity and related adverse cardiovascular risk profile among normal weight younger adults (from the Bogalusa Heart Study). Am J Cardiol. 2009; 104(5):721-4.

86. Turchiano M. BA, Sweat V. MA, Fierman A MD, Convit A MD. Obesity, metabolic syndrome, and insulin resistance in urban high school students of minority race/ethnicity. Arch Pediatr Adolesc Med. 2012; 166(11):10306.

87. Wajchenberg BL. Subcutaneous and visceral adipose tissue: their relation to the metabolic syndrome. Endocr Rev. 2000; 21(6):697-738.

88. Maffeis C, Pietrobelli A, Grezzani A, Provera S, Tatò L. Waist circumference and cardiovascular risk. Obesy Res. 2001; 9(3):179-87. 
89. Choy CS, Chan WY, Chen TL, Shih CC, Wu LC, Liao CC. Waist circumference and risk of elevated blood pressure in children: a crosssectional study. BMC Public Health. 2011, 11:613.

90. Lara M, Bustos $P$, Amigo H, Silva C, Rona RJ. Is waist circumference a better predictor of blood pressure, insulin resistance and blood lipids than body mass index in young Chilean adults? BMC Public Health 2012, $12: 638$.

91. Taylor RW, Williams SM, Grant AM, Ferguson E, Taylor BJ, Goulding A. Waist circumference as a measure of trunk fat mass in children aged 3 to 5 years. Int J Pediatr Obes. 2008; 3 (4):226-33.

92. Freedman DS, Kahn HS, Mei Z, Grummer-Strawn Dietz WH, LM, Srinivasan SR, Berenson GS. Relation of body mass index and waist-toheight ratio to cardiovascular disease risk factors in children and adolescents: the Bogalusa Heart Study. Am J Clin Nutr. 2007; 86(1):3340 .

93. Velasquez MM, Salazar G, Vio F, Hernandez J, Rojas J. Nutritional status and body composition in Chilean preschool children attending day care centers. Food Nutr Bull. 2002; 23(3 Suppl):250-3.

94. Hara M, Saitou E, Iwata F, Okada T, Harada K. Waist-to-height ratio is the best predictor of the cardiovascular disease risk factors in Japanese school children. J Atheroscler Thromb. 2002; 9(3):127-32.

95. Kuba VM, Leone C, Damiani D. Is waist-to-height ratio a useful indicator of cardio-metabolic risk in 6-10-year-old children? BMC Pediatrics. 2013, 13:91.

96. Lin W, Lee L, Chen CY, Lo H, Hsia H, Liu H, Lin R, Shau W, Huang K. Optimal cut-off values for obesity: using simple anthropometric indices to predictcardiovascular risk factors in Taiwan. Int $J$ Obes. 2002, 26(9):12328. 
97. McCarthy, Ashewell M. A study of central fatness using waist-to-height ratios in UK children and adolescents over two decades supports the simple message - 'keep your waist circumference to less than half your height'. Int J Obes (Lond). 2006 Jun;30(6):988-92.

98. Soar C, Vasconcelos FAG, Assis MAA. A relação cintura quadril e o perímetro da cintura associados ao índice de massa corporal em estudo com escolares. Cad Saúde Pública. 2004; 20(6):1609-16.

99. Instituto Brasileiro de Geografia e Estatística. Disponível em: <http://www.ibge.gov.br/estadosat/perfil.php?sigla=sc>. Acesso em 3 dez 2012.

100. World Health Organization. Physical status: the use and interpretation of anthropometry. Geneva: WHO; 1995.

101. Onis M de, Lobstein T. Defining obesity risk status in the general childhood population: which cut-offs should we use? Int $J$ Pediatr Obes. $2010 ; 5(6): 458-60$.

102. Garza C. New growth Standards for the 21st century: a prescriptive approach. Nutr Rev. 2006; 64(5):(II)S55-9.

103. Sant'Anna MSL, Priore SE, Franceschini SCC. Métodos de avaliação da composição corporal em crianças. Rev Paul Pediatr. 2009; 27(3):315-21.

104. McCarthy HD, Jarrett KV, Crawley HF. The development of waist circumference percentiles in British children aged 5.0-16.9 y. Eur J Clin Nutr. 2001; 55(10):902-7.

105. Mokha JS, Srinivasan SR, DasMahapatra P, Fernandez C, Chen W, Xu J, Berenson GS. Utility of waist-to-height ratio in assessing the status of central obesity and related cardiometabolic risk profile among normal weight and overweight/obese children: the Bogalusa Heart Study. BMC Pediatr. 2010;10:73. 
106. Moreno LA, Pineda I, Rodríguez G, Fleta J, Sarría A, Bueno M. Waist circumference for the screening of the metabolic syndrome in children. Acta Paediatr. 2002; 91(12):1307-12.

107. Luma GYB. Spiotta RT. Hypertension in children and adolescents. Am Fam Physician. 2006; 73(9):1558-68.

108. Felisbino-Mendes MS, Campos MD, Lana FCF. Avaliação do estado nutricional de crianças menores de 10 anos no município de Ferros, Minas Gerais. Rev Esc Enferm USP. 2010; 44(2):257-65.

109. National Health Statistics Examination Survey. Anthropometry procedures manual. Disponível em: <http://www.cdc.gov/nchs/data/nhanes/bm.pdf. 2002>. Acesso em: 10 jan 2011.

110. Giuliano ICB, Caramelli B, Pellanda L, Duncan B, Fonseca FH. I Diretriz de prevenção da aterosclerose na infância e na adolescência. Arq Bras Cardiol. 2005; 85(Supl. VI):1-36.

111. Grupo de Trabalho da Sociedade Europeia de Hipertensão (ESH) e da Sociedade Europeia de Cardiologia (ESC) para o tratamento da hipertensão arterial. Guidelines de 2013 da ESH/ESC para o Tratamento da Hipertensão Arterial. J Hypertens. 2013, 31:1281-357.

112. Ministério da Saúde. Departamento de Atenção Básica. Sistema de vigilância alimentar e nutricional. 2009. Disponível em: $<$ http://nutricao.saude.gov.br|lsisvan.php?conteudo=curvas_cresc_oms [2010 Jan 20]>. Acesso em: 10 jul 2011.

113. Frisancho AR. Anthropometric standards for the assessment of growth and nutritional status. University of Michigan, USA. 1996; 1-189.

114. Frisancho AR. Anthopometric standarts: an interactive nutritional reference of body size and body composition for children and adults. Michigan: The University of Michigan Press, 2008. 
115. Frisancho R. New norms of upper limb fat and muscle areas for assessment of nutritional status. Am J Clin Nutr. 1981; 34(11):2540-5.

116. Toschke AM. L Koh L, Mansmann U, Kries RV. Meta-analysis of blood pressure tracking from childhood to adulthood and implications for the design of intervention trials. Acta Pædiatri. 2010; 99(1):24-9.

117. Lee CM, Huxley RR, Wildman RP, Woodward M. Indices of abdominal obesity are better discriminators of cardiovascular risk factors than BMI: a meta-analysis. J Clin Epidemiol. 2008; 61(7):646-53.

118. Baker JL, Olsen LW, Sørensen TIA. Childhood body-mass index and the risk of coronary heart disease in adulthood. N Engl J Med. 2007; 357(23):2329-37.

119. Jelliffe EFP, Jelliffe DB. The arm circumference as a public health índex of protein-calorie malnutrition of early childhood. J Trop Pediatr. 1969; 15(4):179-88.

120. Ellis KJ. Human body composition: in vivo methods. Physiol Rev. 2000; 80(2):649-80.

121. Lukaski $\mathrm{CH}$. Methods for the assessment of human body composition: traditional and new. Am J Clin Nutr. 1987; 46(4):537-56.

122. Tanner JM, Whitehouse RH. Revised standards for triceps and subscapular skinfolds in British children. Arch Dis Child. 1975; 50(2):142-5.

123. Heymsfield SB, Manaus CM, Smith J, Stevens V, Nixon DW. Anthropometric measurement of muscle mass: revised equations for calculating bone-free arm muscle area. Am J Clin Nutr. 1982; 36(4):680-90.

124. Maffeis C, Banzato C, Talamini G, Obesity Study Group of the Italian Society of Pediatric Endocrinology and Diabetology. Waist-to-height ratio, a useful index to identify high metabolic risk in overweight children. $J$ Pediatr. 2008; 152(2):207-13. 
125. Savva SC, Tornaritis M, Savva ME, Kourides Y, Panagi A, Silikiotou N, Georgiou C, Kafatos A. Waist circumference and waist-to-height ratio are better predictors of cardiovascular disease risk factors in children than body mass índex. Int J Obes Relat Metab Disord. 2000; 24(11):1453-8.

126. Taylor RW, Williams SM, Grant AM, Taylor BJ, Goulding A. Predictive ability of waist-to-height in relation to adiposity in children is not improved with age and sex-specific values. Obesity (Silver Spring). 2011; 19(5):1062-8.

127. Tybor DJ, Lichtenstein AH, Dallal GE, Must A. Waist-to-height ratio is correlated with height in US children and adolescents aged 2-18 years. Int J Pediatr Obes. 2008; 3(3):148-51.

128. Mushtaq MU, Gull S, Abdullah HM, Shahid U, Shad MA, Akram J. Waist circumference, waist-hip ratio and waist height ratio percentiles and central obesity among Pakistani children aged five to twelve years. BMC Pediatrics. 2011, 11:105.

129. Oduwole AA, Ladapo TA, Fajolu IB, Ekure EN, Adeniyi OF. Obesity and elevated blood pressure among adolescents in Lagos, Nigeria: a crosssectional study. BMC Public Health. 2012; 12:616.

130. National High Blood Pressure Education Program Working Group on High Blood Pressure in Children and Adolescents. The fourth report on the diagnosis, evaluation and treatment of high blood pressure in children and adolescents. Pediatrics. 2004, 114(2 Suppl 4th Report):555-76.

131. Pinto ICS, Arruda IKG, Diniz AS, Cavalcanti AMTS. Prevalência de excesso de peso e obesidade abdominal, segundo parâmetros antropométricos, e associação com maturação sexual em adolescentes escolares. Cad Saúde Pública. 2010; 26(9):1727-37.

132. YaJun I, Jie Ml. Pubertal hypertension is a strong predictor for the risk of adult hypertension. Biomed Environ Sci. 2011; 24(5):459-66. 
133. Allemande-Jander CL. Clinical diagnosis of metabolic and cardiovascular risks of overweight children: early development of chronic diseases in obese children. Int J Obes. 2010, 34(Supp. 2):S32-6.

134. Kollias A, Pantsiotou K, Karpettas N, Roussias L, Stergiou GS. Tracking of blood pressure from childhood to adolescence in a Greek cohort. Eur $J$ Public Health. 2012; 22(3):389-93.

135. Delisle H. La programmation foetale des maladies chroniques liées à la nutrition. John Libbey Eurotext. 2002; 12(1):56-63. Disponível em: <www. jle.com/fr/print/e-docs/00/03/5B/85/article.phtml>. Acesso em: 10 jul 2012.

136. Dietz WH. Overweight in childhood and adolescence. N Engl J Med. 2004; 350(9):855-7.

137. Tu W, Eckert GJ, Saha C, Pratt JH. Synchronization of adolescent blood pressure and pubertal somatic growth. Clin Endocrin Metab. 2009; 94(12):5019-22.

138. Burgos MS, Reuter CP, Burgos LT, Pohl HH, Pauli LTS, Horta JA, Rezkziegel MB, Franke SIR, Prá D, Camargo D. Uma análise entre índices pressóricos, obesidade e capacidade cardiorrespiratória em escolares. Arq Bras Cardiol. 2010. Disponível em: <http://www.scielo.br/pdf/abc/v94n6/aop04410.pdf>. Acesso em: 20 mai 2013.

139. Khan HS, Imperatore G, Cheng YJ. A population-based comparison of BMI percentiles and waist-to-height ratio for identifying cardiovascular risk in youth. J Pediatr. 2005, 146(4):482-8.

140. Lu X, Shi P, Luo CY, Zhou YF, Yu HT, Guo CY, Wu F. Prevalence of hypertension in overweight and obese children from a large school-based population in Shanghai, China. BMC Public Health. 2013; 13:24. 
141. Raj M, Sundaram KR, Paul M, Deepa AS, Kumar R. Obesity in Indian children: Time trends and relationship with hypertension. Natl Med J India. 2007; 20(6):288-93.

142. Zhan C, Shi J, Huang $H$, Feng L, Ma J. Nutritional status and its relationship with blood pressure among children and adolescents in South China. Eur J Pediatr. 2012; 171(7):1073-9.

143. Sun SS, Grave GD, Siervogel RM, Pickoff AA, Arslanian SS, Daniels SR. Syndrome later in life systolic blood pressure in childhood predicts hypertension and metabolic. Pediatrics. 2007; 119(2):237-46.

144. Shi Y, Groh M, Morrison H. Increasing blood pressure and its associated factors in Canadian children and adolescents from the Canadian Health Measures Survey. BMC Public Health. 2012, 12(1):388.

145. Barath $A$, Boda $A B K$, Tichy $M$, Károly E, Túri S. International comparison of blood pressure and BMI values in schoolchildren aged 11-16 years. Acta Pædiatr. 2010; 99(2):251-5.

146. Ferreira JS, Aydos RD. Prevalência de hipertensão arterial em crianças e adolescentes obesos. Ciênc Saúde Coletiva. 2010; 15(1):97-104.

147. Lo JC, Sinaiko A, Chandra M, Daley MF, Greenspan LC, Parker ED, Kharbanda EO, Margolis KL, Adams K, Prineas R, Magid D, O'Connor PJ.. Prehypertension and hypertension in community-based pediatric practice. Pediatrics. 2013; 131(2):e415-24

148. Bell LM, Byrne S, Thompson A, Ratnan N, Blair E, Bulsara M, Jones TW, Davis EA. Increasing body mass index z-score is continuously associated with complications of overweight in children, even in the healthy weight range. J Clin Endocrinol Metab. 2007; 92(2):517-22. 
149. Falkner B, Gidding SS, Portman R, Rosner B: Hypertension in adolescence: blood pressure variability and classification of prehypertension and hypertension in adolescence. Pediatrics 2008; 122:238-242.

150. Framme J, Dangardt F, Mårild S, Osika W, Währborg P, Friberg P. 24-h Systolic blood pressure and heart rate recordings in lean and obese adolescents. Clin Physiol Funct Imaging. 2006; 26(4):235-9.

151. Chen B, Li HF. Waist circumference as an indicator of high blood pressure in preschool obese children. Asia Pac J Clin Nutr. 2011; 20 (4):557-62.

152. Motswagole BS; Kruger HS; Faber M; van Rooyen JM; de Ridder JH. The sensitivity of waist-to-height ratio in identifying children with high blood. Cardiovasc J Afr. 2011;22(4):208-11.

153. Roswall J, Bergman S, Almqvist-Tangen G, Alm B, Niklasson A, Nierop AFM, Dahlgren J. Population-based waist circumference and waist-toheight ratio reference values in preschool children. Acta Pædiatr. 2009; 98(10):1632-6.

154. Fernadez JR, Redden DT, Pietrobelli A, Allison D. Waist circumference percentiles in nationally representative samples of African-American, European-American and Mexican-American children and adolescents. $J$ Pediatr. 2004, 145(4):439-44.

155. Garnett SP, Baur LA, Cowell CT. Waist-to-height ratio: a simple option for determining excess central adiposity in young people. Int J Obes. 2008, 32(6):1028-30.

156. Goulding A, Taylor RW, Grant AM, Parnell WR, Wilson NC, Williams SM. Waist-to-height ratios in relation to BMI $z$ scores in three ethnic groups from a representative sample of New Zeland children aged 5-14 years. Int J Obes. 2010, 34(7):1188-90. 
157. Sung RYT, So H, Choi K, Nelson EAS, Li AM, Yin JAT, Kwok CWL, Ng P, Fok T. Waist circumference and waist-to-height ratio of Hong Kong Chinese children. BMC Public Health. 2008; 8:324.

158. Aounallah-Skhiri H, El Ati J, Traissac P, Ben Romdhane H, EymardDuvernay S, Delpeuch F, Achour N, Maire B. North African adolescent population. A national cross sectional study in Tunisia. BMC Public Health. $2012 ; 12: 98$.

159. Yan W, Bingxian H, Hua Y, Jianghong D, Jun C, Dongliang G, Yujian Z, Ling L, Yanying G, Kaiti X, Xiaohai F, Da M. Waist-to-height ratio is an accurate and easier index for evaluating obesity in children and adolescents. Obesity. 2007; 15(3):748-52.

160. Nambiar S, Hughes I, Davies PSW. Developing waist-to-height ratio cutoffs to define overweight and obesity in children and adolescents. Public Health Nutr. 2009, 13(10):1566-1574.

161. Ribeiro RC, Coutinho M, Bramorski MA, Giuliano IC. Pavani J. Association of the Waist-to-Height Ratio with Cardiovascular Risk Factors in Children and Adolescents: The Three Cities Heart Study. Int J Prev Med. 2010; $1(1): 39-49$.

162. Ashwell M, Hsieh SD. Six reasons why the waist-to-height ratio is a rapid and effective global indicator for health risks of obesity and how its use could simplify the international public health message on obesity. Int $J$ Food Sci Nutr. 2005; 56(5):303-7.

163. Abdulrazzaq YM, Nagelkerke N, Moussa MM. UAE population reference standard charts for body mass index and skinfold thickness, at ages 0-18 years. Int J Food Sci Nutr. 2011; 62(7):692-702.

164. Cicek B, Ozturk A, Mazicioglu MM, Elmali F, Turp N, Kurtoglu S. The risk analysis of arm fat area in Turkish children and adolescents. Ann Hum Biol. 2009; 36(1):28-37. 
165. Ozturk A, Budak N, Cicek B, Mazicioglu MM, Bayram F, Kurtoglu S. Cross-sectional reference values for mid-upper arm circumference, triceps skinfold thickness and arm fat area of Turkish children and adolescents. Int J Food Scien Nutr. 2009; 60(4):267-81.

166. Ralt D. The muscle - Fat duel or why obese children are taller? $B M C$ Pediatr. 2006; 13(6):33.

167. Ying-Xiu Z, Shu-Rong W. Distribution of skinfold thickness and blood pressure among children and adolescents in Shandong. $J$ Trop Pediatr. 2011; 57(4):258-62. 


\section{ANEXOS}

\section{Anexo A - Aprovação do Comitê de Ética em Pesquisa da Faculdade de Saúde Pública da Universidade de São Paulo}

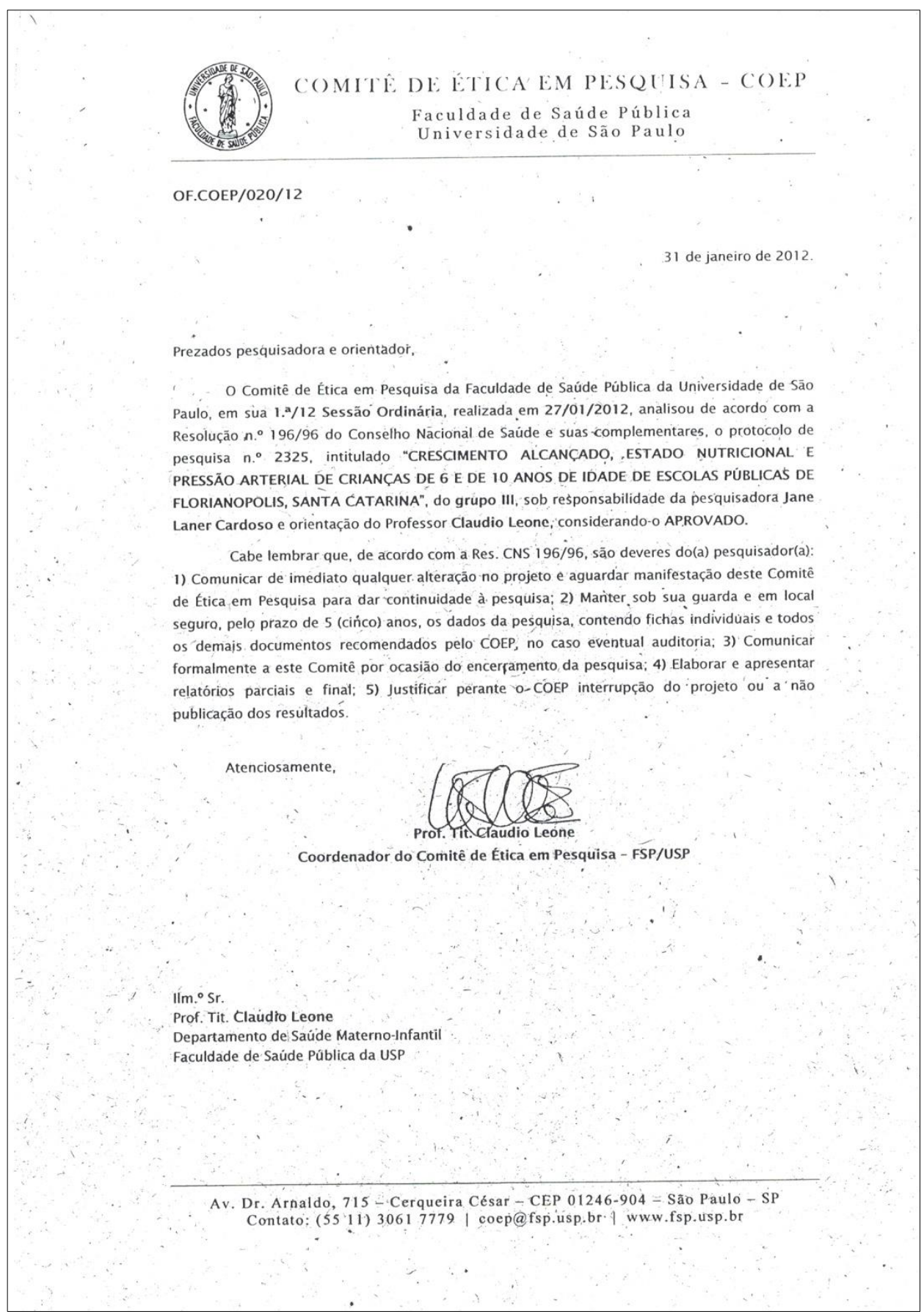




\title{
Anexo B - Termo de Consentimento Livre e Esclarecido
}

\author{
TERMO DE CONSENTIMENTO LIVRE E ESCLARECIDO
}

Título do Projeto: CRESCIMENTO ALCANÇADO, ESTADO NUTRICIONAL E PRESSÂO ARTERIAL DE CRIANÇAS DE 6 E DE 10 ANOS DE IDADE DE ESCOLAS PÚBLICAS DE FLORIANÓPOLIS, SANTA CATARINA.

Pesquisador Responsável: Jane Laner Cardoso

Pesquisador Orientador: Claudio Leone

Este projeto tem o objetivo de conhecer o perfil nutricional e da pressão arterial das crianças de 6 a 7 anos e de 9 a 10 anos de idade de escolas municipais e estaduais de Florianópolis, por meio da obtenção das medidas de peso, estatura, cintura abdominal e braquial, pregas cutâneas e pressão arterial. As avaliações ocorrerão na escola onde a criança estuda, sendo combinado previamente com a direção dessa o horário mais adequado e farão parte das atividades do Programa Saúde na Escola das Secretarias Municipais de Educação e Saúde. Os resultados ajudarão a entender como crescem as crianças em idade escolar em Florianópolis. Também estou ciente de que eventuais problemas de saúde ou nutricionais identificados em meu filho me serão devidamente comunicados com as devidas orientações e/ou encaminhamentos sempre que necessário.

Declaro que, após ler e receber explicações sobre a pesquisa fui informado (a) que a participação na mesma incorrerá em riscos ou prejuízos mínimos de qualquer natureza e que poderei desistir a qualquer momento, inclusive sem nenhum motivo, bastando para isso, informar minha decisão de desistência, à direção da escola onde meu filho estuda ou ao próprio pesquisador no endereço ou telefones abaixo relatados. Tenho direitos também, de receber resposta a qualquer pergunta e esclarecimento sobre os procedimentos, riscos, benefícios e outros relacionados à pesquisa, sempre que o solicitar. Ainda, tenho o direito de não ser identificado e ser mantido o caráter confidencial das informações relacionadas à privacidade, sendo os dados manuseados somente pelos pesquisadores, que poderão utilizá-los para fins de estudos científicos.

Caso necessite maiores esclarecimentos poderei entrar em contato com o Comitê de Ética em Pesquisa da Faculdade de Saúde Pública da Universidade de São Paulo, no telefone 11 3061-7779 ou na Av. Dr. Arnaldo, 715 - Cerqueira César, São Paulo - SPE, ou no Programa Saúde na Escola pelo telefone (48) 32391538/84119781, na Secretaria Municipal de Saúde de Florianópolis.

Declaro estar ciente do exposto e desejo que participe da pesquisa.

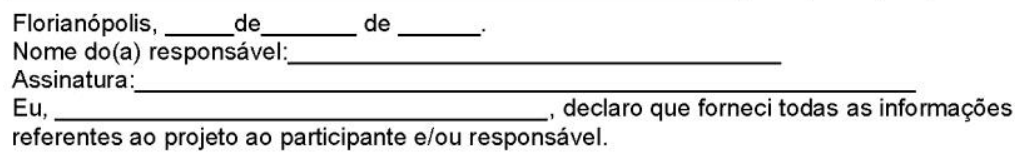


